\title{
Antithrombotic Therapy for Atrial Fibrillation
}

\section{Antithrombotic Therapy and Prevention of Thrombosis, 9th ed: American College of Chest Physicians Evidence-Based Clinical Practice Guidelines}

\author{
John J. You, MD; Daniel E. Singer, MD; Patricia A. Howard, PharmD; \\ Deirdre A. Lane, PhD; Mark H. Eckman, MD; Margaret C. Fang, MD, MPH; \\ Elaine M. Hylek, MD, MPH; Sam Schulman, MD, PhD; Alan S. Go, MD; \\ Michael Hughes, PhD; Frederick A. Spencer, MD; Warren J. Manning, MD; \\ Jonathan L. Halperin, MD; and Gregory Y. H. Lip, MD
}

\begin{abstract}
Background: The risk of stroke varies considerably across different groups of patients with atrial fibrillation (AF). Antithrombotic prophylaxis for stroke is associated with an increased risk of bleeding. We provide recommendations for antithrombotic treatment based on net clinical benefit for patients with $\mathrm{AF}$ at varying levels of stroke risk and in a number of common clinical scenarios.

Methods: We used the methods described in the Methodology for the Development of Antithrombotic Therapy and Prevention of Thrombosis Guidelines: Antithrombotic Therapy and Prevention of Thrombosis, 9th ed: American College of Chest Physicians Evidence-Based Clinical Practice Guidelines article of this supplement.

Results: For patients with nonrheumatic AF, including those with paroxysmal AF, who are (1) at low risk of stroke (eg, $\mathrm{CHADS}_{2}$ [congestive heart failure, hypertension, age $\geq 75$ years, diabetes mellitus, prior stroke or transient ischemic attack] score of 0 ), we suggest no therapy rather than antithrombotic therapy, and for patients choosing antithrombotic therapy, we suggest aspirin rather than oral anticoagulation or combination therapy with aspirin and clopidogrel; (2) at intermediate risk of stroke (eg, $\mathrm{CHADS}_{2}$ score of 1 ), we recommend oral anticoagulation rather than no therapy, and we suggest oral anticoagulation rather than aspirin or combination therapy with aspirin and clopidogrel; and (3) at high risk of stroke (eg, $\mathrm{CHADS}_{2}$ score of $\geq 2$ ), we recommend oral anticoagulation rather than no therapy, aspirin, or combination therapy with aspirin and clopidogrel. Where we recommend or suggest in favor of oral anticoagulation, we suggest dabigatran $150 \mathrm{mg}$ bid rather than adjusted-dose vitamin $\mathrm{K}$ antagonist therapy.

Conclusions: Oral anticoagulation is the optimal choice of antithrombotic therapy for patients with $\mathrm{AF}$ at high risk of stroke $\left(\mathrm{CHADS}_{2}\right.$ score of $\left.\geq 2\right)$. At lower levels of stroke risk, antithrombotic treatment decisions will require a more individualized approach.
\end{abstract}

CHEST 2012; 141(2)(Suppl):e531S-e575S

Abbreviations: AAD = antiarrythmic drug; ACS = acute coronary syndrome; ACTIVE $=$ Atrial Fibrillation Clopidogrel Trial With Irbesartan for Prevention of Vascular Events; AF = atrial fibrillation; AFASAK = Atrial Fibrillation Aspirin and Anticoagulation; AFFIRM = Atrial Fibrillation Follow-up Investigation of Rhythm Management; CHADS $_{2}=$ congestive heart failure, hypertension, age $\geq 75$ years, diabetes mellitus, prior stroke or transient ischemic attack; $\mathrm{CHA}_{2} \mathrm{DS}_{2}$ VASc $=$ congestive heart failure (or left ventricular systolic dysfunction), hypertension, age $\geq 75$ years, diabetes mellitus, prior stroke or transient ischemic attack, vascular disease, age 65 to 74 years, female sex; EAFT = European Atrial Fibrillation Trial; ESPS = European Stroke Prevention Study; INR = international normalized ratio; LAA = left atrial appendage; $\mathrm{MI}=$ myocardial infarction; $\mathrm{PAF}=$ paroxysmal atrial fibrillation; $\mathrm{RCT}=$ randomized controlled trial; RE-LY = Randomized Evaluation of Long-Term Anticoagulation Therapy; SPAF = Stroke Prevention in Atrial Fibrillation; TEE $=$ transesophageal echocardiography; TIA $=$ transient ischemic attack; VKA $=$ vitamin $\mathrm{K}$ antagonist 
SUMMARY OF RECOMMENDATIONS

Note on Shaded Text: Throughout this guideline, shading is used within the summary of recommendations sections to indicate recommendations that are newly added or have been changed since the publication of Antithrombotic and Thrombolytic Therapy: American College of Chest Physicians EvidenceBased Clinical Practice Guidelines (8th Edition). Recommendations that remain unchanged are not shaded.

2.1.8. For patients with $\mathrm{AF}$, including those with paroxysmal AF, who are at low risk of stroke (eg, CHADS ${ }_{2}$ [congestive heart failure, hypertension, age $\geq 75$ years, diabetes mellitus, prior stroke or transient ischemic attack] score $=0$ ), we suggest no therapy rather than antithrombotic therapy (Grade 2B). For patients who do choose antithrombotic therapy, we suggest aspirin $(75 \mathrm{mg}$ to $325 \mathrm{mg}$ once daily) rather than

Revision accepted August 31, 2011.

Affiliations: From the Department of Medicine (Drs You, Schulman, and Spencer) and Department of Clinical Epidemiology and Biostatistics (Dr You), McMaster University, Hamilton, ON, Canada; Department of Medicine (Dr Singer), Harvard Medical School, and Clinical Epidemiology Unit (Dr Singer), General Medicine Division, Massachusetts General Hospital, Boston, MA; School of Pharmacy (Dr Howard), University of Kansas Medical Center, Kansas City, KS; University of Birmingham Centre for Cardiovascular Sciences (Drs Lane and Lip), City Hospital, Birmingham, England; Department of Clinical Medicine (Dr Eckman), Division of General Internal Medicine and Center for Clinical Effectiveness, University of Cincinnati, Cincinnati, OH; Department of Medicine (Dr Fang), Division of Hospital Medicine, University of California, San Francisco, San Francisco, CA; Boston University Medical Center Research Unit (Dr Hylek), Section of General Internal Medicine, Boston, MA; Comprehensive Clinical Research Unit (Dr Go), Division of Research, Kaiser Permanente Northern California, Oakland, CA; Decision Resources Inc (Dr Hughes), London, England; Section of Non-invasive Cardiac Imaging (Dr Manning), Beth Israel Deaconess Medical Center, Boston, MA; and The Cardiovascular Institute (Dr Halperin), Mount Sinai Medical Center, New York, NY.

Funding/Support: The Antithrombotic Therapy and Prevention of Thrombosis, 9th ed: American College of Chest Physicians Evidence-Based Clinical Practice Guidelines received support from the National Heart, Lung, and Blood Institute [R13 HL104758] and Bayer Schering Pharma AG. Support in the form of educational grants was also provided by Bristol-Myers Squibb; Pfizer, Inc; Canyon Pharmaceuticals; and sanofi-aventis US.

Disclaimer: American College of Chest Physician guidelines are intended for general information only, are not medical advice, and do not replace professional medical care and physician advice, which always should be sought for any medical condition. The complete disclaimer for this guideline can be accessed at http://chestjournal.chestpubs.org/content/141/2_suppl/1S.

Correspondence to: Gregory Y. H. Lip, MD, University of Birmingham Centre for Cardiovascular Sciences, City Hospital, Birmingham, B18 7QH, England; e-mail: g.y.h.lip@bham.ac.uk (C) 2012 American College of Chest Physicians. Reproduction of this article is prohibited without written permission from the American College of Chest Physicians (http://www.chestpubs.org/ site/misc/reprints.xhtml).

DOI: $10.1378 /$ chest.11-2304 oral anticoagulation (Grade $2 \mathrm{~B}$ ) or combination therapy with aspirin and clopidogrel (Grade 2B).

Remarks: Patients who place an exceptionally high value on stroke reduction and a low value on avoiding bleeding and the burden associated with antithrombotic therapy are likely to choose antithrombotic therapy rather than no antithrombotic therapy. Other factors that may influence the choices above are a consideration of patient-specific bleeding risk and the presence of additional risk factors for stroke, including age 65 to 74 years and female gender, which have been more consistently validated, and vascular disease, which has been less well validated (see section 2.1.12). The presence of multiple non$\mathrm{CHADS}_{2}$ risk factors for stroke may favor oral anticoagulation therapy.

2.1.9. For patients with $\mathrm{AF}$, including those with paroxysmal $\mathrm{AF}$, who are at intermediate risk of stroke $\left(\mathrm{eg}, \mathrm{CHADS}_{2}\right.$ score $\left.=1\right)$, we recommend oral anticoagulation rather than no therapy (Grade 1B). We suggest oral anticoagulation rather than aspirin (75 $\mathrm{mg}$ to $325 \mathrm{mg}$ once daily) (Grade $2 \mathrm{~B}$ ) or combination therapy with aspirin and clopidogrel (Grade $2 \mathrm{~B}$ ). For patients who are unsuitable for or choose not to take an oral anticoagulant (for reasons other than concerns about major bleeding), we suggest combination therapy with aspirin and clopidogrel rather than aspirin (75 $\mathrm{mg}$ to $325 \mathrm{mg}$ once daily) (Grade 2B).

Remarks: Patients who place an exceptionally high value on stroke reduction and a low value on avoiding bleeding and the burden associated with anticoagulant therapy are likely to choose oral anticoagulation rather than antiplatelet therapy. Other factors that may influence the choice among antithrombotic therapies are a consideration of bleeding risk and the presence of additional risk factors for stroke, including age 65 to 74 years and female gender, which have been more consistently validated, and vascular disease, which has been less well validated (see section 2.1.12). The presence of multiple additional non-CHADS 2 risk factors for stroke may favor oral anticoagulation therapy.

2.1.10. For patients with AF, including those with paroxysmal $\mathrm{AF}$, who are at high risk of stroke (eg, CHADS ${ }_{2}$ score $=2$ ), we recommend oral anticoagulation rather than no therapy (Grade 1A), aspirin (75 mg to $325 \mathrm{mg}$ once daily) (Grade 1B), or combination therapy with aspirin and clopidogrel (Grade 1B). For patients who are unsuitable for or choose not to take an oral anticoagulant (for reasons other than concerns 
about major bleeding), we recommend combination therapy with aspirin and clopidogrel rather than aspirin (75 $\mathrm{mg}$ to $325 \mathrm{mg}$ once daily) (Grade 1B).

2.1.11. For patients with AF, including those with paroxysmal AF, for recommendations in favor of oral anticoagulation (including 2.1.9, 2.1.10, and excluding $2.2,3.1,3.2,3.3$ ), we suggest dabigatran $150 \mathrm{mg}$ twice daily rather than adjusted-dose vitamin $K$ antagonist (VKA) therapy (target INR range, 2.0-3.0) (Grade 2B).

Remarks: Dabigatran is excreted primarily by the kidney. It has not been studied and is contraindicated in patients with severe renal impairment (estimated creatinine clearance of $30 \mathrm{~mL} / \mathrm{min}$ or less). Clinicians should be aware that there is no antidote for dabigatran.

2.2. For patients with $\mathrm{AF}$ and mitral stenosis, we recommend adjusted-dose VKA therapy (target INR range, 2.0-3.0) rather than no therapy, aspirin (75 $\mathrm{mg}$ to $325 \mathrm{mg}$ once daily), or combination therapy with aspirin and clopidogrel (all Grade 1B). For patients with AF and mitral stenosis who are unsuitable for or choose not to take adjusted-dose VKA therapy (for reasons other than concerns about major bleeding), we recommend combination therapy with aspirin and clopidogrel rather than aspirin $(75 \mathrm{mg}$ to $325 \mathrm{mg}$ once daily) alone (Grade $1 \mathrm{~B}$ ).

3.1. For patients with AF and stable coronary artery disease (eg, no acute coronary syndrome within the previous year) and who choose oral anticoagulation, we suggest adjusted-dose VKA therapy alone (target international normalized ratio $[I N R]$ range, 2.0-3.0) rather than the combination of adjusted-dose VKA therapy and aspirin (Grade $2 \mathrm{C}$ ).

3.2. For patients with $\mathrm{AF}$ at high risk of stroke (eg, CHADS ${ }_{2}$ score of 2 or greater) during the first month after placement of a bare-metal stent or the first 3 to 6 months after placement of a drug-eluting stent, we suggest triple therapy (eg, VKA therapy, aspirin, and clopidogrel) rather than dual antiplatelet therapy (eg, aspirin and clopidogrel) (Grade 2C). After this initial period of triple therapy, we suggest a VKA (INR 2.0-3.0) plus a single antiplatelet drug rather than VKA alone (Grade $2 \mathrm{C}$ ). At 12 months after intracoronary stent placement, antithrombotic therapy is suggested as for patients with $\mathrm{AF}$ and stable coronary artery disease (see section 3.1).
For patients with $\mathrm{AF}$ at low to intermediate risk of stroke (eg, $\mathrm{CHADS}_{2}$ score of 0 or 1) during the first 12 months after placement of an intracoronary stent (bare metal or drug eluting), we suggest dual antiplatelet therapy rather than triple therapy (Grade 2C). At 12 months after intracoronary stent placement, antithrombotic therapy is suggested as for patients with AF and stable coronary artery disease (see section 3.1 ).

Remarks: Patients who place an exceptionally high value on stroke reduction and a low value on avoiding bleeding and the burden associated with anticoagulant therapy are likely to choose triple therapy rather than dual antiplatelet therapy. Other factors that may influence this choice are a consideration of bleeding risk and the presence of additional non$\mathrm{CHADS}_{2}$ risk factors for stroke (see section 2.1.12).

3.3. For patients with $\mathrm{AF}$ at intermediate to high risk of stroke (eg, $\mathrm{CHADS}_{2}$ score of 1 or greater) who experience an acute coronary syndrome and do not undergo intracoronary stent placement, we suggest for the first 12 months, adjusted-dose VKA therapy (INR 2.0-3.0) plus single antiplatelet therapy rather than dual antiplatelet therapy (eg, aspirin and clopidogrel) or triple therapy (eg, warfarin, aspirin, and clopidogrel) (Grade 2C). After the first 12 months, antithrombotic therapy is suggested as for patients with AF and stable coronary artery disease (see section 3.1 ).

For patients with $\mathrm{AF}$ at low risk of stroke (eg, $\mathrm{CHADS}_{2}$ score of 0), we suggest dual antiplatelet therapy (eg, aspirin and clopidogrel) rather than adjusted-dose VKA therapy (INR 2.0-3.0) plus single antiplatelet therapy or triple therapy (eg, warfarin, aspirin, and clopidogrel) (Grade 2C). After the first 12 months, antithrombotic therapy is suggested as for patients with AF and stable coronary artery disease (see section 3.1 ).

Remarks: Patients who place an exceptionally high value on stroke reduction and a low value on avoiding bleeding and the burden associated with anticoagulant therapy are likely to choose adjusted-dose VKA therapy plus single antiplatelet therapy rather than dual antiplatelet therapy. Other factors that may influence this choice are a consideration of bleeding risk and the presence of additional non-CHADS ${ }_{2}$ risk factors for stroke (see section 2.1.12).

3.4. For patients with AF being managed with a rhythm control strategy (pharmacologic or 
catheter ablation), we suggest that antithrombotic therapy decisions follow the general riskbased recommendations for patients with $\mathrm{AF}$ in section 2.1, regardless of the apparent persistence of normal sinus rhythm (Grade 2C).

3.5. For patients with atrial flutter, we suggest that antithrombotic therapy decisions follow the same risk-based recommendations as for AF.

4.1.1. For patients with $\mathrm{AF}$ of greater than $48 \mathrm{~h}$ or unknown duration undergoing elective electrical or pharmacologic cardioversion, we recommend therapeutic anticoagulation (adjusted-dose VKA therapy, target INR range 2.0-3.0, lowmolecular-weight heparin at full venous thromboembolism treatment doses, or dabigatran) for at least 3 weeks before cardioversion or a transesophageal echocardiography (TEE)guided approach with abbreviated anticoagulation before cardioversion rather than no anticoagulation (Grade $1 \mathrm{~B}$ ). We recommend therapeutic anticoagulation for at least 4 weeks after successful cardioversion to sinus rhythm rather than no anticoagulation, regardless of the baseline risk of stroke (Grade 1B). Decisions about anticoagulation beyond 4 weeks should be made in accordance with our risk-based recommendations for long-term antithrombotic therapy in section 2.1 .

4.1.2. For patients with AF of documented duration of $48 \mathrm{~h}$ or less undergoing elective cardioversion (electrical or pharmacologic), we suggest starting anticoagulation at presentation (low-molecular-weight heparin or unfractionated heparin at full venous thromboembolism treatment doses) and proceeding to cardioversion rather than delaying cardioversion for 3 weeks of therapeutic anticoagulation or a TEE-guided approach (Grade 2C). After successful cardioversion to sinus rhythm, we recommend therapeutic anticoagulation for at least 4 weeks rather than no anticoagulation, regardless of baseline stroke risk (Grade 2C). Decisions about long-term anticoagulation after cardioversion should be made in accordance with our risk-based recommendations for long-term antithrombotic therapy in section 2.1 .

4.2. For patients with $\mathrm{AF}$ and hemodynamic instability undergoing urgent cardioversion (electrical or pharmacologic), we suggest that therapeutic-dose parenteral anticoagulation be started before cardioversion, if possible
(Grade 2C), but that initiation of anticoagulation must not delay any emergency intervention (Grade 2C). After successful cardioversion to sinus rhythm, we suggest therapeutic anticoagulation for at least 4 weeks after successful cardioversion to sinus rhythm rather than no anticoagulation, regardless of baseline stroke risk (Grade 2C). Decisions about anticoagulation beyond 4 weeks should be made in accordance with our risk-based recommendations for longterm antithrombotic therapy in section 2.1.

4.3. For patients with atrial flutter undergoing elective or urgent pharmacologic or electrical cardioversion, we suggest that the same approach to thromboprophylaxis be used as for patients with atrial fibrillation undergoing cardioversion.

$\mathbf{A}^{\mathrm{t}}$ trial fibrillation $(\mathrm{AF})$ is the most common sustained cardiac arrhythmia. One in four individuals aged 40 years will develop AF during his or her lifetime, and it has been estimated that by the year 2050, up to 16 million Americans will have AF.1,2 Nonrheumatic AF is a strong, independent predictor of ischemic stroke associated with a fivefold increase in risk. ${ }^{3}$ Without thromboprophylaxis, the risk of ischemic stroke in patients with nonrheumatic $\mathrm{AF}$, as seen in the control arms of the original trials of antithrombotic therapy in $\mathrm{AF}$, is $\sim 5 \%$ per year. ${ }^{4}$ Over the past 2 decades, considerable work has been done to evaluate antithrombotic therapies to prevent stroke in patients with $\mathrm{AF}$, and the field continues to evolve with the emergence of a new generation of oral anticoagulants.

This article begins with a discussion of the methods used to develop our recommendations for antithrombotic therapy in patients with AF. Next, we provide our treatment recommendations, divided into the following sections:

1. Antithrombotic therapy in patients with AF in general (includes patients with permanent, persistent, or paroxysmal AF [PAF])

2. Antithrombotic therapy in patients with $\mathrm{AF}$ in special situations:

- Stable coronary artery disease

- Acute coronary syndrome (ACS)

- Intracoronary artery stent

- Acute ischemic stroke

- Management with a rhythm control strategy

- Chronic atrial flutter

3. Antithrombotic therapy for patients with AF undergoing cardioversion 
The article ends with a discussion of practical issues in the use of adjusted-dose vitamin $\mathrm{K}$ antagonist (VKA) therapy in patients with $\mathrm{AF}$ and suggestions for future research.

Table 1 specifies the clinical question being addressed in this article (in PICO [population, intervention, comparator, outcomes] format) and the types of studies used. This article does not give recommendations for antithrombotic therapy in patients with $\mathrm{AF}$ around the time of surgical or invasive procedures (see Douketis et $\mathrm{al}^{5}$ ), at the time of presentation with acute stroke (see Lansberg et $\mathrm{al}^{6}$ ), or in patients with $\mathrm{AF}$ who have prosthetic heart valves (see Whitlock et $\mathrm{al}^{7}$ ). This article does not give recommendations for patients with $\mathrm{AF}$ who are pregnant. For general recommendations on antithrombotic therapy during pregnancy (ie, not specific to $\mathrm{AF}$ ), see Bates et al. ${ }^{8}$ Finally, the recommendations in this article apply to patients with persistent and permanent $\mathrm{AF}$ and to patients with PAF but do not apply to patients with a single, transient, self-limited episode of AF associated with acute illness.

\subsection{Methods}

To inform our guideline development, we searched for relevant articles published since the last literature search performed for the Antithrombotic and Thrombolytic Therapy: American College of Chest Physicians Evidence-Based Clinical Practice Guidelines (8th Edition). Specifically, for literature regarding the assessment of stroke risk in patients with AF, we searched Medline for articles published from January 1, 2005, to October 2009 using the search terms "atrial fibrillation," "atrial flutter," "risk assessment," "risk factors," "risk stratification," "stroke," and "thromboembolism." For literature regarding prevention of stroke and thromboembolism in patients with AF, we searched Medline for articles published from January 1, 2005, to October 2009 using the search terms "coumarins," "warfarin," "dicumarol," "phenprocoumon," "acenocoumarol," "fondaparinux," “idraparinux," "aspirin," "triflusal," "indobufen," "dabigatran," "ximelagatran," "rivaroxaban," "apixaban," "ticlopidine," "clopidogrel," "catheter ablation," “watchman," "PLAATO," “cardioversion," “atrial fibrillation," and "atrial flutter."

\subsection{Outcomes of Interest}

The outcomes most relevant to patients with AF include death, nonfatal stroke, systemic embolism, nonfatal major extracranial bleeding, and the burden and lifestyle limitations associated with outpatient antithrombotic therapy. To facilitate decision-making, the term stroke in this article includes ischemic stroke and intracranial hemorrhage (intracerebral, subdural, and subarachnoid hemorrhage). Although there may be some differences in the impact of these intracranial events (eg, subdural hemorrhage) on quality of life, we judged that on average, the impact would be similar. We also explicitly considered that outpatient antithrombotic therapy was associated with a burden to the patient, which in some cases, such as aspirin, is a requirement to take a daily medication, or in other cases, such as adjusted-dose VKA therapy, is not only a requirement to take a daily medication but also a requirement to limit one's lifestyle, restrict one's diet, and undergo frequent blood testing and clinic visits. For recommendations about patients with $\mathrm{AF}$ and stable coronary artery disease, intracoronary stent placement, or recent ACS (sections 3.1-3.3), we also considered the effect of different treatment options on the outcome of nonfatal myocardial infarction (MI).

\subsection{Patient Values and Preferences}

In developing our treatment recommendations, we attempted to account for patient values and preferences regarding these health states. In this guideline, a systematic review of studies assessing values and preferences related to antithrombotic therapy found that values for health states and preferences for treatments vary appreciably among individuals (MacLean et $\mathrm{al}^{9}$ ). The available literature has several limitations. The studies eliciting preferences were small and used different methods and tools, and most included a sizeable proportion of participants who had previously taken or were currently taking VKAs. Furthermore, there are inconsistencies across studies that often are difficult to explain, leaving considerable uncertainty about average patient values. Nevertheless, to make our recommendations, we required an estimate of average patient values for the relevant outcomes so that we could judge whether the trade-offs between benefit and harm would favor one course of treatment over another.

As described by Guyatt et $\mathrm{a}^{10}$ in this guideline, to obtain our estimates of average patient values, we have used ratings of key health states from participating guideline panelists informed by our systematic review of the relevant literature. The results of the panelist value rating exercise suggest that on average, patients would find a typical nonfatal stroke (ischemic or hemorrhagic) approximately three times as aversive as a nonfatal major extracranial bleed (typically a GI bleed) and a typical nonfatal MI as aversive as a nonfatal major extracranial bleed.

With the exception of the choice between VKA therapy and no therapy, the choice of one antithrombotic treatment over another for long-term stroke prevention in $\mathrm{AF}$ will not lead to differences in all-cause mortality (section 2). Thus, for these choices that are not expected to result in a difference in mortality, for every 1,000 patients treated for 1 year, if the number of nonfatal strokes prevented is less than one-third of the number of nonfatal major extracranial bleeds caused by a given antithrombotic therapy, we have recommended against that intervention. If the number of nonfatal strokes prevented is appreciably more than one-third of the number of nonfatal major extracranial bleeding events that result from a given antithrombotic therapy, we have recommended in favor.

Making these trade-offs requires not only estimates regarding average patient values for the relevant outcomes but also best estimates of (1) the effect of a given treatment on these outcomes against a given comparator (ie, relative risk) and (2) the absolute event rates for these outcomes in untreated patients (or, for PICO questions of a treatment vs an active comparator, the absolute event rates in patients receiving the active comparator). In the following section, we present the methods used to obtain these estimates for our guidelines.

\subsection{Estimating the Magnitude of Treatment Effect}

For each clinical question, we extracted data regarding the previously discussed outcomes from the relevant clinical trials. When there were multiple randomized controlled trials (RCTs) addressing the same clinical question, we conducted metaanalyses using random-effects models and the Mantel-Haenszel method to obtain pooled estimates of treatment effect, expressed as relative risk. For studies that did not report the proportion of strokes that were fatal and nonfatal, we used all available data in the published report to obtain a best estimate of the effect of 


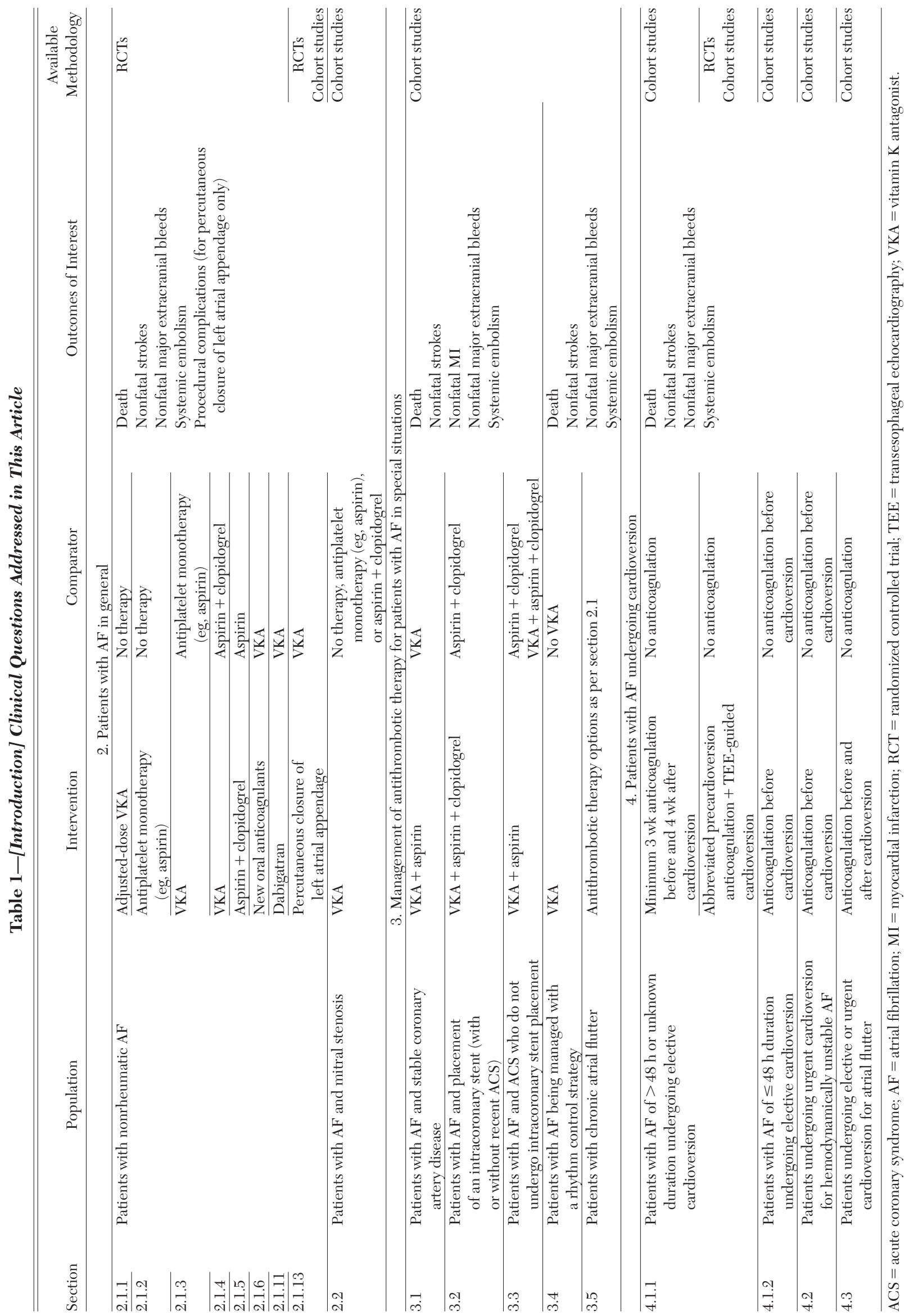


treatment on nonfatal stroke by assuming a case fatality rate of $50 \%$ for hemorrhagic stroke and $25 \%$ for ischemic stroke based on population-based stroke registry data and the case fatality rates observed in the RCTs of patients with AF that reported such data. ${ }^{11}$ For nonfatal major extracranial bleeding, we accepted the definition of major bleeding from the individual studies, and when the proportion of major extracranial bleeds that were fatal vs nonfatal was not reported, we applied the average case fatality rate for major extracranial bleeding reported across the relevant clinical trials $(\sim 15 \%)$. For the outcome of systemic embolism, we used the total number of events (fatal and nonfatal) because systemic embolism was an infrequent event and typically not reported as fatal vs nonfatal.

\subsection{Deriving Baseline Risk of Stroke in Patients With AF}

The risk of stroke varies considerably across different groups of patients with AF. ${ }^{12}$ Simple validated tools for the assessment of stroke risk in patients with $\mathrm{AF}$ help in identifying those who are more likely to benefit than be harmed from antithrombotic therapy.

1.4.1 Pattern of AF: Guidelines have categorized the pattern of AF into (1) PAF, in which recurrent episodes terminate spontaneously within 7 days and usually in $<48 \mathrm{~h}$; (2) persistent $\mathrm{AF}$, in which the episode of $\mathrm{AF}$ does not self-terminate within 7 days or is terminated by cardioversion; and (3) permanent AF, in which $\mathrm{AF}$ is present for some time and cardioversion either has failed or has not been attempted.13

For patients with PAF, periods of sinus rhythm theoretically should lessen the risk of stroke, yet transitions from AF to sinus rhythm may acutely heighten risk in a manner similar to the increase in risk caused by cardioversion. Although some studies suggest that PAF is associated with a lower risk of stroke than persistent or permanent $\mathrm{AF}$, patients with $\mathrm{PAF}$ generally are younger and have a lower prevalence of other stroke risk factors, and clinical trial data suggest that PAF confers a relative risk of stroke similar to persistent or permanent $\mathrm{AF}$ when controlling for associated stroke risk factors. ${ }^{14-17}$ Pending further evidence, it seems reasonable to treat patients with PAF in a manner similar to those with persistent and permanent AF; thus, our risk-based treatment recommendations apply to patients with $\mathrm{PAF}$ and persistent and permanent $\mathrm{AF}$.

1.4.2 Independent Risk Factors for Stroke in Patients With AF: Two recent systematic reviews have identified clinical and echocardiographic factors that are independently associated with an increased risk of stroke in patients with AF. ${ }^{18,19}$ The individual studies from these systematic reviews, in addition to articles identified in an updated literature search performed for this guideline, are summarized in Tables S1 through S12 (tables that contain an "S" before the number denote supplementary tables not contained in the body of the article and available instead in an online data supplement; see the "Acknowledgments" for more information). In terms of clinical applicability, the most consistently identified risk factors for ischemic stroke among patients with AF are a history of ischemic stroke or transient ischemic attack (TIA) - the strongest dichotomous predictor of stroke risk-older age, hypertension, and diabetes. Although impaired left ventricular systolic function is a risk factor for stroke in $\mathrm{AF}$, there are conflicting data about whether a history of congestive heart failure per se raises the risk of ischemic stroke in AF. Although age thresholds often are used in stroke risk schemes, stroke risk in AF increases continuously with age, appreciably rising from age 65 years onward..$^{20}$ There is moderate-quality evidence that women face a higher risk of stroke than men. ${ }^{18} \mathrm{~A}$ history of coronary artery disease has not consistently been found to be an independent risk factor for stroke in patients with AF. ${ }^{18}$ However, there is low-quality evidence that the presence of atherosclerotic vascular disease (eg, complex aor- tic plaque in the descending aorta seen on transesophageal echocardiography [TEE] or a history of peripheral arterial disease) independently predicts stroke risk among patients with AF. ${ }^{21-23}$

1.4.3 Stroke Risk Stratification Schema: Many risk stratification schema, which use various combinations of the risk factors discussed previously, have been developed to aid clinicians in the assessment of stroke risk in patients with nonrheumatic AF (Table S13). ${ }^{12}$ Despite substantial efforts in this field over the past several decades, all available schema have only modest ability to predict stroke in patients with $\mathrm{AF}$, with $\mathrm{C}$ statistics typically between 0.55 and $0.70 .4,24-43$ (A C statistic of 0.50 indicates a model that does not discriminate better than chance alone, and a C statistic of 1.00 indicates perfect discrimination.)

The $\mathrm{CHADS}_{2}$ score is the most validated risk scheme, having been independently tested in at least 10 separate cohorts after its original derivation. . $^{24,32,35-46}$ The $\mathrm{CHADS}_{2}$ score gives a single point for each of congestive heart failure (originally defined as a recent exacerbation of congestive heart failure), hypertension (defined as a history of hypertension, rather than a presence of elevated BP), age $\geq 75$ years, and diabetes mellitus and two points for prior stroke or TIA (Table 2). ${ }^{30}$

Despite its widespread adoption and ease of use, the $\mathrm{CHADS}_{2}$ score has limitations. First, congestive heart failure is not a consistently demonstrated independent predictor of stroke. Second, the risk associated with a history of hypertension may differ among patients with well-treated vs poorly treated hypertension. ${ }^{46-48}$ Third, in most studies, the CHADS, score has only a modest ability to predict stroke in patients with $\mathrm{AF}$ (C statistic, 0.56-0.70).24,32,35-46 Finally, the threshold of stroke risk at which treatment with oral anticoagulation will be preferred is likely to decrease with the emergence of new oral anticoagulants that do not require regular monitoring of the international normalized ratio (INR) and that may be associated with greater reductions in stroke and less risk of bleeding compared with adjusted-dose VKA therapy. ${ }^{49}$ Thus, stroke risk stratification schema will need to evolve to more accurately identify patients who are at sufficiently low risk of stroke and can be treated with aspirin or no antithrombotic therapy, whereas all other patients with AF can be considered for oral anticoagulation.

The $\mathrm{CHA}_{2} \mathrm{DS}_{2}$-VASc (congestive heart failure [or left ventricular systolic dysfunction], hypertension, age $<75$ years; diabetes mellitus, prior stroke or transient ischemic attack, vascular disease, age 65 to 74 years, female sex) score is a new risk scheme that combines the $\mathrm{CHADS}_{2}$ score with additional moderate risk factors, which were also included in the 2006 American College of Cardiology/American Heart Association/European Society of Cardiology and National Institute for Health and Clinical Excellence AF practice guidelines. ${ }^{29,50}$ Specifically, the $\mathrm{CHA}_{2} \mathrm{DS}_{2}$-VASc score assigns points as in the original CHADS, score (Table 2) with the exception of age $\geq 75$ years, which is assigned two points. It also assigns a single point for each of the following additional

\section{Table 2-[Section 1.4.3] $\mathrm{CHADS}_{2}$ Score $^{30}$ for Assessment of Stroke Risk in Patients With Nonrheumatic AF}

\begin{tabular}{lc}
\hline \hline Risk Factor & Points \\
\hline Recent Congestive heart failure exacerbation & 1 \\
\hline History of Hypertension & 1 \\
\hline Age $\geq 75$ y & 1 \\
\hline Diabetes mellitus & 1 \\
\hline Prior history of Stroke or transient ischemic attack & 2
\end{tabular}

$\mathrm{CHADS}_{2}=$ congestive heart failure, hypertension, age $\geq 75$ years, diabetes mellitus, prior stroke or transient ischemic attack. See Table 1 legend for expansion of other abbreviation. 
risk factors: female sex, age 65 to 74 years, and vascular disease (defined as a history of MI, peripheral arterial disease, or complex aortic plaque). The $\mathrm{CHA}_{2} \mathrm{DS}_{2}$-VASc score has been evaluated in at least five separate cohorts since its original description. With the exception of a recent study by Olesen et al, ${ }^{24}$ all other studies have found that the predictive ability of $\mathrm{CHA}_{2} \mathrm{DS}_{2}-\mathrm{VASc}$ is similar to that of the $\mathrm{CHADS}_{2}$ score (C statistics of each risk score is $\sim 0.6$ across the various studies) and not statistically significantly greater than that of $\mathrm{CHADS}_{2}{ }^{36,40-43}$ Because the $\mathrm{CHADS}_{2}$ score has been extensively validated and is easy for clinicians to remember and use, we use the $\mathrm{CHADS}_{2}$ score as the principal approach for our risk-based treatment recommendations.

1.4.4 Estimating the Baseline Risk of Nonfatal Stroke by $\mathrm{CHADS}_{2}$ Score: To develop our recommendations, we required estimates of the absolute rate of nonfatal stroke (ischemic or hemorrhagic) for patients according to their underlying risk of stroke, as characterized by their $\mathrm{CHADS}_{2}$ score. Ideally, we would obtain these estimates of baseline risk from published annual rates of stroke, by $\mathrm{CHADS}_{2}$ score, among untreated patients. However, such data are not available.

Therefore, to obtain estimates of annual stroke risk, we used pooled data from aspirin-treated patients enrolled in six clinical trials of antithrombotic therapy for stroke prevention in AF ${ }^{37}$ This published report presented data regarding ischemic stroke rates (fatal and nonfatal combined) on aspirin, stratified by $\mathrm{CHADS}_{2}$ score. We used the following calculations to estimate the annual risk of nonfatal stroke (ie, ischemic and hemorrhagic) on aspirin: (1) multiplication of reported rates of ischemic stroke by 1.08 to account for additional hemorrhagic strokes on aspirin therapy (based on the observed ratio of ischemic:hemorrhagic strokes in aspirin arms of RCTs in patients with AF) and (2) an estimation that $50 \%$ and $25 \%$ of hemorrhagic and ischemic strokes, respectively, were fatal.

Depending on the clinical question being addressed by a particular recommendation, we adjusted these absolute rates of nonfatal stroke on aspirin to reflect the clinical scenario being addressed. For the recommendation addressing VKA therapy vs no treatment, for example, to estimate absolute rates of nonfatal stroke on no treatment, we increased our estimates of the rate of nonfatal stroke on aspirin by $21 \%$ to account for the estimated efficacy of aspirin in preventing stroke in AF). We therefore used the following absolute rates of nonfatal stroke in untreated patients to develop our recommendations: $0.8 \%, 2.2 \%$, $4.5 \%$, and $9.6 \%$ per year for patients with $\mathrm{CHADS}_{2}$ scores of 0,1 , 2 , and 3 to 6 , respectively.

We have chosen to base our treatment recommendations on absolute rates of stroke derived from clinical trials, recognizing that these data have important limitations. Less than $10 \%$ of patients screened were enrolled in these historical trials, there was limited racial and ethnic diversity, and there is some evidence suggesting that stroke rates may now be lower than at the time these RCTs were conducted 2 decades ago possibly because of improved treatment of cardiovascular risk factors, such as hypertension.51,52 However, despite these limitations, these clinical trial-based data regarding stroke events were systematically and prospectively collected, and they remain the best available source of stroke rates stratified by $\mathrm{CHADS}_{2}$ score.

\subsection{Deriving Baseline Risk of Death in Patients With AF}

We used data from an observational health plan database study of 11,526 patients with nonvalvular AF (the Anticoagulation and Risk Factors in Atrial Fibrillation [ATRIA] Study) to obtain an estimate of the risk of all-cause mortality in patients with $\mathrm{AF}$ not treated with warfarin (53 deaths per 1,000 patientyears). Untreated patients in this cohort had a mean $\mathrm{CHADS}_{2}$ score of 1.5 , and a substantial majority $(78 \%)$ of patients in the cohort had a CHADS 2 score of $\geq 1.44$ Although CHADS $_{2}$-specific rates of all-cause mortality are not available from this cohort, the risk of death is expected to be lower in low-risk patients with a $\mathrm{CHADS}_{2}$ score of 0 because of their younger age, lower prevalence of vascular risk factors, and lower rates of fatal ischemic stroke.

\subsection{Deriving Baseline Risk of Nonfatal Major Extracranial Bleeding}

To develop our recommendations, we also required estimates of the baseline risk of nonfatal major extracranial bleeding in patients with AF. We obtained this estimate from observational studies of VKA therapy in cohorts that included exclusively or predominantly patients with $\mathrm{AF}$ (median rate of $1.3 \%$ per year across these studies). ${ }^{44,53,54}$ To estimate the baseline risk of nonfatal major extracranial bleeding off VKA therapy, we used this median rate of bleeding on VKA therapy from the observational studies (1.3\% per year) and divided by the pooled relative risk (2.58) of nonfatal major extracranial bleeding associated with VKA therapy, as obtained from RCTs of VKA therapy vs no therapy. Therefore, our estimate of the baseline risk of nonfatal major extracranial bleeding off therapy was $0.5 \%$ per year.

\subsection{ANTITHROMBOTIC THERAPY FOR Patients With AF in General}

Over the past 2 decades, numerous RCTs have investigated antithrombotic therapies to reduce the risk of thromboembolism, principally ischemic stroke, in patients with AF. In this section, we summarize the evidence and give treatment recommendations for VKA therapy, antiplatelet monotherapy (eg, aspirin), dual antiplatelet therapy with aspirin and clopidogrel, and new oral anticoagulants (eg, dabigatran) in patients with AF.

\subsection{Patients With Nonrheumatic AF}

2.1.1 VKAs vs No Therapy: Six RCTs that enrolled a total of 2,584 patients and address the primary prevention (Atrial Fibrillation Aspirin and Anticoagulation [AFASAK] 1, Boston Area Anticoagulation Trial for Atrial Fibrillation [BAATAF], Canadian Atrial Fibrillation Anticoagulation [CAFA], Stroke Prevention in Atrial Fibrillation [SPAF] I, Stroke Prevention in Nonrheumatic Atrial Fibrillation [SPINAF]) and secondary prevention (European Atrial Fibrillation Trial [EAFT]) of stroke in patients with AF provide highquality evidence that VKA therapy reduces the risk of death by one-fourth and the risk of nonfatal stroke by two-thirds compared with no therapy (Table 3). ${ }^{55-61}$ For patients with a CHADS $_{2}$ score of 0 , the studies provide moderate-quality evidence that VKA therapy increases the risk of nonfatal major extracranial bleeding due to imprecision of the estimate (wide CIs). The studies provide high-quality evidence for patients with higher $\mathrm{CHADS}_{2}$ scores. 


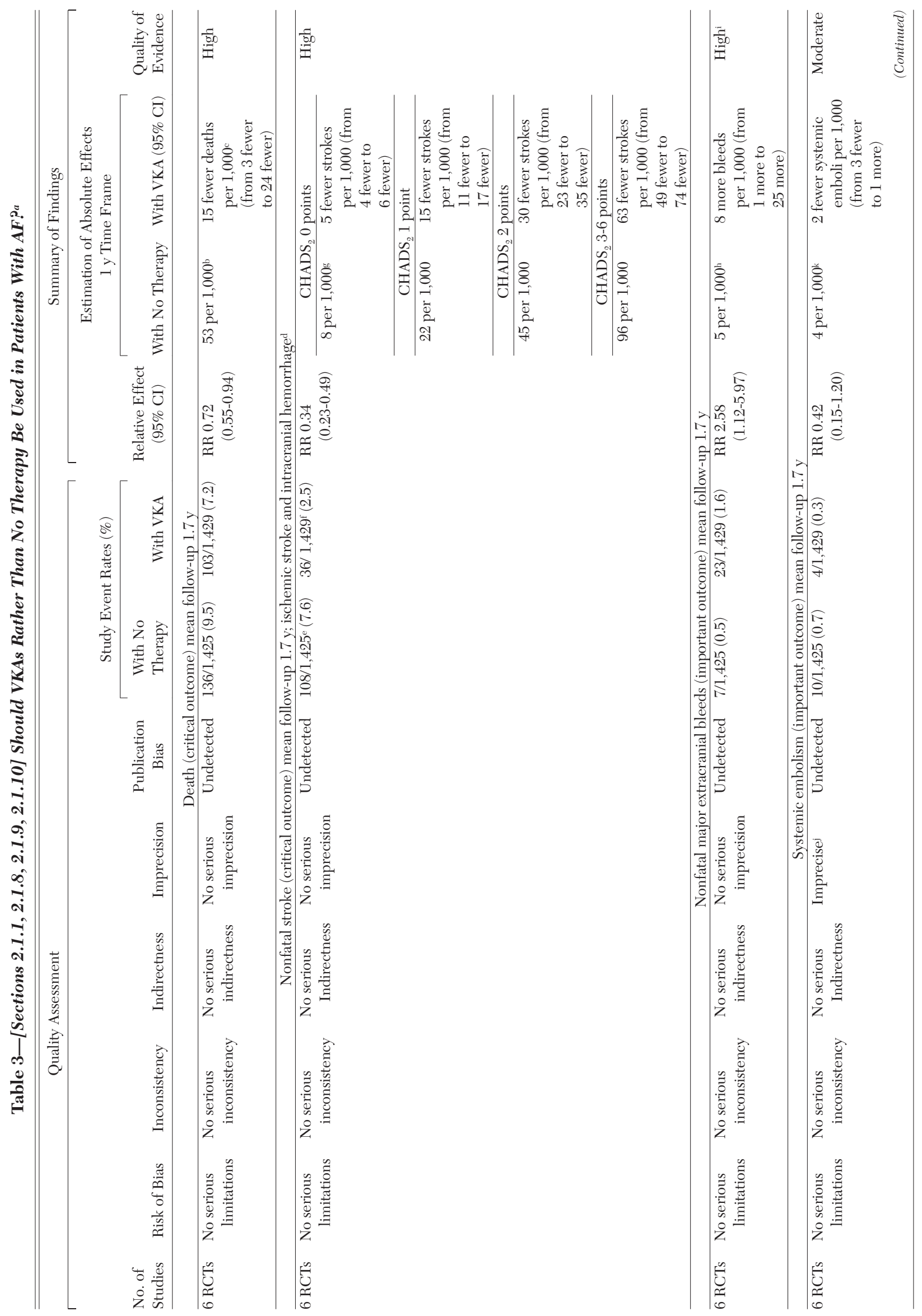




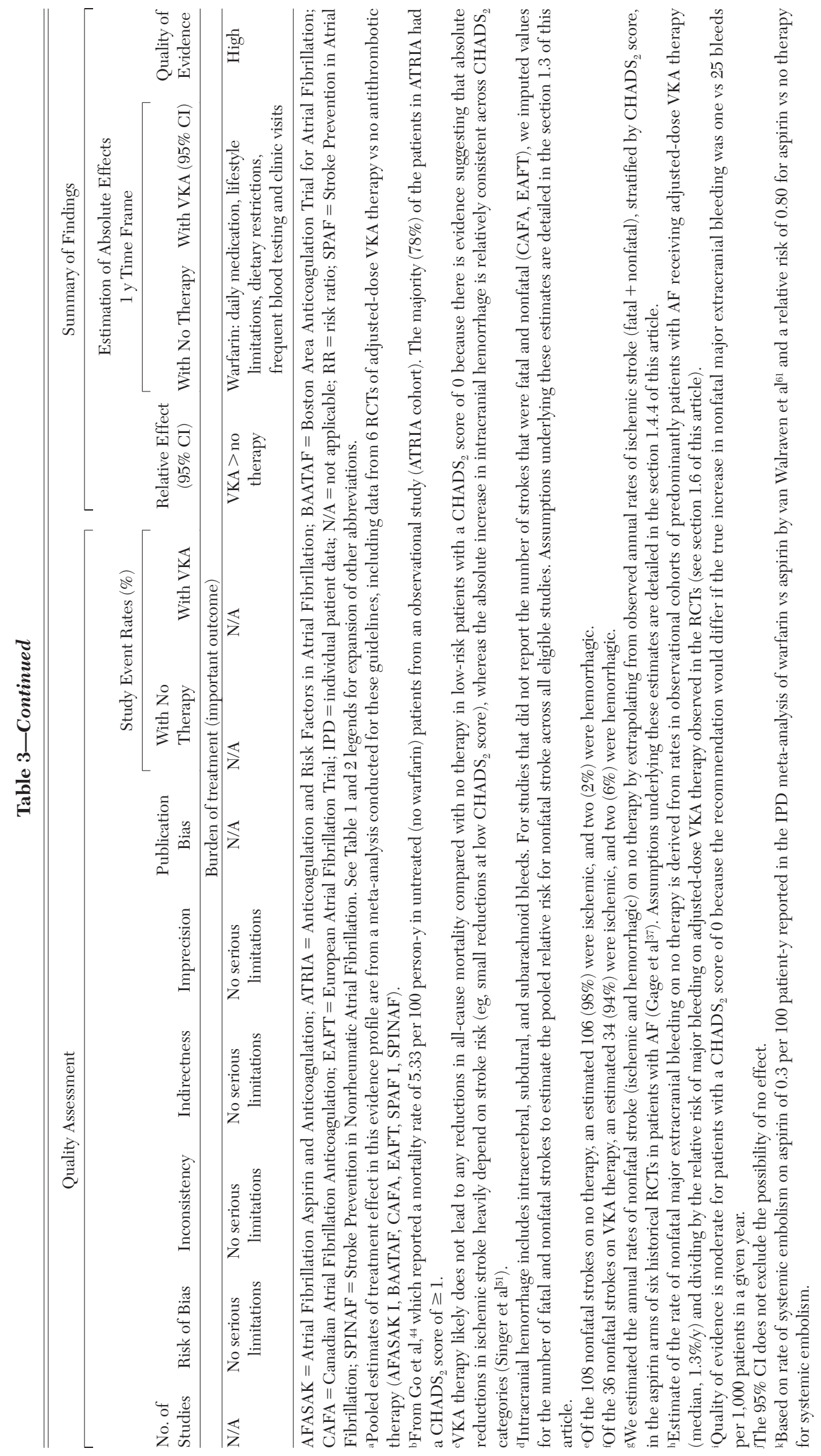


The studies also provide moderate-quality evidence that VKA therapy reduces the risk of systemic embolism (rated down for imprecision).

2.1.2 Antiplatelet Monotherapy (Aspirin) vs No Therapy: Several RCTs of antiplatelet monotherapy vs no therapy in patients with AF have shown that antiplatelet therapy leads to, at best, a modest reduction in the risk of nonfatal stroke. Antiplatelet monotherapy in these trials was either with aspirin alone (AFASAK 1; SPAF I; EAFT; United Kingdom Transient Ischaemic Attack Aspirin trial [UK-TIA]; LowDose Aspirin, Stroke, Atrial Fibrillation [LASAF]; European Stroke Prevention Study [ESPS]-2; and Japan Atrial Fibrillation Stroke Trial [JAST]), aspirin in combination with fixed (ineffective) minidose warfarin (Swedish Atrial Fibrillation Trial [SAFT]), or dipyridamole (ESPS-2).55,58,60,62-66 Aspirin dosing in these trials typically ranged from 50 to $325 \mathrm{mg} / \mathrm{d}$. In the LASAF, JAST, and SAFT trials, aspirin was compared with a no-treatment control arm, whereas in the remaining trials, comparison was to placebo. ${ }^{63,64,66}$ ESPS-2 and UK-TIA were stroke prevention trials conducted primarily in non-AF populations, and only the data from the subset of patients with AF are considered here. ${ }^{62,65}$

Pooled data from these trials provide moderatequality evidence (rated down for imprecision) that antiplatelet monotherapy is associated with a $21 \%$ relative reduction in risk of nonfatal stroke compared with no treatment (Table 4). Although our confidence in the benefits of aspirin therapy is moderate, our confidence in its bleeding risk is high. Although the trials of antiplatelet monotherapy in patients with $\mathrm{AF}$ were underpowered to precisely estimate the risk of nonfatal major extracranial bleeding, trials of aspirin for the primary and secondary prevention of cardiovascular disease have conclusively demonstrated that aspirin is associated with an increased risk of major hemorrhage. An individual patient data meta-analysis combining data from six cardiovascular primary prevention trials $(95,000$ subjects) and a meta-analysis of 60 cardiovascular secondary prevention trials $(94,000$ subjects) found that aspirin is associated with a significant $50 \%$ to $60 \%$ relative increase, respectively, in the risk of major extracranial bleeding. ${ }^{67,68}$ For the outcomes of death and systemic embolism, pooled estimates of treatment effect from trials of antiplatelet monotherapy in patients with AF were imprecise, leaving uncertainty about the impact of antiplatelet monotherapy on these outcomes when compared with no treatment (Table 4).

2.1.3 VKAs vs Antiplatelet Monotherapy (Aspirin): The evidence summarized in sections 2.1.1 and
2.1.2 implies that adjusted-dose warfarin is far superior to aspirin for the prevention of stroke in patients with AF but is likely to be associated with a greater risk of bleeding complications. Direct evidence regarding this clinical question comes from 11 RCTs (total of 6,526 patients) comparing adjusted-dose VKA therapy to antiplatelet monotherapy (AFASAK 1, AFASAK 2, Birmingham Atrial Fibrillation Treatment of the Aged [BAFTA], EAFT, National Study for Prevention of Embolism in Atrial Fibrillation [NASPEAF], Primary Prevention of Arterial Thromboembolism in Nonrheumatic AF in Primary Care Trial [PATAF], Studio Italiano Fibrillazione Atriale [SIFA], SPAF II, SPAF III, Vemmos et al, ${ }^{69}$ and Warfarin vs Aspirin for Stroke Prevention in Octogenarians With AF [WASPO]) (Table 5).55,60,70-77 Antiplatelet therapy was typically with aspirin 75 to $325 \mathrm{mg} / \mathrm{d}$, but in the SIFA and NASPEAF studies, it was with indobufen and triflusal, respectively. ${ }^{72,74}$ In SPAF III and one of the two antiplatelet arms of AFASAK II, aspirin was given in combination with fixed minidose (ineffective) warfarin..$^{70,76}$

These trials provide high-quality evidence that adjusted-dose VKA therapy reduces by one-half the risk of nonfatal stroke compared with antiplatelet monotherapy. These trials suggest that VKA therapy increases the risk of nonfatal major extracranial bleeding by about $50 \%$ compared with aspirin (pooled risk ratio, 1.42; 95\% CI, 0.89-2.29), but the quality of evidence was rated down to moderate because of imprecision. Indirect evidence from RCTs of adjusteddose VKA therapy vs aspirin in other populations suggest that VKA therapy is likely associated with a true twofold to 2.5-fold increase in major bleeding risk. ${ }^{78,79}$ For the outcomes of death and systemic embolism, pooled estimates of treatment effect from trials of VKA therapy in patients with AF were imprecise, leaving uncertainty about the impact of VKA therapy on these outcomes compared with antiplatelet monotherapy.

2.1.4 VKAs vs Dual Antiplatelet Therapy With Aspirin and Clopidogrel: The Atrial Fibrillation Clopidogrel Trial With Irbesartan for Prevention of Vascular Events (ACTIVE) W trial assessed dual antiplatelet therapy with aspirin and clopidogrel as a potential alternative to VKA therapy (INR 2.0-3.0).80 The trial was stopped early because of findings of superiority of VKA therapy (for their primary outcome of stroke, systemic embolism, MI, or vascular death) and did not find evidence of a difference in the risk of major bleeding (Table 6). Most patients (77\%) were receiving VKA therapy before randomization, raising some concerns about generalizability of these findings to patients with $\mathrm{AF}$ who are being newly started on VKA therapy (ie, by enrolling mostly 


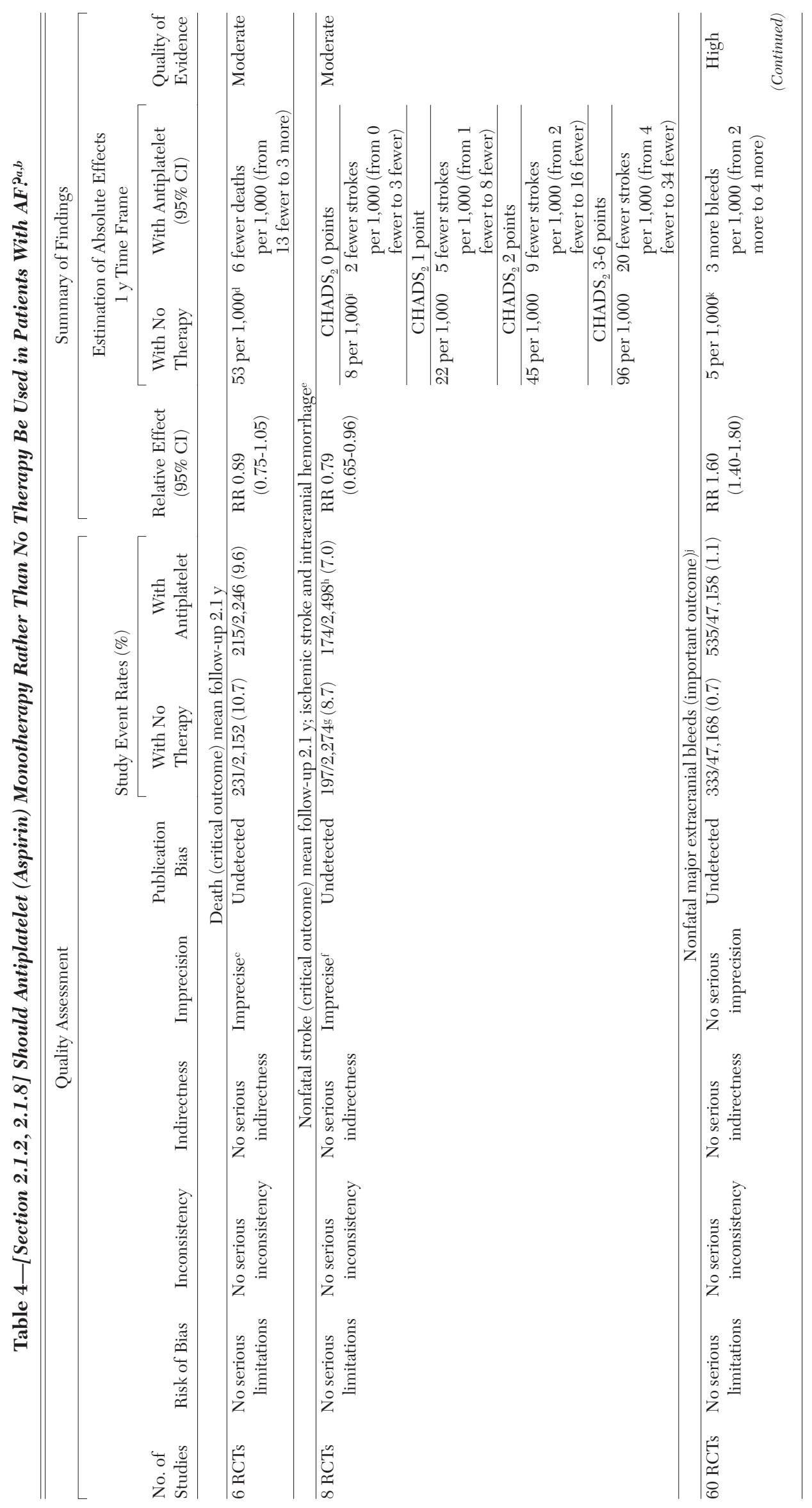




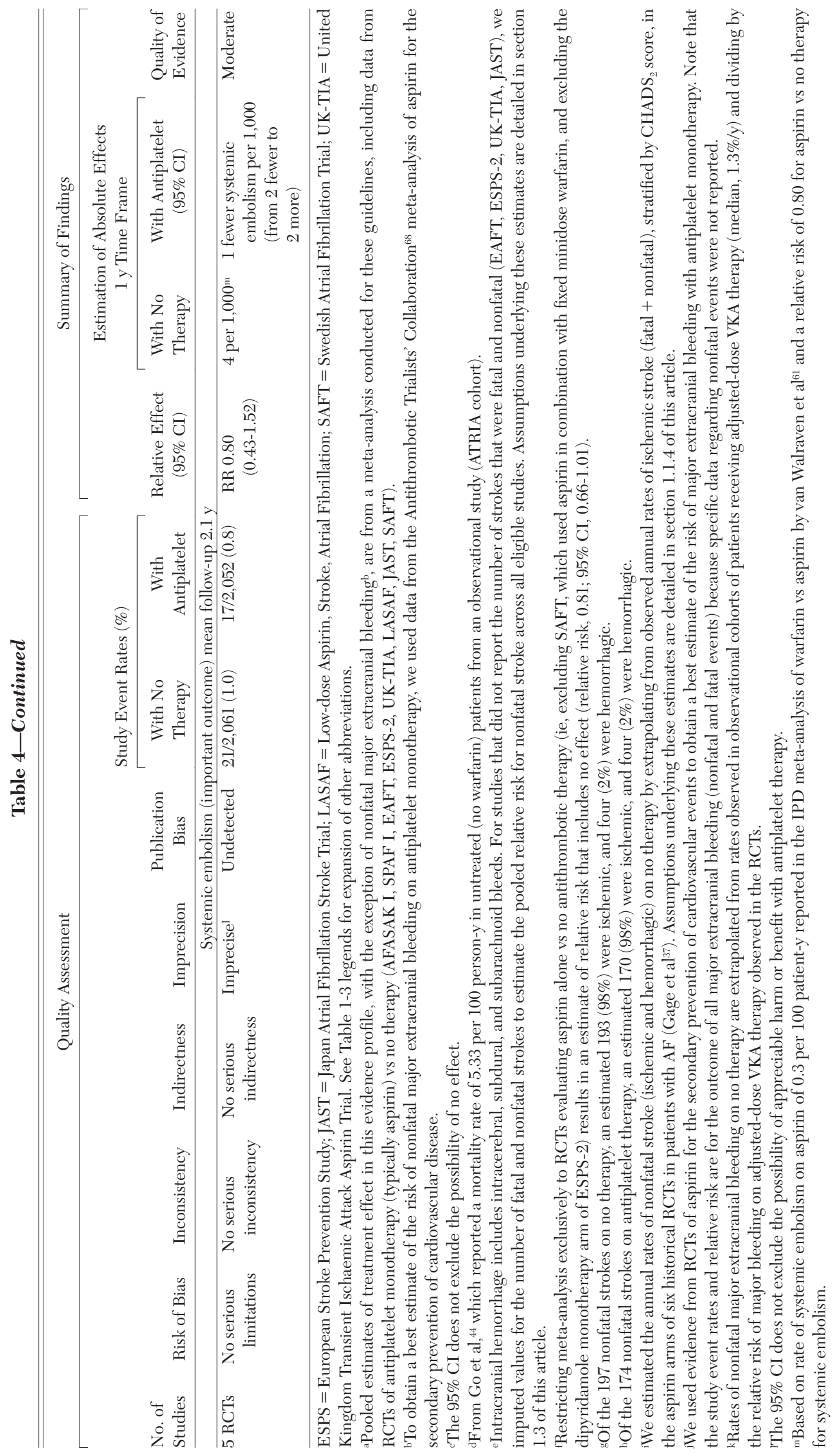




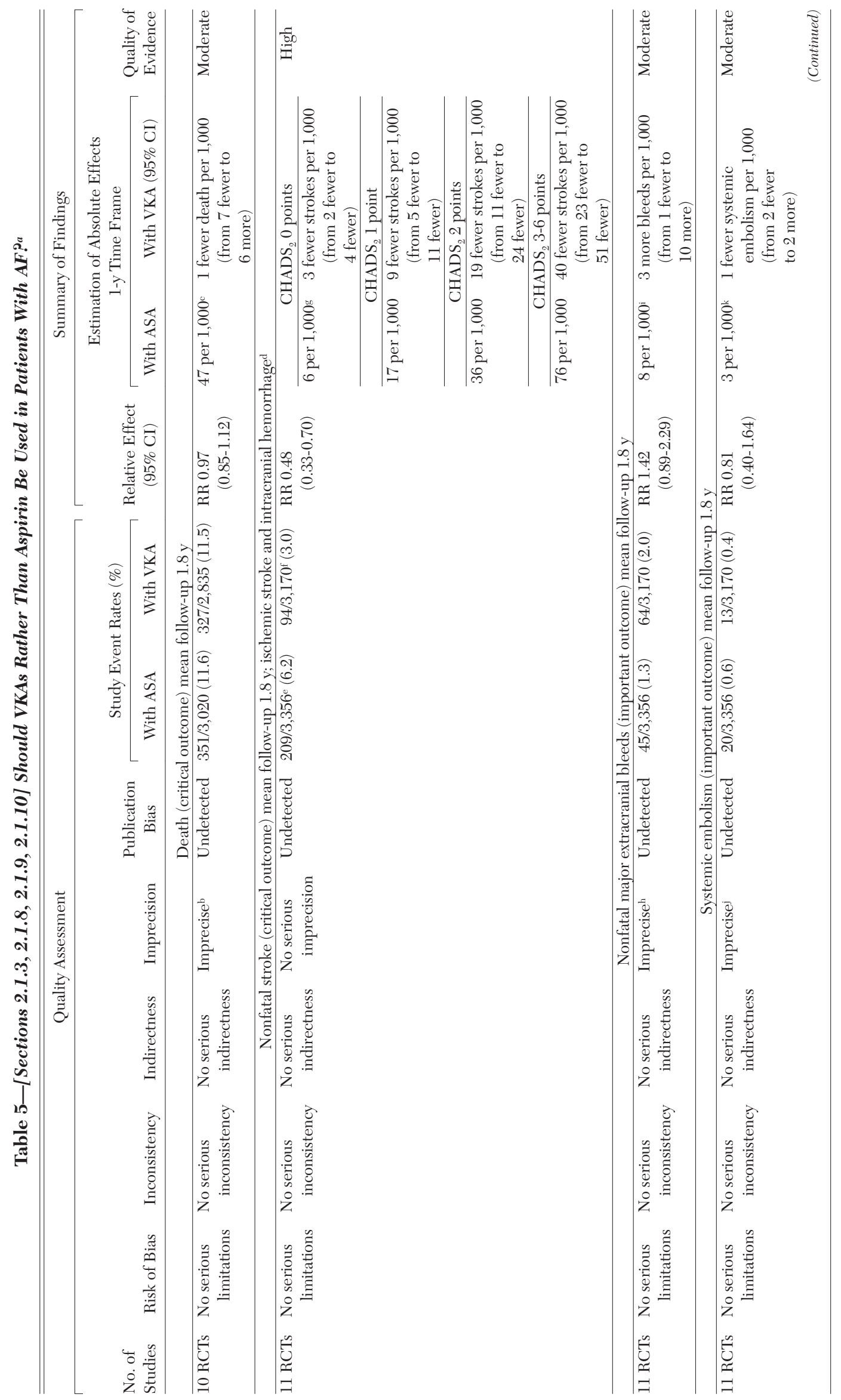




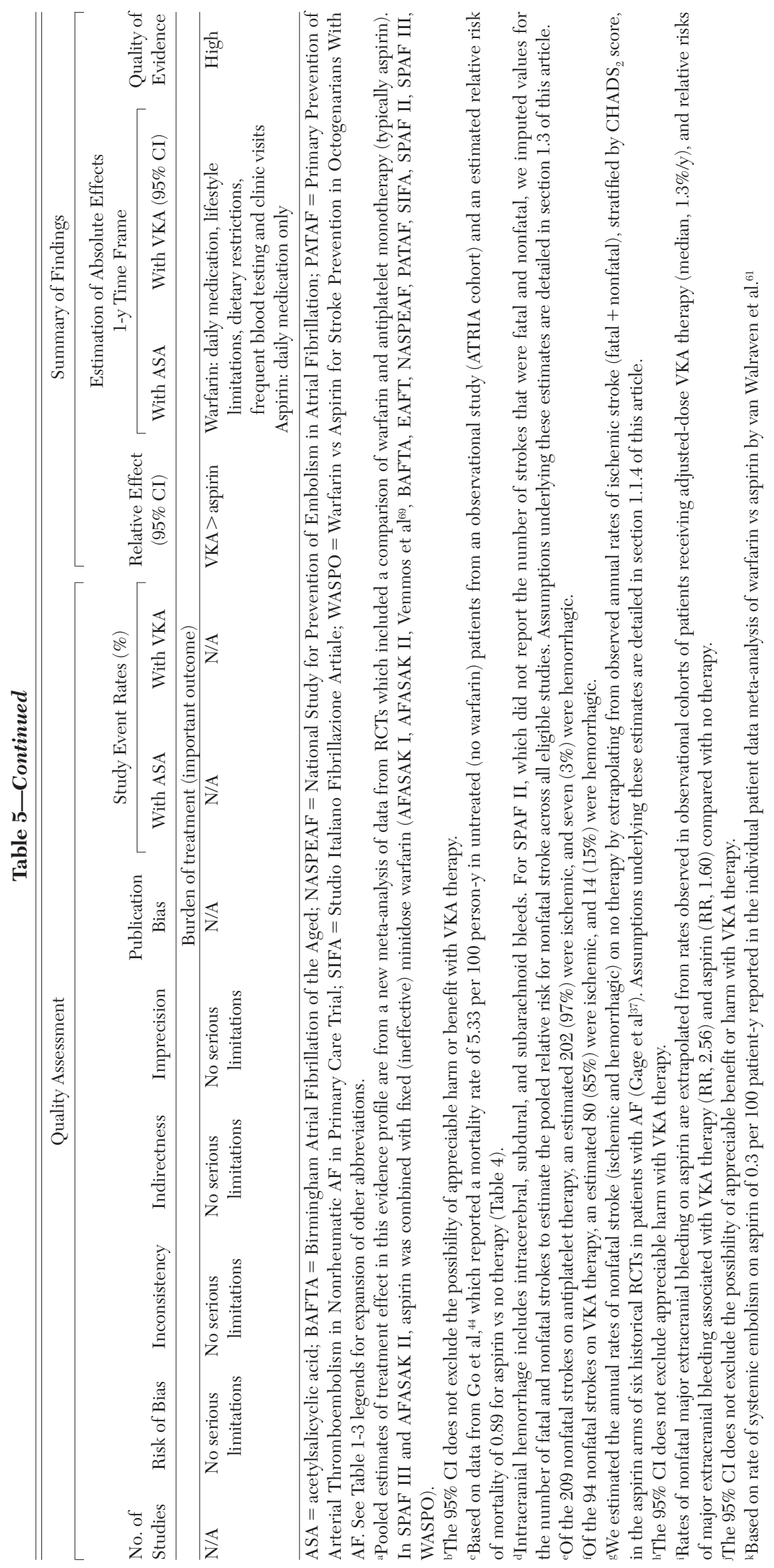




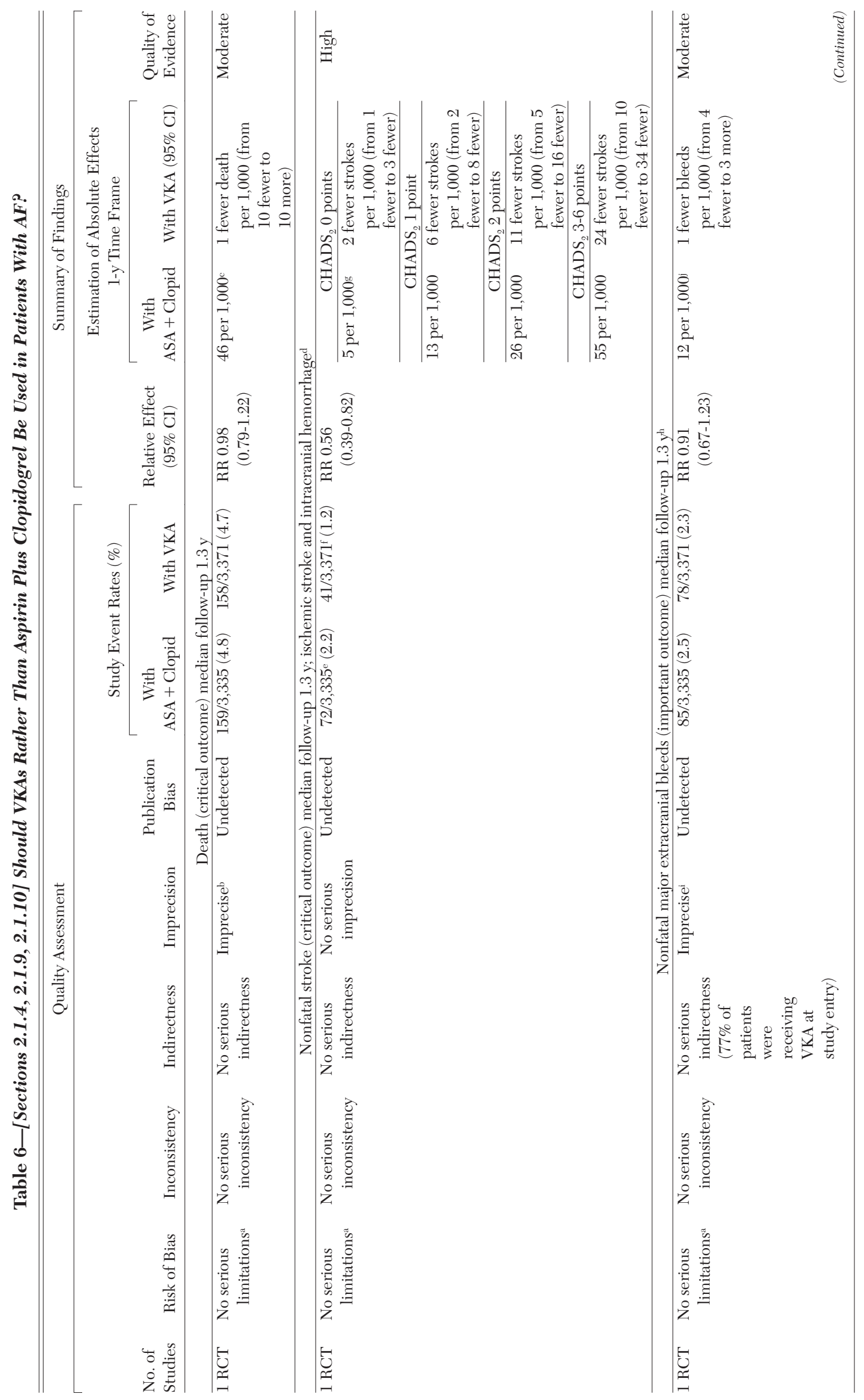




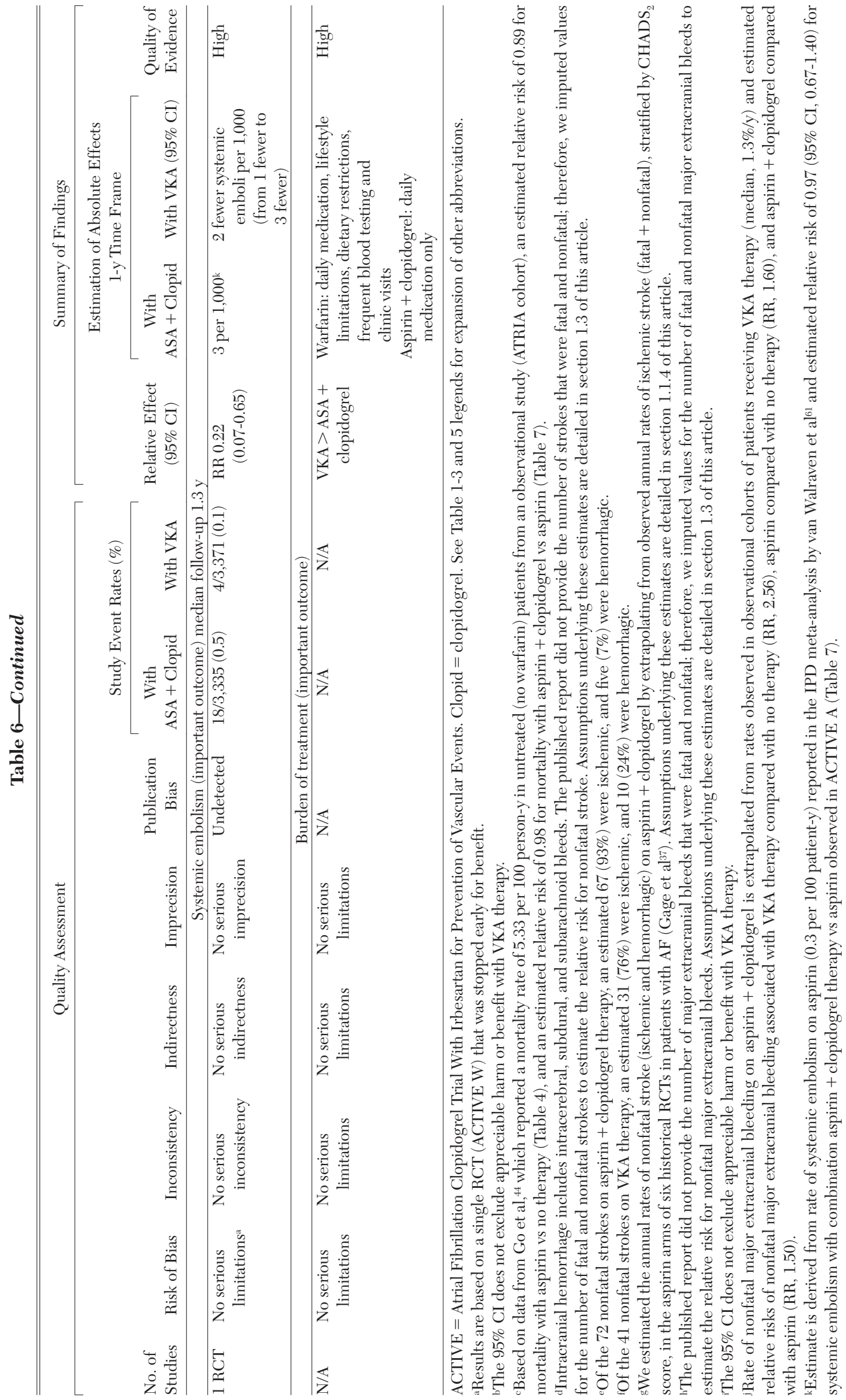


prior users of VKA therapy, the study sample may be more representative of patients in whom VKA therapy is well tolerated). In prespecified subgroup analyses, the investigators did not find evidence of a difference in the effect of VKA therapy on primary outcome in patients who were and were not receiving VKA therapy at study entry. However, there was a significant difference (interaction $P=.03$ ) in the effect on major bleeding, depending on whether patients were prior users of VKA therapy. For patients who were not receiving VKA therapy at study entry, VKA therapy was associated with a nonsignificant trend toward a $69 \%$ relative increase in major bleeding compared with dual antiplatelet therapy, whereas in patients already receiving VKA therapy at study entry, VKA therapy was associated with a nonsignificant trend toward a $24 \%$ relative decrease in major bleeding compared with dual antiplatelet therapy.

2.1.5 Dual Antiplatelet Therapy With Aspirin and Clopidogrel vs Aspirin Alone: The ACTIVE A study compared combination aspirin and clopidogrel therapy with aspirin alone. ${ }^{81}$ The trial enrolled 7,554 patients considered unsuitable for VKA therapy (approximately one-half because of a physician's judgment that VKA was inappropriate, one-fourth because of a specific risk of bleeding, and one-fourth because of the patient's preference not to take a VKA as the sole reason) and found that combination therapy is more effective in reducing the risk of nonfatal stroke in patients with AF but also increases the risk of nonfatal major extracranial bleeds compared with treatment with aspirin alone (Table 7).

2.1.6 New Oral Anticoagulants vs VKAs: Antithrombotic therapy for $\mathrm{AF}$ is evolving rapidly because of the development of new oral anticoagulants that directly target different parts of the coagulation pathway, have a more predictable anticoagulant effect, and do not require INR monitoring. Included in this new group of drugs are direct thrombin inhibitors (eg, dabigatran) and direct factor Xa inhibitors (apixaban, rivaroxaban, edoxaban). Results of large phase 3 clinical trials of these agents in patients with $\mathrm{AF}$ have been recently published or will be reported soon (Table 8). Although ximelagatran is no longer approved for use by regulatory agencies because of concerns about severe liver toxicity, the Stroke Prevention Using an Oral Thrombin Inhibitor in Patients With AF (SPORTIF) III and V trials were a proof of principle that a direct thrombin inhibitor can achieve similar protection against stroke compared with warfarin (ie, findings met the investigators' prespecified noninferiority criterion) with no evidence of increased bleeding risk. ${ }^{82,83}$

The Randomized Evaluation of Long-Term Anticoagulation Therapy (RE-LY) trial reported the results of a three-arm RCT of 18,113 patients with $\mathrm{AF}$ in which dabigatran $110 \mathrm{mg}$ bid, and dabigatran $150 \mathrm{mg}$ bid, were compared with open-label, adjusted-dose warfarin (target INR 2.0-3.0). ${ }^{84}$ Based on best estimates of the proportion of strokes and major extracranial bleeds that were nonfatal (the published report did not present the number or proportion of fatal and nonfatal events), dabigatran at a dose of $150 \mathrm{mg}$ bid is associated with a statistically significant one-third reduction in nonfatal stroke, with no evidence of a difference in the risk of nonfatal major extracranial bleeding compared with warfarin. Moreover, the data raised the possibility that dabigatran $150 \mathrm{mg}$ bid may reduce all-cause mortality compared with warfarin (relative risk, 0.89; 95\% CI, 0.79-1.01) (Table 9). In contrast, dabigatran at a dose of $110 \mathrm{mg}$ bid was not associated with a significant difference in the risk of death, nonfatal stroke, nonfatal major extracranial bleeding, or systemic embolism (Table 10).

ROCKET-AF (Rivaroxaban Once Daily Oral direct Factor Xa inhibition Compared with Vitamin K Antagonism for Prevention of Stroke and Embolism Trial in Atrial Fibrillation) was a double-blind, doubledummy RCT comparing rivaroxaban $20 \mathrm{mg}$ once daily to adjusted-dose warfarin (INR 2.0-3.0) in 14,264 patients with $\mathrm{AF}$ at increased risk of stroke (mean $\mathrm{CHADS}_{2}$ score of 3.5). ${ }^{85}$ In the intention-totreat analysis, rivaroxaban was noninferior to warfarin for the primary end point of stroke (ischemic or hemorrhagic) or systemic embolism but was not superior to warfarin (hazard ratio, $0.88 ; 95 \% \mathrm{CI}, 0.74-1.03$ ). The trial did not find evidence of a difference in major bleeding between rivaroxaban and warfarin (hazard ratio, 1.04; 95\% CI, 0.90-1.20). Major GI bleeding was more common with rivaroxaban than with warfarin $(3.2 \%$ and $2.2 \%$, respectively, $P<.001)$. Mortality was not significantly different between rivaroxaban and warfarin.

The Apixaban vs Acetylsalicylic Acid to Prevent Strokes (AVERROES) RCT compared apixaban $5 \mathrm{mg}$ bid to aspirin in 5,599 patients with AF who were demonstrated or expected to be unsuitable candidates for adjusted-dose VKA therapy. ${ }^{86}$ The trial was stopped early for benefit and was consistent with the trials of VKA therapy vs aspirin (section 2.1.3), reporting that apixaban reduces by one-half the occurrence of the primary outcome of stroke and systemic embolism compared with aspirin (hazard ratio, $0.45 ; 95 \% \mathrm{CI}, 0.32-0.62$ ). The trial failed to demonstrate or exclude a difference in the risk of major extracranial bleeding with apixaban compared with aspirin (hazard ratio, 1.23; 95\% CI, 0.74-2.05), and the results were consistent with those of earlier trials of VKA therapy vs aspirin (section 2.1.3), which suggest an increase in the risk of major extracranial 


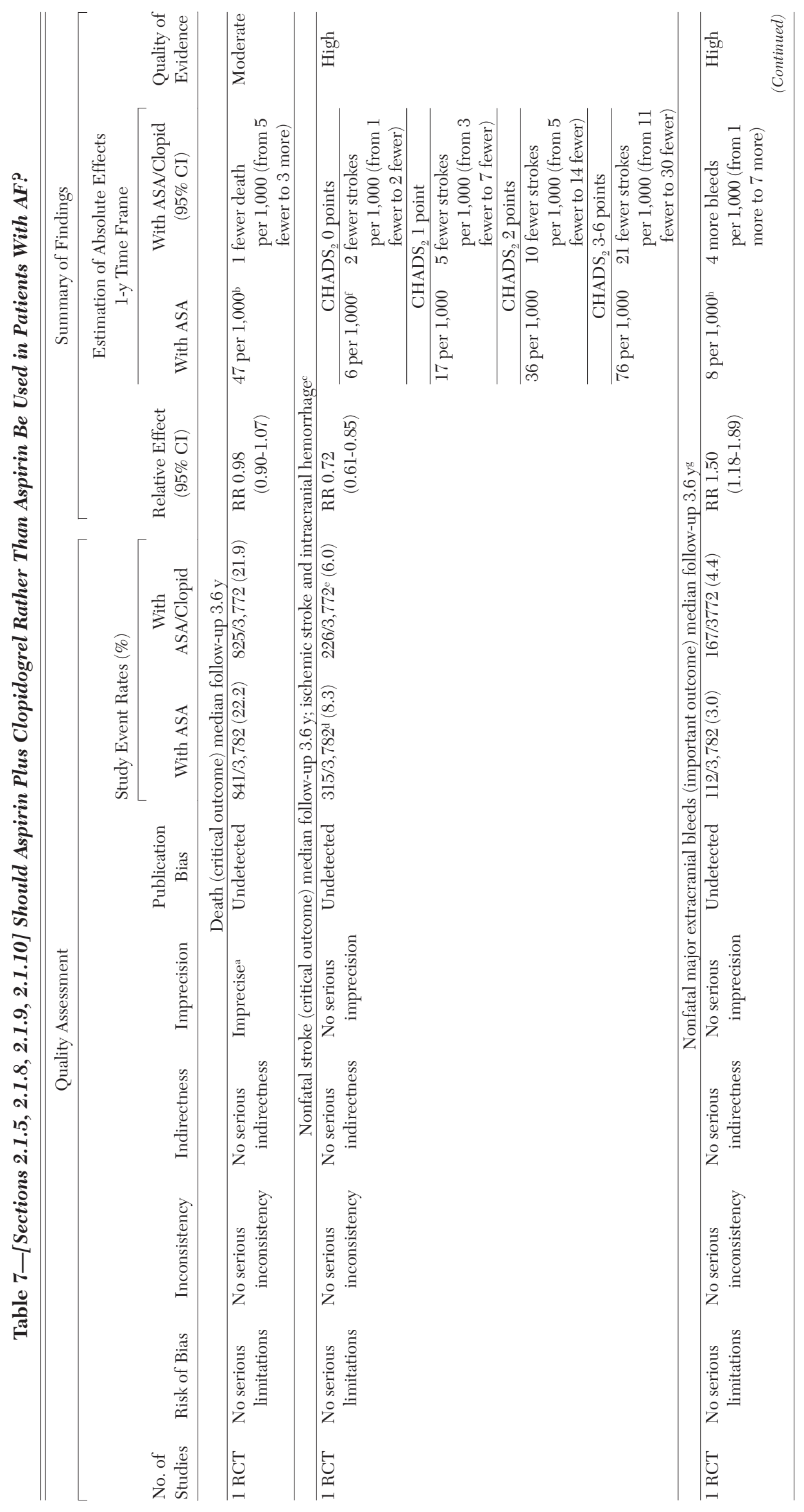




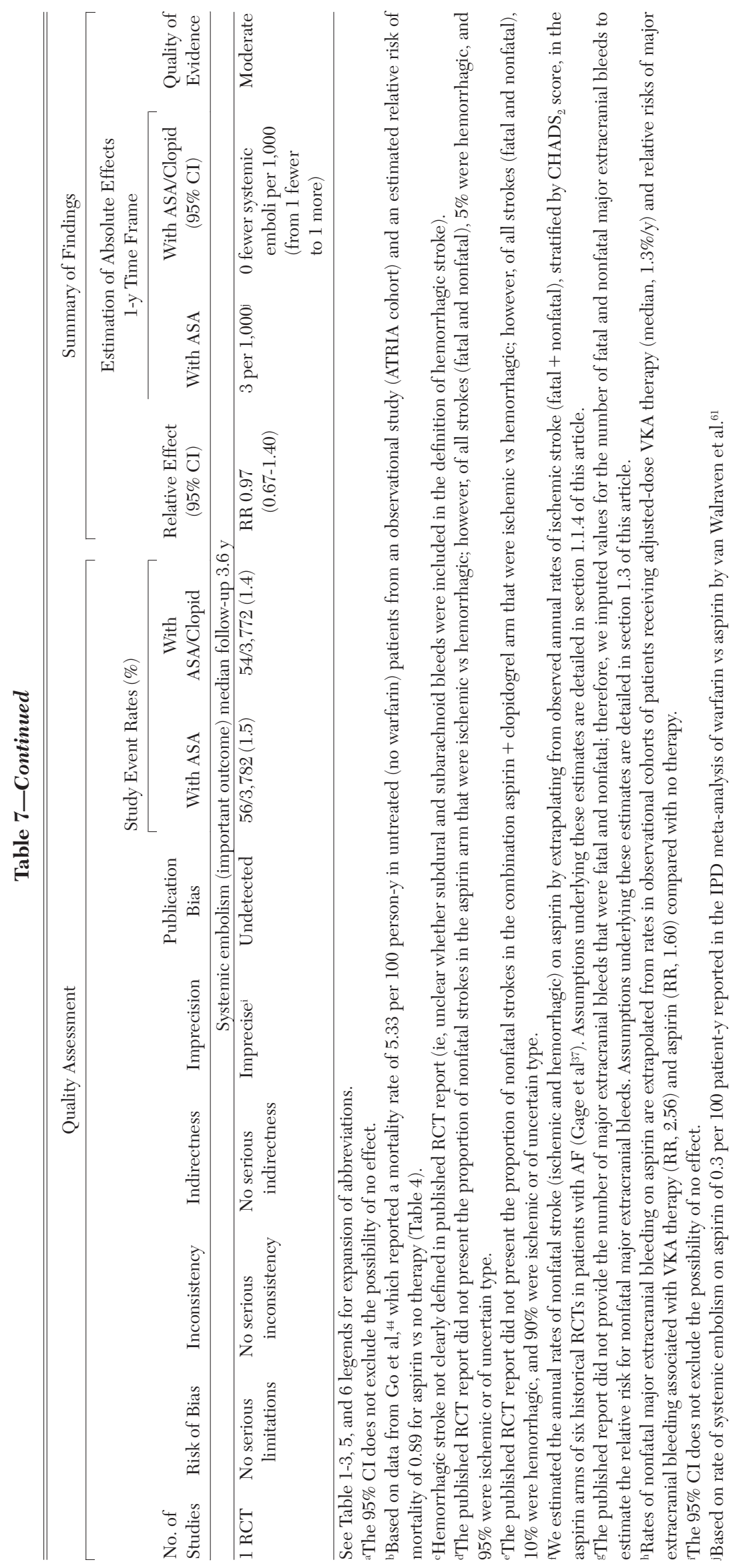


Table 8-[Section 2.1.6] Phase 3 RCTs of New Oral Anticoagulants in Patients With AF

\begin{tabular}{|c|c|c|c|}
\hline Trial & Intervention & Comparator & Status \\
\hline $\begin{array}{l}\text { SPORTIF III } \\
\text { SPORTIF V }\end{array}$ & Ximelagatran & Warfarin (INR, 2.0-3.0) & Published ${ }^{82,83}$ \\
\hline RE-LY & Dabigatran (150 or $110 \mathrm{mg}$ bid) & Warfarin (INR, 2.0-3.0) & Published $^{84}$ \\
\hline AVERROES & Apixaban ( $5 \mathrm{mg}$ bid) & Aspirin (81-324 mg daily) & Published $^{86}$ \\
\hline ROCKET-AF & Rivaroxaban (20 mg once daily) & Warfarin (INR, 2.0-3.0) & Published $^{85}$ \\
\hline ARISTOTLE & Apixaban $(5 \mathrm{mg}$ bid $)$ & Warfarin (INR, 2.0-3.0) & Published $^{87}$ \\
\hline ENGAGE-AF TIMI 48 & Edoxaban (high- and low-dose regimens) & Warfarin (INR, 2.0-3.0) & Currently recruiting \\
\hline
\end{tabular}

bleeding with oral anticoagulation compared with aspirin.

ARISTOTLE (Apixaban for the Prevention of Stroke in Subjects With Atrial Fibrillation) was a double-blind, double-dummy RCT comparing apixaban $5 \mathrm{mg}$ bid to warfarin (INR 2.0-3.0) in 18,201 patients with AF (mean $\mathrm{CHADS}_{2}$ score of 2.1). ${ }^{87}$ Apixaban reduced by $21 \%$ the risk of the primary outcome of stroke (ischemic or hemorrhagic) or systemic embolism (hazard ratio, 0.79; 95\% CI, 0.66-0.95) and reduced by $31 \%$ the risk of major bleeding (hazard ratio, 0.69; 95\% CI, 0.60-0.80) compared with warfarin. There was no evidence of a difference in major GI bleeding between apixaban and warfarin (hazard ratio, $0.89 ; 95 \%$ CI, 0.70-1.15). All-cause mortality was lower with apixaban compared with warfarin (hazard ratio, 0.89; 95\% CI, 0.80-0.998). In all three recently completed trials of novel anticoagulants vs warfarin (RE-LY, ROCKET-AF, and ARISTOTLE), the rate of intracranial hemorrhage (including both hemorrhagic stroke and other intracranial bleeds) was lower in patients assigned to the novel anticoagulant than in patients assigned to warfarin..$^{84,85,87,88}$

\subsubsection{General Approach to Recommendations} About New Oral Anticoagulants in This Article: Our guideline panel elected to make recommendations only for those drugs that have received regulatory approval for use in AF (ie, dabigatran). ${ }^{89}$ Although based on the results of a single trial, there is evidence from RE-LY that dabigatran is no worse than VKA therapy with respect to nonfatal major extracranial bleeding and that it is similar or superior to warfarin with respect to nonfatal stroke, systemic embolism, and all-cause mortality in patients with nonvalvular $\mathrm{AF}$ (section 2.1.6). Therefore, for patients with nonrheumatic AF, wherever we recommend (or suggest) VKA therapy, we also recommend (or suggest) the use of dabigatran, and in these situations, our recommendations simply refer to oral anticoagulation..$^{88}$ We address the specific question of whether to use dabigatran over adjusted-dose VKA therapy in section 2.1.11.

The data from RE-LY do not directly address the use of dabigatran in patients with $\mathrm{AF}$ and mitral stenosis (patients with hemodynamically relevant valvular disease were excluded from this study), or in patients with $\mathrm{AF}$ in other special situations (sections 2.2 and 3.0). Therefore, we have not extrapolated the data from RE-LY to these clinical situations and have instead restricted those recommendations for oral anticoagulation to adjusted-dose VKA therapy. There is direct evidence from RE-LY regarding the use of dabigatran in patients with $\mathrm{AF}$ undergoing cardioversion, and these data are summarized in section 4.1.1.

\subsubsection{Recommendations for Patients With AF at} Low Risk of Stroke (eg, $\mathrm{CHADS}_{2}$ Score of 0): Patients at sufficiently low risk of ischemic stroke may opt for no treatment rather than antithrombotic therapy with either aspirin or an oral anticoagulant. For instance, for every 1,000 patients at low risk of stroke with a $\mathrm{CHADS}_{2}$ score of 0 , VKA therapy compared with no treatment is anticipated to result in five fewer nonfatal strokes at the expense of eight more nonfatal major extracranial bleeds and the additional burden of adjusted-dose VKA treatment (Table 3). Although VKA therapy is expected to reduce all-cause mortality in patients with AF in general, it is likely that this mortality benefit does not extend to low-risk patients. The absolute reduction in fatal ischemic stroke with VKA therapy will be far fewer such patients, whereas their absolute increase in fatal intracranial hemorrhage will be similar to those with higher $\mathrm{CHADS}_{2}$ scores. ${ }^{51}$

For patients with a $\mathrm{CHADS}_{2}$ score of 0 , treatment with aspirin for 1 year may result in the prevention of two nonfatal strokes per 1,000 patients (moderatequality evidence due to imprecision) at the expense of three additional nonfatal major extracranial bleeds per 1,000 patients compared with no treatment (Table 4). If stroke rates are truly declining over time, 


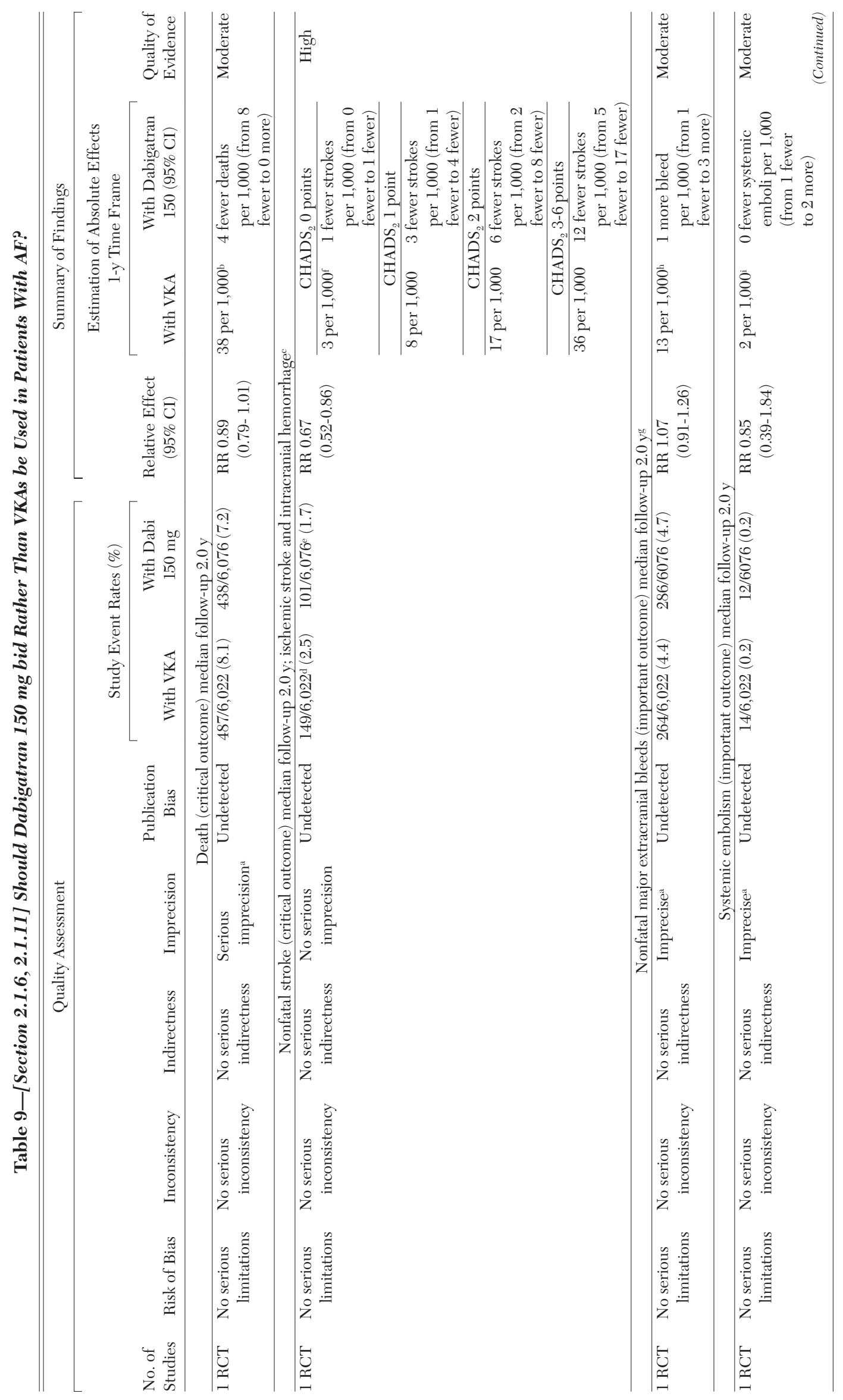




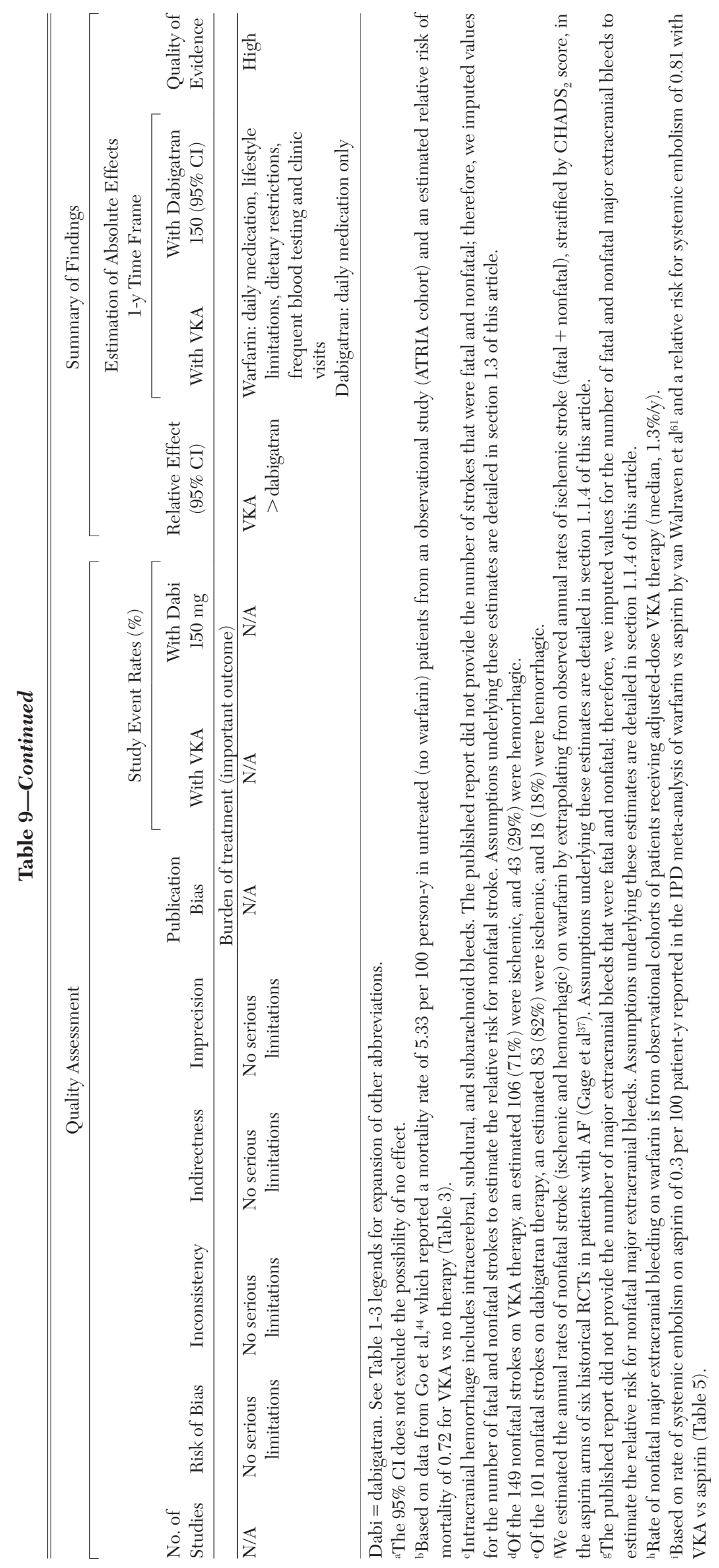




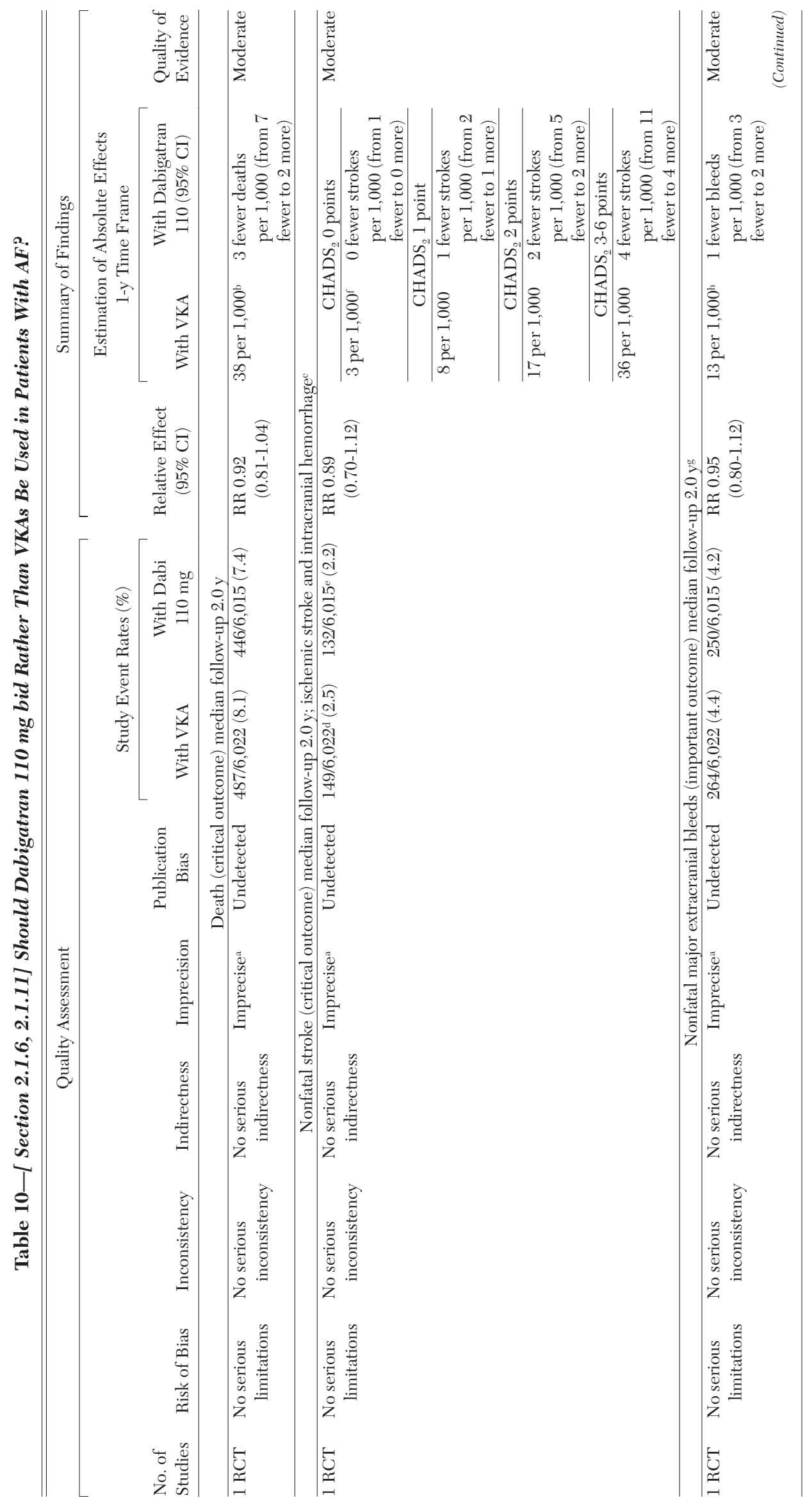




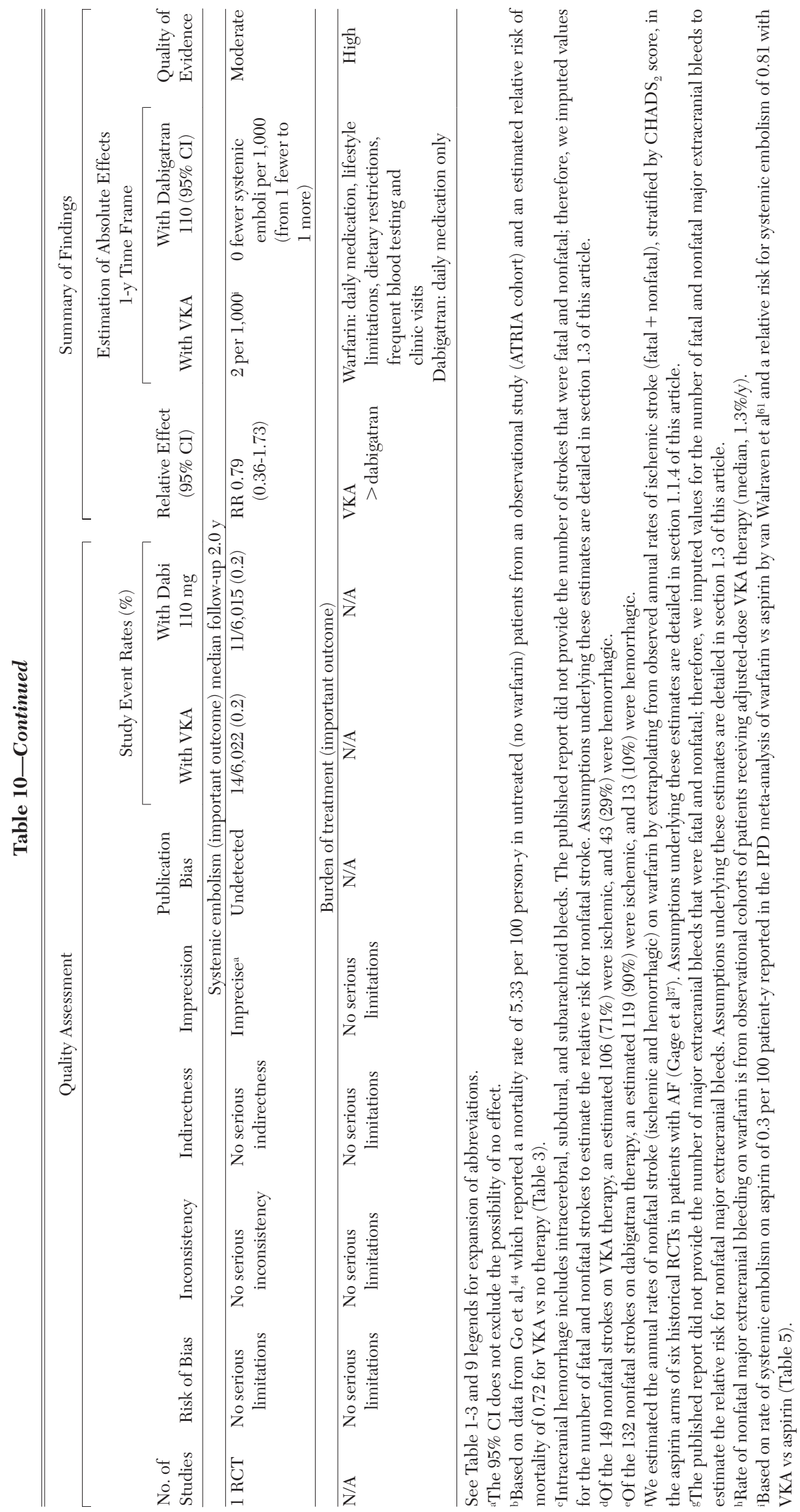


then the already small benefits of antithrombotic therapy (number needed to treat for 1 year to prevent one nonfatal stroke of 500 for aspirin and 200 for VKA therapy) will be even smaller.

For patients who do choose antithrombotic therapy, the potential choices are aspirin, dual antiplatelet therapy with aspirin and clopidogrel, or oral anticoagulation. For every 1,000 patients with a $\mathrm{CHADS}_{2}$ score of 0 , treatment for 1 year with adjusted-dose VKA therapy or with combination aspirin and clopidogrel therapy compared with aspirin is anticipated to result in small reductions in nonfatal stroke and an increase in nonfatal major extracranial bleeding such that the net benefits of either VKA therapy or dual antiplatelet therapy with aspirin and clopidogrel would be small, particularly given the possibility of declining stroke rates over time (Tables 5, 7).

Recommendation

2.1.8. For patients with $\mathrm{AF}$, including those with paroxysmal AF, who are at low risk of stroke $\left(\right.$ eg, $\mathrm{CHADS}_{2}$ score $=$ ) $)$, we suggest no therapy rather than antithrombotic therapy (Grade $2 \mathrm{~B}$ ). For patients who do choose antithrombotic therapy, we suggest aspirin $(75 \mathrm{mg}$ to $325 \mathrm{mg}$ once daily) rather than oral anticoagulation (Grade 2B) or combination therapy with aspirin and clopidogrel (Grade 2B).

Remarks: Patients who place an exceptionally high value on stroke reduction and a low value on avoiding bleeding and the burden associated with antithrombotic therapy are likely to choose antithrombotic therapy rather than no antithrombotic therapy. Other factors that may influence the choices above are a consideration of patient-specific bleeding risk and the presence of additional risk factors for stroke, including age 65 to 74 years and female sex, which have been more consistently validated, and vascular disease, which has been less well validated (see section 2.1.12). The presence of multiple non$\mathrm{CHADS}_{2}$ risk factors for stroke may favor oral anticoagulation therapy.

2.1.9 Recommendations for Patients With AF at Intermediate Risk of Stroke (eg, $\mathrm{CHADS}_{2}$ Score of 1): For patients at intermediate risk of stroke with a $\mathrm{CHADS}_{2}$ score of 1, compared with no therapy, 1 year of VKA therapy is expected to result in 15 fewer deaths and 15 fewer nonfatal strokes per 1,000 patients at the cost of eight more nonfatal major extracranial bleeds (Table 3). Regarding the choice between VKA therapy and aspirin, VKA therapy is anticipated to prevent nine nonfatal strokes for every 1,000 patients treated for 1 year compared with aspirin but will result in three additional bleeds and no reduction in all-cause mortality. However, because absolute rates of stroke may have fallen over the past 2 decades, we may be overestimating the absolute reduction in nonfatal stroke achieved with VKA therapy. Moreover, the true extent of bleeding risk with VKA therapy compared with aspirin therapy is unclear because the pooled estimate of the relative risk of bleeding from the relevant RCTs is imprecise (Table 5). The limited ability of $\mathrm{CHADS}_{2}$ to accurately predict stroke risk (C statistic, $0.6-0.7$ ), the considerable variability in patient values and preferences, and the burden and lifestyle limitations associated with adjusted-dose VKA therapy, introduce further uncertainty.

Compared with combination therapy with aspirin and clopidogrel, VKA therapy is expected to result in six fewer nonfatal strokes per 1,000 patients over a 1-year period, anywhere from four fewer to three more nonfatal major extracranial bleeds, and no reduction in all-cause mortality (Table 6). Uncertainty regarding the small net clinical benefit at a $\mathrm{CHADS}_{2}$ score of 1 arises as a result of the limitations of the $\mathrm{CHADS}_{2}$ score in estimating stroke risk and the possibility of declining absolute stroke rates over time. Uncertainty regarding the value of the small net benefit arises from the variability in patient values and preferences and the burden and lifestyle limitations associated with adjusted-dose VKA therapy.

For patients at intermediate risk of stroke with a CHADS $_{2}$ score of 1 who are unsuitable for or choose not to take an oral anticoagulant for reasons other than concerns about major bleeding (eg, difficulty maintaining a stable INR, lifestyle limitations of regular INR monitoring, dietary restrictions that are too burdensome, or costs of new anticoagulant drugs that are too high), combination therapy with aspirin and clopidogrel provides additional benefit of stroke reduction at the cost of additional bleeding (ACTIVE A trial) (Table 7). Patients opting for combination antiplatelet therapy rather than treatment with an oral anticoagulant should be informed that they are choosing an inferior treatment with regard to stroke prevention.

\section{Recommendation}

2.1.9. For patients with $A F$, including those with paroxysmal $\mathrm{AF}$, who are at intermediate risk of stroke (eg, $\mathrm{CHADS}_{2}$ score $=1$ ), we recommend oral anticoagulation rather than no therapy (Grade 1B). We suggest oral anticoagulation rather than aspirin (75 $\mathrm{mg}$ to $325 \mathrm{mg}$ once daily) (Grade 2B) or combination therapy with aspirin and clopidogrel (Grade 2B). For patients who are unsuitable for or choose not to take an oral anticoagulant (for reasons other than concerns 
about major bleeding), we suggest combination therapy with aspirin and clopidogrel rather than aspirin (75 mg to $325 \mathrm{mg}$ once daily) (Grade $2 \mathrm{~B}$ ).

Remarks: Patients who place an exceptionally high value on stroke reduction and a low value on avoiding bleeding and the burden associated with anticoagulant therapy are likely to choose oral anticoagulation rather than antiplatelet therapy. Other factors that may influence the choice among antithrombotic therapies are a consideration of bleeding risk and the presence of additional risk factors for stroke, including age 65 to 74 years and female gender, which have been more consistently validated, and vascular disease, which has been less well validated (see section 2.1.12). The presence of multiple non-CHADS risk factors for stroke may favor oral anticoagulation therapy.

2.1.10 Recommendations for Patients With AF at High Risk of Stroke (eg, CHADS 2 Score of $\geq 2$, Which Includes Prior Ischemic Stroke or TIA): Patients at high risk of ischemic stroke, which includes patients with a history of ischemic stroke or TIA, can anticipate large benefits (ie, 15 fewer deaths and 30 fewer nonfatal strokes per 1,000 patients during 1 year of VKA therapy) with anticoagulation (Table 3 ).

For every 1,000 patients with a CHADS score of $_{2}$ 2 treated for 1 year with VKA therapy rather than aspirin, we anticipate 19 fewer nonfatal strokes at the expense of three more nonfatal major extracranial bleeds (Table 5). For every 1,000 such patients treated with VKA rather than combination therapy with aspirin and clopidogrel, we anticipate 11 fewer strokes and anywhere between four fewer to three more nonfatal major extracranial bleeds (Table 6). There is therefore a substantial net clinical benefit with oral anticoagulation.

For patients at high risk of ischemic stroke with a CHADS $_{2}$ score of $\geq 2$ who are unsuitable for or who choose not to take an oral anticoagulant for reasons other than concerns about major bleeding (eg, difficulty maintaining a stable INR, lifestyle limitations of regular INR monitoring, dietary restrictions that are too burdensome, or costs of new anticoagulant drugs that are too high), aspirin and clopidogrel therapy will result in a substantial reduction in stroke compared with aspirin alone (ACTIVE A trial) (Table 7). Patients opting for combination antiplatelet therapy rather than treatment with an oral anticoagulant should be informed that they are choosing an inferior treatment with regard to stroke prevention.

Recommendation

2.1.10. For patients with AF, including those with paroxysmal AF, who are at high risk of stroke (eg, $\mathrm{CHADS}_{2}$ score $\geq 2$ ), we recommend oral anticoagulation rather than no therapy (Grade 1A), aspirin (75 mg to $325 \mathrm{mg}$ once daily) (Grade 1B), or combination therapy with aspirin and clopidogrel (Grade 1B). For patients who are unsuitable for or choose not to take an oral anticoagulant (for reasons other than concerns about major bleeding), we recommend combination therapy with aspirin and clopidogrel rather than aspirin ( $75 \mathrm{mg}$ to $325 \mathrm{mg}$ once daily) (Grade 1B).

\subsubsection{Recommendation Regarding Dabigatran} vs Adjusted-Dose VKA Therapy: The RE-LY trial showed that dabigatran, at the higher dose of $150 \mathrm{mg}$ bid, leads to reductions in nonfatal stroke, probable reductions in all-cause mortality, and no apparent increase in the risk of nonfatal major extracranial bleeding compared with VKA therapy (Table 9), whereas there was no evidence that dabigatran $110 \mathrm{mg}$ bid leads to a significant reduction in relevant outcomes compared with VKA therapy (Table 10). In the United States, the Food and Drug Administration approved the use of dabigatran for the prevention of thromboembolism in patients with $\mathrm{AF}$ at a dose of $150 \mathrm{mg}$ bid but not at a dose of $110 \mathrm{mg}$ bid. However, the Food and Drug Administration did approve, based on pharmacokinetic considerations rather than direct evidence from RCTs in AF populations, a dose of $75 \mathrm{mg}$ bid for patients with severe renal insufficiency (defined as a creatinine clearance $15-30 \mathrm{~mL} / \mathrm{min}) .89$

For the question of whether to use dabigatran vs adjusted-dose VKA therapy, the evidence suggests net clinical benefit at the $150-\mathrm{mg}$ dose. At the time of this writing, however, knowledge regarding the efficacy and safety of the new oral anticoagulants for patients with AF is still limited to one large randomized trial per agent. Uncommon but serious adverse effects may emerge with large-scale use of the drugs. Performance in usual clinical care may deteriorate because of less-restricted patient selection and suboptimal adherence to the unmonitored drug. For patients who do experience bleeding complications, clinicians need to be aware that there is no antidote to reverse the anticoagulant effects of dabigatran. ${ }^{90}$ Given these concerns, it would be reasonable for VKA-experienced patients who are well controlled (ie, INR within therapeutic range a high proportion of the time) to continue on VKA therapy if they are satisfied with it and are tolerating it well rather than switching to dabigatran.

There is evidence from meta-analyses of $\mathrm{RCTS}^{92}$ that home monitoring of VKA therapy reduces thromboembolic events by $42 \%$ compared with usual monitoring (see also Holbrook et al $^{91}$ ), which is 
similar to the $33 \%$ relative reduction in stroke achieved with dabigatran $150 \mathrm{mg}$ bid compared with VKA therapy (Table 9). ${ }^{84}$ Therefore, any advantages of dabigatran with respect to thromboembolism would likely not exist for motivated patients who are able to participate in home monitoring of their VKA therapy. Although home monitoring will reduce the burden of INR testing and VKA dose adjustment, the burdens of VKA therapy related to dietary restrictions and drug interactions will still exist, and there will be a cost for the home monitoring device and test strips. Therefore, depending on how patients value these burdens, some may choose dabigatran rather than home monitoring of VKA therapy.

Before prescribing dabigatran, clinicians need to judge whether the patient is similar enough to those enrolled in RE-LY that the clinical trial results are still likely to apply. In particular, the RE-LY study excluded patients with severe renal impairment (estimated creatinine clearance $30 \mathrm{~mL} / \mathrm{min}$ or less). ${ }^{84}$ The cost-effectiveness of the new anticoagulants compared with VKA therapy is another consideration. An economic analysis based on pricing of dabigatran in the United Kingdom (US \$13 per day) estimated that dabigatran $150 \mathrm{mg}$ bid would cost $\$ 45,372$ more per quality-adjusted life year gained compared with warfarin for patients with $\mathrm{AF}$ aged 65 years with risk factors for stroke CHADS $_{2}$ score of $\geq 1$ ). The cost-effectiveness estimates in this model were sensitive to the pricing of dabigatran..$^{93}$

Recommendation

2.1.11. For patients with AF, including those with paroxysmal AF, for recommendations in favor of oral anticoagulation (including 2.1.9, 2.1.10, and excluding 2.2, 3.1, 3.2, 3.3), we suggest dabigatran $150 \mathrm{mg}$ twice daily rather than adjusted-dose VKA therapy (target INR range, 2.0-3.0) (Grade 2B).

Remarks: Dabigatran is excreted primarily by the kidney. It has not been studied and is contraindicated in patients with severe renal impairment (estimated creatinine clearance of $\leq 30 \mathrm{~mL} / \mathrm{min}$ ). Clinicians should be aware that there is no antidote for dabigatran.

\subsubsection{Tailoring These Recommendations to Indi-} vidual Patients: As with all weak recommendations, treatment decisions should be individualized based on patient values and preferences, and in this case, an assessment of bleeding risk, and a consideration of additional risk factors for stroke.

Bleeding Risk Assessment-We have not made separate recommendations depending on patient bleeding risk because there are insufficient data to estimate reliably the absolute bleeding rates for patients in different categories of bleeding risk on different antithrombotic regimens. However, the following evidence regarding bleeding risk assessment may help to guide individualized treatment decisions for patients with AF.

One challenge in bleeding risk assessment for patients with AF is that many of the factors associated with an increased risk of major bleeding are also risk factors for ischemic stroke. For instance, older age, hypertension, congestive heart failure, and prior history of ischemic stroke-all of which are components of the $\mathrm{CHADS}_{2}$ score-have been found in various studies of patients with $\mathrm{AF}$ to be independent predictors of bleeding while on VKA therapy. ${ }^{94}$

Several bleeding risk scores have been evaluated in cohorts of patients with AF (see Table 11).53,95-98 However, these scores have not been extensively validated. Their ability to predict major bleeding is modest, with comparable $\mathrm{C}$ statistics across external validation studies (range, 0.61-0.66).53,97-99 In scenarios where we make weak recommendations in favor of oral anticoagulation (eg, patients with a $\mathrm{CHADS}_{2}$ score of 1), patients at high risk of major bleeding may decline oral anticoagulation.

Additional Risk Factors for Stroke in Patients With AF-In addition to consideration of bleeding risk and patient values and preferences, for patients with a $\mathrm{CHADS}_{2}$ score of 0 or 1 , clinicians may wish to consider additional stroke risk factors when individualizing decisions about antithrombotic therapy. For instance, there is high-quality evidence that stroke risk increases continuously with age (rather than as a dichotomous function of age $<75$ or $\geq 75$ years) and moderate-quality evidence that female sex is an independent predictor of stroke risk in patients with AF. ${ }^{18,20}$ Thus, patients may be inclined to choose the more aggressive treatment option (eg, antithrombotic therapy rather than no therapy for patients with a CHADS ${ }_{2}$ score of 0 and oral anticoagulation rather than aspirin for patients with a $\mathrm{CHADS}_{2}$ score of 1) when these additional risk factors for stroke are present. The presence of multiple non-CHADS risk factors for stroke may favor oral anticoagulation therapy. There is less-consistent evidence supporting an independent association between vascular disease (ie, prior MI, complex aortic plaque seen on $\mathrm{TEE}$, and peripheral arterial disease) and the risk of stroke in patients with $\mathrm{AF}$ (section 1.4.2). ${ }^{21-23}$

\subsubsection{Percutaneous Closure of the Left Atrial} Appendage: Percutaneous closure of the left atrial appendage (LAA) has recently been evaluated as a nondrug alternative for stroke prevention in patients with AF. The PROTECT-AF (WATCHMAN Left 
Table 11-[Section 2.1.12] Bleeding Risk Scores

\begin{tabular}{|c|c|c|c|c|}
\hline & Low & Moderate & High & Calculation of Bleeding Risk Score \\
\hline $\begin{array}{l}\text { Outpatient Bleeding Risk } \\
\text { Index }{ }^{95,96}\end{array}$ & 0 & $1-2$ & $\geq 3$ & $\begin{array}{l}1 \text { point for each of: } \\
\text { Age } \geq 65 \mathrm{y} \\
\text { GI bleed in past } 2 \mathrm{wk} \\
\text { Previous stroke } \\
\text { Comorbidities (recent MI, Hct }<30 \% \text {, diabetes, or creatinine }>1.5 \mathrm{mg} / \mathrm{dL} \text { ) }\end{array}$ \\
\hline $\mathrm{HEMORR}_{2} \mathrm{HAGES}^{9 \mathrm{~s}}$ & $0-1$ & $2-3$ & $\geq 4$ & $\begin{array}{l}1 \text { point for each of: } \\
\text { Hepatic or renal disease } \\
\text { Ethanol abuse } \\
\text { Malignancy } \\
\text { Older age (>75 yr) } \\
\text { Reduced platelet count or function } \\
\text { Hypertension (uncontrolled) } \\
\text { Anemia } \\
\text { Genetic factors (CYP2C9 polymorphisms) } \\
\text { Excessive fall risk } \\
\text { Stroke } \\
2 \text { points for: } \\
\text { Rebleeding risk (ie, prior bleed) }\end{array}$ \\
\hline Shireman et a ${ }^{97}$ & $\leq 1.07$ & $>1.07$ to $<2.19$ & $\geq 2.19$ & $\begin{array}{l}(0.49 \times \text { age }>70)+(0.32 \times \text { female })+(0.58 \times \text { remote bleed })+ \\
(0.62 \times \text { recent bleed })+(0.71 \times \text { alcohol } / \text { drug abuse })+ \\
(0.27 \times \text { diabetes })+(0.86 \times \text { anemia })+(0.32 \times \text { antiplatelet drug use }) \\
\text { with } 1 \text { point for presence of each and } 0 \text { if absent }\end{array}$ \\
\hline HAS-BLED 53,99 & 0 & $1-2$ & $\geq 3$ & $\begin{array}{l}\text { Hypertension (ie, uncontrolled BP) } \\
\text { Abnormal renal/liver function (1 point each) } \\
\text { Stroke } \\
\text { Bleeding history or predisposition } \\
\text { Labile INR } \\
\text { Elderly (eg, age }>65 \text { y) } \\
\text { Drugs (eg, concomitant antiplatelet/NSAID) or alcohol (1 point each) } \\
\text { Maximum } 9 \text { points }\end{array}$ \\
\hline
\end{tabular}

Hct $=$ hematocrit; NSAID $=$ nonsteroidal antiinflammatory drug. See Table 1 and 8 legends for expansion of other abbreviations.

Atrial Appendage System for Embolic PROTECTion in Patients With Atrial Fibrillation) study randomized 707 patients with $\mathrm{AF}$ to percutaneous closure of the LAA using the WATCHMAN device (Atritech, Inc) or adjusted-dose warfarin to achieve a target INR of 2.0 to 3.0. ${ }^{100}$ Percutaneous LAA closure was associated with a statistically nonsignificant reduction in the risk of their primary efficacy outcome of stroke (ischemic or hemorrhagic), cardiovascular or unexplained death, or systemic embolism compared with warfarin (absolute risk reduction, $1.9 \%$ per year; $95 \%$ CI, $3.2 \%$ per year less to $1.2 \%$ per year more, with percutaneous LAA closure compared with adjusted-dose warfarin). However, there was a significantly higher rate of adverse events (excessive bleeding, procedurerelated complications) in the percutaneous LAA closure arm (absolute risk increase, $3.0 \%$ per year). In particular, serious pericardial effusion (ie, requiring percutaneous or surgical drainage) occurred in $4.8 \%$ of patients in the percutaneous LAA closure arm. Another occlusion device, PLAATO [percutaneous LAA transcatheter occlusion], has not been tested in a randomized trial but has been evaluated in prospective, multicenter cohort studies in patients ineligible for warfarin. ${ }^{101,102}$ At this time, we make no formal recommendations regarding LAA closure devices, pending more definitive research in this field.

\subsection{Patients With AF and Mitral Stenosis}

Patients with AF in the setting of rheumatic mitral valve disease, particularly mitral stenosis, are at high risk of stroke. Most RCTs of adjusted-dose VKA therapy in AF excluded such patients. We believe that the results of randomized clinical trials in patients with nonrheumatic AF can be generalized to patients with mitral stenosis.

Recommendation

2.2. For patients with $\mathrm{AF}$ and mitral stenosis, we recommend adjusted-dose VKA therapy (target INR range, 2.0-3.0) rather than no therapy, aspirin ( $75 \mathrm{mg}$ to $325 \mathrm{mg}$ once daily), or combination therapy with aspirin and clopidogrel (all Grade 1B). For patients with AF and mitral stenosis who are unsuitable for or choose not to take adjusted-dose VKA therapy (for reasons other than concerns about major bleeding), we recommend combination therapy with aspirin 
and clopidogrel rather than aspirin $(75 \mathrm{mg}$ to $325 \mathrm{mg}$ once daily) alone (Grade $1 \mathrm{~B}$ ).

\subsection{Antithrombotic Therapy FOR PATIENTS With AF in Special Situations}

\subsection{Patients With AF and Stable \\ Coronary Artery Disease}

Approximately one-third of patients with $\mathrm{AF}$ also have coronary artery disease. ${ }^{51} \mathrm{~A}$ recurring question is whether patients with $\mathrm{AF}$ for whom oral anticoagulation is indicated because of a high risk of stroke (eg, $\mathrm{CHADS}_{2}$ score of $\geq 2$ ) and who have concomitant stable coronary artery disease should also use aspirin to prevent coronary heart disease events. In this article, we define stable coronary artery disease as the presence (or absence) of angina but no revascularization procedure (percutaneous coronary intervention or coronary artery bypass graft surgery) or hospitalization for ACS (ie, unstable angina, non-STsegment elevation MI, or ST-segment elevation MI) in the past year. The studies discussed next provide low-quality evidence that combination therapy with adjusted-dose VKA therapy plus aspirin is not associated with reductions in stroke or MI but that it does increase by 1.5 to 2 times the risk of major bleeding compared with adjusted-dose VKA therapy alone.

The FFAACS (Fluindione, Fibrillation Auriculaire, Aspirin et Contraste Spontane) trial is the only RCT that directly compared adjusted-dose VKA therapy and aspirin to adjusted-dose VKA therapy alone. In this study, patients in both arms received fluindione (INR 2.0-2.6), and patients in the combination therapy arm also received aspirin $100 \mathrm{mg} / \mathrm{d}$. The trial was stopped early after enrollment of only 157 patients because of excessive hemorrhage in the group receiving fluindione plus aspirin. ${ }^{103}$ No conclusion can be drawn regarding efficacy for prevention of stroke or MI because there were so few events during a short duration of follow-up.

There is direct evidence from a nonrandomized comparison of patients enrolled in the SPORTIF trials that combination therapy (with warfarin [INR 2.0-3.0] plus aspirin) is associated with a nearly twofold greater risk of major bleeding compared with warfarin alone, with no significant reduction in stroke or MI. ${ }^{104}$ Patients receiving aspirin were different from those not receiving aspirin (eg, those receiving aspirin more often had diabetes, coronary artery disease, and previous stroke or TIA). Although the analyses were adjusted for baseline differences in patient characteristics, there remains a high risk for bias.

A similar nonrandomized comparison of patients enrolled in the RE-LY trial reported that rates (likely unadjusted) of major bleeding were roughly 2 times higher for patients receiving aspirin in conjunction with either warfarin (INR 2.0-3.0) or dabigatran. ${ }^{105}$ Analyses of observational data from a large population-based registry of hospitalized patients with $\mathrm{AF}$ also found a nearly twofold increase in the risk of bleeding requiring hospitalization or causing death when patients with AF received combination therapy with warfarin and aspirin vs warfarin alone. ${ }^{106}$

A systematic review of RCTs in diverse (mostly non-AF) patient populations that compared aspirin plus VKA therapy with VKA therapy alone, in which VKAs were administered to achieve the same target INR or given at the same fixed dose in both arms, found that combination VKA plus aspirin therapy was associated with a lower risk of cardiovascular events compared with VKA therapy alone but that this benefit was restricted to RCTs enrolling patients with mechanical heart valves. No benefit was seen with combination therapy in studies of patients with $\mathrm{AF}$ or coronary artery disease, although estimates of treatment effect were very imprecise. Combination therapy with VKA and aspirin was associated with a greater risk of major bleeding (pooled OR, 1.43; 95\% CI, 1.00-2.02) compared with VKA therapy alone. ${ }^{107}$

Recommendation

3.1. For patients with $\mathrm{AF}$ and stable coronary artery disease (eg, no acute coronary syndrome within the previous year) and who choose oral anticoagulation, we suggest adjusted-dose VKA therapy alone (target INR range, 2.0-3.0) rather than the combination of adjusted-dose VKA therapy and aspirin (Grade 2C).

\subsection{Patients With AF and Placement of an Intracoronary Stent (With or Without Recent ACS)}

Patients benefit from dual antiplatelet therapy (eg, aspirin and clopidogrel) for a finite duration following placement of an intracoronary stent (4 weeks after placement of a bare-metal stent; 3 to 6 months after placement of a drug-eluting stent [typically 3 months for -olimus stents and 6 months for -taxel stents]) (see Vandvik et al). ${ }^{108}$ The principal objective of dual antiplatelet therapy after placement of an intracoronary stent is the prevention of stent thrombosis. Before the adoption of dual antiplatelet therapy in clinical practice, stent thrombosis occurred in $6 \%$ to $24 \%$ of patients after bare-metal stent placement and was associated with a high case fatality rate of nearly $50 \% .^{109-113}$ Concomitantly, a number of studies compared a new strategy, aspirin plus ticlopidine (a thienopyridine precursor to clopidogrel), to the previously most successful strategy of aspirin plus warfarin in patients undergoing stent placement. A Cochrane systematic review of four randomized 
trials including 2,436 patients found that a 30- to 42-day course of ticlopidine plus aspirin vs warfarin plus aspirin reduced the 30- to 42-day risk of nonfatal MI (relative risk, 0.50; 95\% CI, 0.30-0.83; number needed to treat, 55) and revascularization (relative risk, 0.29; 95\% CI, 0.16-0.56; number needed to treat, 33) with a possible reduction in major bleeding (relative risk, 0.36; 95\% CI, 0.14-1.02) (see Table 11 in Vandvik et al, ${ }^{108}$ sections 3.1-3.5).114

Based on these data, we recommend aspirin and clopidogrel over warfarin plus aspirin for a finite period following stent placement. For patients with AF receiving oral anticoagulation who undergo placement of an intracoronary stent, the dilemma arises about whether patients should be continued on oral anticoagulation during the time they are recommended to be on dual antiplatelet therapy, given the lack of direct evidence from RCTs addressing this question.

Treatment decisions in this scenario must balance the effect of each drug combination on (1) the risk of stroke, systemic embolism, and mortality due to AF; (2) the risk of recurrent MI (including stent thrombosis); and (3) the risk of bleeding related to antithrombotic therapy. Because of the very high risk for bias in the available observational studies that compare cardiovascular event rates in patients receiving triple therapy vs dual antiplatelet therapy after stent placement, ${ }^{115-120}$ we have instead used indirect evidence from relevant RCTs to inform our recommendations. We assumed that the relative impact of triple therapy on death, nonfatal MI, and nonfatal major extracranial bleeds compared with dual antiplatelet therapy would be similar to that seen in 10 RCTs of warfarin plus aspirin compared with aspirin in patients with ACS. ${ }^{121}$ For nonfatal stroke and systemic embolism, we assumed that the relative impact of triple therapy vs dual therapy would be similar to that seen in the ACTIVE W trial, which compared warfarin vs aspirin plus clopidogrel in patients with AF (Table 6)..$^{80}$ This assumption may be underestimating the true effect of triple therapy on stroke and systemic embolism compared with dual therapy.

We used the same annual baseline event rates (ie, on dual antiplatelet therapy) for death, nonfatal stroke, and systemic embolism as were used in the evidence profile comparing VKA to aspirin plus clopidogrel in the general AF population (Table 6). For the annual risk of nonfatal MI and nonfatal major extracranial bleeding on aspirin plus clopidogrel, we used the rates reported in the clopidogrel arm of the PLATO (Study of Platelet Inhibition and Patient Outcomes) trial, which compared ticagrelor to clopidogrel in patients with ACS receiving aspirin. ${ }^{122}$

The indirect data summarized in Table 12 suggest that triple therapy may be associated with net clinical benefit compared with dual antiplatelet therapy for patients at high risk of stroke (eg, $\mathrm{CHADS}_{2}$ score of $\geq 2$ ), whereas the net benefit at lower levels of stroke risk is uncertain. The duration of triple therapy should be kept as brief as possible given the associated increase in bleeding risk. Because the risk of stent thrombosis falls significantly after 30 days with bare-metal stents and 3 to 6 months after drug-eluting stents, triple therapy should be continued only during this high-risk period and only among patients at higher risk of stroke. After the initial period of triple therapy, patients may be given VKA therapy plus a single antiplatelet drug until 12 months have elapsed from the time of stent placement (particularly if stent placement was performed in the setting of a recent ACS [see section 3.3] or if a drug-eluting stent was used).

It should be noted that patients with $\mathrm{AF}$ who have received a drug-eluting stent and who are at increased risk of late stent thrombosis (eg, ACS at presentation, diabetes, long lesions, narrow diameter of target vessel) ${ }^{123}$ may choose to continue triple therapy for a full 12 months after stent placement if they place a low value on avoiding bleeding. At 12 months after stent placement, antithrombotic therapy can be given according to our recommendations for $\mathrm{AF}$ and stable coronary artery disease (section 3.1).

Recommendation

3.2. For patients with $\mathrm{AF}$ at high risk of stroke (eg, $\mathrm{CHADS}_{2}$ score of 2 or greater) during the first month after placement of a bare-metal stent or the first 3 to 6 months after placement of a drug-eluting stent, we suggest triple therapy (eg, VKA therapy, aspirin, and clopidogrel) rather than dual antiplatelet therapy (eg, aspirin and clopidogrel) (Grade 2C). After this initial period of triple therapy, we suggest a VKA (INR 2.0-3.0) plus a single antiplatelet drug rather than VKA alone (Grade 2C). At 12 months after intracoronary stent placement, antithrombotic therapy is suggested as for patients with $\mathrm{AF}$ and stable coronary artery disease (see section 3.1 ).

For patients with $\mathrm{AF}$ at low to intermediate risk of stroke (eg, $\mathrm{CHADS}_{2}$ score of 0 or 1$)$ during the first 12 months after placement of an intracoronary stent (bare metal or drug eluting), we suggest dual antiplatelet therapy rather than triple therapy (Grade 2C). At 12 months after intracoronary stent placement, antithrombotic therapy is suggested as for patients with $\mathrm{AF}$ and stable coronary artery disease (see section 3.1 ).

Remarks: Patients who place an exceptionally high value on stroke reduction and a low value on avoiding 


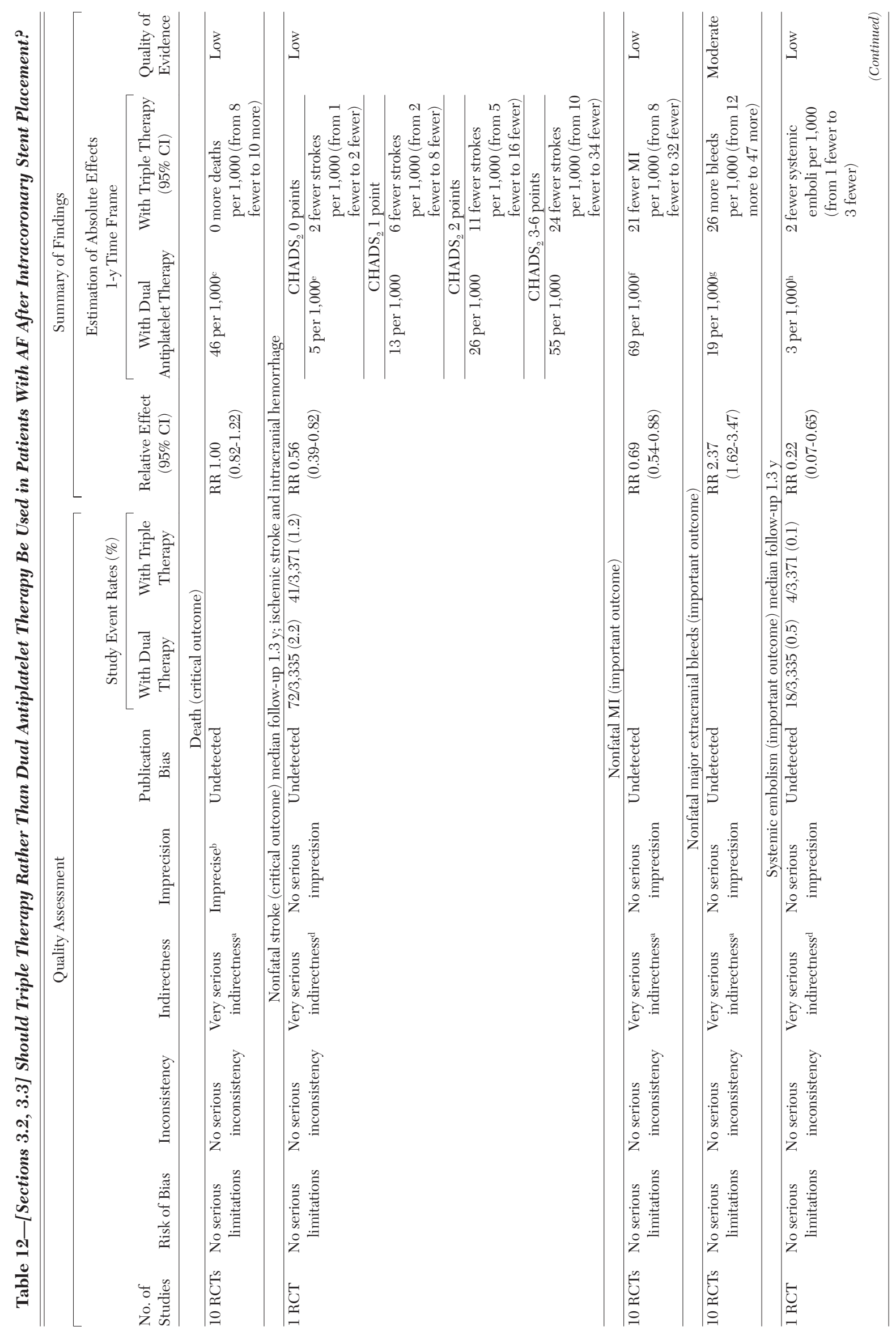




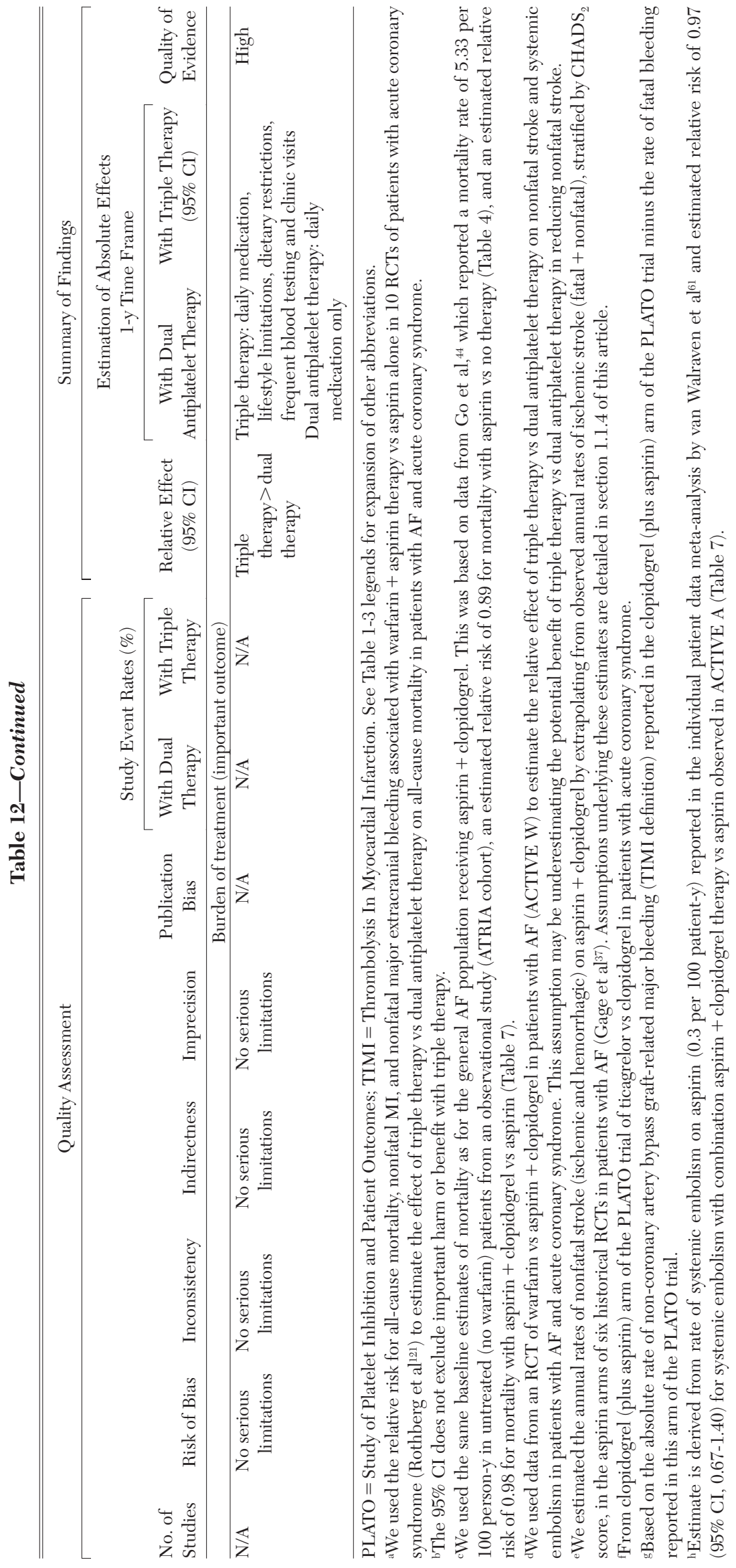


bleeding and the burden associated with anticoagulant therapy are likely to choose triple therapy rather than dual antiplatelet therapy. Other factors that may influence this choice are a consideration of bleeding risk and the presence of additional non-CHADS ${ }_{2}$ risk factors for stroke (see section 2.1.12).

\subsection{Patients With AF and ACS Who Do Not Undergo Intracoronary Stent Placement}

Dual antiplatelet therapy (eg, with aspirin and clopidogrel) rather than aspirin alone is recommended during the first 12 months after an ACS, regardless of whether patients also receive an intracoronary stent (Vandvik et al $\left.{ }^{108}\right)$. Many patients with AF (eg, CHADS, score of $\geq 1$ ) will choose VKA therapy (eg, warfarin) to prevent future stroke (section 2.1). Therefore, treatment options in patients with $\mathrm{AF}$ and recent ACS may include warfarin plus dual antiplatelet therapy (ie, triple therapy), dual antiplatelet therapy, or warfarin plus single antiplatelet therapy. In this section, we specifically address patients with $\mathrm{AF}$ and ACS who do not undergo placement of an intracoronary stent.

The indirect data summarized in Table 12 suggest that triple therapy may not be associated with net clinical benefit compared with dual antiplatelet therapy unless patients are at substantially high risk of stroke (eg, $\mathrm{CHADS}_{2}$ score of $\geq 2$ ), whereas the net benefit at lower levels of stroke risk is uncertain. Rather than triple therapy, a third therapeutic option in this clinical scenario (where stent thrombosis is not a concern) is to use a VKA plus single antiplatelet therapy. Unfortunately, there are no RCTs comparing warfarin plus single antiplatelet therapy to dual antiplatelet therapy. As described in Author et al (section 2.4) in this guideline, warfarin plus aspirin is associated with a significant reduction in risk of subsequent MI (relative risk, 0.69; 95\% CI, 0.54-0.88) and stroke (relative risk, 0.56; 95\% CI, 0.39-0.82) compared with aspirin alone in patients post-ACS. ${ }^{121}$ The point estimates for these reductions in MI and stroke are greater than those seen with clopidogrel plus aspirin (relative risk, 0.77; 95\% CI, 0.67-0.89) vs aspirin alone (relative risk, 0.86; 95\% CI, 0.63-1.18) in the Clopidogrel in Unstable Angina to Prevent Recurrent Events (CURE) trial. ${ }^{124}$ These data suggest that warfarin plus aspirin is at least as effective, and potentially more effective, than clopidogrel plus aspirin for the prevention of cardiovascular events after ACS. Warfarin plus aspirin was not given a recommendation in Author et al either as an alternative or in preference to dual antiplatelet therapy for patients post-ACS because of pragmatic issues (physician reluctance, burden of use, etc). However, these issues are not relevant for patients already receiving warfarin for $\mathrm{AF}$.

Finally, there are no studies comparing warfarin plus aspirin to triple therapy (eg, warfarin, aspirin, and clopidogrel) in patients with $\mathrm{AF}$ and recent ACS. Use of triple therapy in this situation would be appropriate only if the risk reduction in MI and stroke achieved by adding the second antiplatelet agent is greater than the increase in bleeding risk. This seems unlikely in patients who are not undergoing stent placement and, thus, where there is no concern regarding stent thrombosis. Given the lack of direct evidence and mindful of the principle to first do no harm, we do not advocate the use of triple therapy in patients with AF who experience ACS but do not receive an intracoronary stent. However, patients placing a high value on MI and stroke reduction and a low value on avoiding bleeding may opt for an initial period of triple therapy (eg, 3-6 months) followed by warfarin plus aspirin.

\section{Recommendation}

3.3. For patients with $\mathrm{AF}$ at intermediate to high risk of stroke (eg, $\mathrm{CHADS}_{2}$ score of 1 or greater) who experience an acute coronary syndrome and do not undergo intracoronary stent placement, we suggest, for the first 12 months, adjusteddose VKA therapy (INR 2.0-3.0) plus single antiplatelet therapy rather than dual antiplatelet therapy (eg, aspirin and clopidogrel) or triple therapy (eg, warfarin, aspirin, and clopidogrel) (Grade 2C). After the first 12 months, antithrombotic therapy is suggested as for patients with AF and stable coronary artery disease (see section 3.1).

For patients with $\mathrm{AF}$ at low risk of stroke (eg, $\mathrm{CHADS}_{2}$ score of 0), we suggest dual antiplatelet therapy (eg, aspirin and clopidogrel) rather than adjusted-dose VKA therapy (INR 2.0-3.0) plus single antiplatelet therapy or triple therapy (eg, warfarin, aspirin, and clopidogrel) (Grade 2C). After the first 12 months, antithrombotic therapy is suggested as for patients with AF and stable coronary artery disease (see section 3.1).

Remarks: Patients who place an exceptionally high value on stroke reduction and a low value on avoiding bleeding and the burden associated with anticoagulant therapy are likely to choose adjusted-dose VKA therapy plus single antiplatelet therapy rather than dual antiplatelet therapy. Other factors that may influence this choice are a consideration of bleeding risk and the presence of additional non-CHADS 2 risk factors for stroke (see section 2.1.12). 


\subsection{Patients With AF Managed by a Rhythm Control Strategy}

Some patients with AF will be managed with antiarrhythmic drugs (AADs) to achieve and maintain normal sinus rhythm. Increasingly, patients with $\mathrm{AF}$ are also receiving catheter radiofrequency ablation procedures (pulmonary vein isolation) to maintain normal sinus rhythm. In the Atrial Fibrillation Follow-up Investigation of Rhythm Management (AFFIRM) trial, in which many patients in the rhythm control arm did not receive anticoagulation, patients in a rhythm control strategy had a similar risk of stroke compared with patients in a rate control strategy (see also section 4.1.1).125

There are several RCTs of catheter ablation vs AAD therapy in patients with AF, typically those who have failed first-line therapy with AADs. ${ }^{126-132}$ All trials found a significant reduction in $\mathrm{AF}$ recurrence at $\sim 1$ year of follow-up. However, AF recurrence in the catheter ablation arms ranged from $11 \%$ to $44 \%$ at $\sim 1$ year. The studies rarely reported on stroke outcomes, and all were underpowered to address this question. Given the results of the AFFIRM trial, the lack of longer-term follow-up data from catheter ablation RCTs regarding AF recurrence rates, and poor reporting of stroke outcomes, it would be prudent to base decisions about long-term antithrombotic therapy on a patient's underlying risk for stroke as recommended in section 2.1, and not on their underlying rhythm.

\section{Recommendation}

\subsection{For patients with $\mathrm{AF}$ being managed with a rhythm control strategy (pharmacologic or cath- eter ablation), we suggest that antithrombotic therapy decisions follow the general risk-based recommendations for patients with $\mathrm{AF}$ in sec- tion 2.1, regardless of the apparent persistence of normal sinus rhythm (Grade $2 \mathrm{C}$ ).}

\subsection{Patients With Atrial Flutter}

Many patients with persistent atrial flutter have periods of atrial flutter alternating with periods of AF. ${ }^{133,134}$ The prevalence of thrombus in the body of the atria and atrial appendage on TEE in patients with atrial flutter ranges from $1 \%$ to $21 \%$. ${ }^{135-138}$ There are few data from longitudinal studies assessing the risk of thromboembolism with well-documented sustained atrial flutter. A study describing a series of 191 consecutive, unselected patients hospitalized for treatment of atrial flutter reported thromboembolism in $7 \%$ of patients during a mean follow-up of 26 months. ${ }^{134}$ The role of anticoagulant therapy for patients with atrial flutter has not been evaluated in clinical trials, but because these patients often have concomitant AF or are at increased risk of developing $\mathrm{AF}$, it is reasonable to base decisions regarding antithrombotic therapy on the risk stratification schemes used for AF (section 1.1).

Recommendation

3.5. For patients with atrial flutter, we suggest that antithrombotic therapy decisions follow the same risk-based recommendations as for $\mathrm{AF}$.

\subsection{ANTITHRombotic Therapy for Patients WiTh AF UNDERGOING CARDIOVERSION}

To minimize the risk of stroke and systemic embolism associated with cardioversion, therapeutic anticoagulation (eg, with adjusted-dose oral VKAs; INR 2.0-3.0) conventionally is recommended for a minimum of 3 weeks before, during, and for a minimum of 4 weeks after the procedure. For some patients with AF of documented short duration (eg, $\leq 48 \mathrm{~h}$ ), a common practice is to cardiovert without prolonged precardioversion anticoagulation. For patients with AF duration of $>48 \mathrm{~h}$ or unknown duration, a TEE-guided approach is an alternative strategy that can simplify anticoagulation management before cardioversion. In this section, we summarize the evidence and give recommendations for the use of antithrombotic therapy in patients undergoing electrical or pharmacologic cardioversion for $\mathrm{AF}$ (or atrial flutter).

\subsection{Patients Undergoing Elective Cardioversion of $A F$}

4.1.1 Cardioversion of AF of More Than $48 \mathrm{~h}$ or Unknown Duration: Evidence favoring the efficacy of pericardioversion anticoagulation is based on observational studies in mostly patients undergoing electrical rather than pharmacologic cardioversion. There is moderate-quality evidence from a systematic review of 18 observational studies suggesting that the risk of stroke or thromboembolism is substantially lower in patients receiving pericardioversion anticoagulation than in those who receive no anticoagulation $(0.3 \%$ vs $2.0 \%)$, translating to a relative risk of 0.16 (95\% CI, 0.05-0.48) in favor of anticoagulation. ${ }^{139}$ No data regarding major hemorrhagic events were reported in this systematic review.

The conventional duration of a minimum of 3 weeks therapeutic anticoagulation before cardioversion and a minimum 4 weeks afterward is based on indirect pathophysiologic data and evidence from observational studies and remains arbitrary. Observational data showing that thromboembolism was significantly more common at an INR of 1.5 to 2.4 before 
cardioversion than an INR of $\geq 2.5(0.93 \%$ vs $0 \%$, $P=.012$ ) suggests the importance of maintaining a therapeutic INR in the pericardioversion period. ${ }^{140}$ After cardioversion, results of observational studies suggest that the highest risk of stroke and thromboembolism is in the first $72 \mathrm{~h}$ after cardioversion and that the majority of thromboembolic complications will occur within 10 days of cardioversion. ${ }^{141}$ However, TEE studies have demonstrated that despite restoration of sinus rhythm on the ECG, atrial mechanical dysfunction may persist for several weeks postcardioversion. ${ }^{142}$

A nonrandomized comparison of 1,270 patients enrolled in the RE-LY trial who underwent 1,983 cardioversions suggests that there may be no excess harm with dabigatran compared with warfarin when used for pericardioversion anticoagulation. Most cardioversions in this study $(\sim 80 \%)$ were performed after the protocol-assigned study anticoagulant was given for a minimum of 3 weeks before the procedure, and rates of stroke and systemic embolism at 30 days after cardioversion were low when oral anticoagulation with either warfarin or dabigatran was given before cardioversion $(0.8 \%, 0.3 \%$, and $0.6 \%$ with dabigatran $110 \mathrm{mg}$ bid, dabigatran $150 \mathrm{mg}$ bid, and warfarin, respectively). ${ }^{143}$

A TEE-guided approach with abbreviated anticoagulation before cardioversion is an alternative to the conventional approach of using a minimum of 3 weeks therapeutic precardioversion anticoagulation. ${ }^{144}$ Under a TEE-guided strategy, patients receive anticoagulation and once therapeutic, undergo screening TEE. If thrombus is seen in either atrial appendage or atrium at the time of TEE, cardioversion is postponed, given the presumed high risk of thromboem- bolism. If no thrombus is seen, the patient proceeds immediately to cardioversion. A TEE-guided strategy requires an experienced echocardiographer because accurate visualization of thrombus may be operator dependent.

The Assessment of Cardioversion Using Transesophageal Echocardiography (ACUTE) RCT compared a TEE-guided strategy of abbreviated therapeutic anticoagulation with IV unfractionated heparin (started $24 \mathrm{~h}$ before cardioversion) or warfarin (INR 2.0-3.0) (started 5 days before cardioversion) to a strategy of therapeutic anticoagulation for at least 3 weeks before cardioversion. ${ }^{145}$ The evidence is of low quality given the wide $95 \%$ CIs around the point estimates of effect on patient-important outcomes (Table 13). Thus, the results do not exclude with confidence the possibility of important benefit or harm with a TEEguided approach compared with a conventional approach of 3 weeks anticoagulation precardioversion.

Acknowledging these uncertainties, a TEE-guided approach may be best suited for patients who are very symptomatic while in AF because cardioversion can be done sooner if the TEE is negative for thrombus. It may also suit patients who would prefer to avoid prolonged oral anticoagulation before cardioversion and those at increased risk for bleeding. However, the ability to avoid anticoagulation with a TEE-guided strategy is most relevant for patients without stroke risk factors and at low risk of recurrent $\mathrm{AF}$ in whom long-term anticoagulation beyond 4 weeks after cardioversion would not be required.

For patients undergoing a TEE-guided approach, low-molecular-weight heparin at full VTE treatment doses or IV unfractionated heparin (to maintain an activated partial thromboplastin time prolongation

Table 13-[Section 4.1] Abbreviated Anticoagulation With TEE-Guided Cardioversion vs Conventional Anticoagulation for at Least 3 Weeks Before Cardioversion

\begin{tabular}{|c|c|c|c|c|c|}
\hline \multirow[b]{2}{*}{ Outcomes } & \multicolumn{2}{|c|}{$\begin{array}{l}\text { Anticipated Absolute Effects } \\
\text { (Time Frame Is } 8 \text { wk) }\end{array}$} & \multirow[b]{2}{*}{$\begin{array}{l}\text { Relative Effect } \\
\quad(95 \% \mathrm{CI})\end{array}$} & \multirow[b]{2}{*}{$\begin{array}{l}\text { No. of Participants } \\
\text { (Studies), Follow-up }\end{array}$} & \multirow[b]{2}{*}{$\begin{array}{c}\text { Quality of The } \\
\text { Evidence (GRADE }\end{array}$} \\
\hline & $\begin{array}{c}\text { Risk With Conventional } \\
\text { Anticoagulation }\end{array}$ & $\begin{array}{c}\text { Risk Difference With } \\
\text { TEE + Abbreviated } \\
\text { Anticoagulation }{ }^{\mathrm{a}}(95 \% \mathrm{CI})\end{array}$ & & & \\
\hline Death & 10 per $1,000^{\mathrm{b}}$ & $\begin{array}{c}14 \text { more deaths per } 1,000 \\
(0 \text { more to } 52 \text { more })\end{array}$ & RR $2.44(0.95-6.24)$ & 1,222 (1 RCT), 8 wk & Low $^{\mathrm{c}}$ \\
\hline Nonfatal strokes & 3 per $1,000^{b}$ & $\begin{array}{c}5 \text { more strokes per } 1,000 \\
(2 \text { fewer to } 38 \text { more })\end{array}$ & RR $2.44(0.47-12.50)$ & 1,222 (1 RCT), 8 wk & Low $^{\mathrm{c}}$ \\
\hline $\begin{array}{l}\text { Nonfatal major } \\
\text { extracranial bleeds }^{\mathrm{d}}\end{array}$ & 15 per $1,000^{b}$ & $\begin{array}{c}7 \text { fewer bleeds per } 1,000 \\
\text { (12 fewer to } 9 \text { more })\end{array}$ & RR $0.54(0.18-1.61)$ & 1,222 (1 RCT), 8 wk & Low $^{\mathrm{c}}$ \\
\hline
\end{tabular}

ACUTE = Assessment of Cardioversion Using Transesophageal Echocardiography; GRADE = Grades of Recommendations, Assessment, Development, and Evaluation; TEE = transesophageal echocardiography. See Tables 1 and 8 for expansion of other abbreviations.

a Abbreviated anticoagulation refers to either IV unfractionated heparin (started $24 \mathrm{~h}$ before cardioversion) or adjusted-dose warfarin (INR 2.0-3.0) (started 5 d before cardioversion).

${ }^{\mathrm{b}}$ Assumed risk is the observed event rate from the control arm (ie, conventional anticoagulation) of the RCT by Klein et al145 (ACUTE trial).

'No statistically significant effect, and CIs are very wide. Trial was not sufficiently large to demonstrate comparable safety between conventional and TEE-based strategies.

${ }^{\mathrm{d}}$ Most of these were GI bleeds. 
that corresponds to plasma heparin levels of 0.3-0.7 International Units/mL antifactor Xa activity) should be started at the time of TEE and cardioversion performed within $24 \mathrm{~h}$ of the TEE if no thrombus is seen. A few observational studies and one RCT have suggested that low-molecular-weight heparin has similar efficacy compared with heparin or warfarin for immediate anticoagulation before TEE. ${ }^{146-150}$ Outpatients undergoing a TEE-guided approach may be started on a VKA (INR 2.5; range, 2.0-3.0) and the TEE and subsequent cardioversion scheduled for 5 days later (if the INR is in therapeutic range at that time). The new oral anticoagulants may also be suitable for outpatient treatment before TEE-guided cardioversion given their ease of use (eg, dabigatran achieves steady-state concentrations in 2-3 days after bid administration), ${ }^{151}$ but they have not yet been studied for this purpose.

There is no direct evidence to guide decisions about the long-term management of anticoagulation in patients who appear to be in sinus rhythm 4 weeks after cardioversion. Several observational studies indicate that approximately one-half of patients will have recurrence of $\mathrm{AF}$ at 1 year after cardioversion. ${ }^{152-156}$ The AFFIRM study, in which many patients stopped anticoagulation after initial (apparently) successful restoration of sinus rhythm, found similar rates of thromboembolism with a rhythm control strategy compared with a rate control strategy. ${ }^{125}$ Finally, patients with PAF often are asymptomatic during episodes of AF recurrence, with one series suggesting that only one in every 12 paroxysms are symptomatic. ${ }^{157}$ These observations suggest that decisions about long-term antithrombotic therapy should be primarily based on a patient's risk for stroke (see section 2.1) rather than on the prevailing rhythm at 4 weeks postcardioversion.

Recommendation

4.1.1. For patients with AF of greater than $48 \mathrm{~h}$ or unknown duration undergoing elective electrical or pharmacologic cardioversion, we recommend therapeutic anticoagulation (adjusted-dose VKA therapy, target INR range 2.0-3.0, lowmolecular-weight heparin at full venous thromboembolism treatment doses, or dabigatran) for at least 3 weeks before cardioversion or a TEEguided approach with abbreviated anticoagulation before cardioversion, rather than no anticoagulation (Grade $1 \mathrm{~B}$ ). We recommend therapeutic anticoagulation for at least 4 weeks after successful cardioversion to sinus rhythm, rather than no anticoagulation, regardless of the baseline risk of stroke (Grade 1B). Decisions about anticoagulation beyond 4 weeks should be made in accordance with our risk-based recommendations for long-term antithrombotic therapy in section 2.1.

4.1.2 Cardioversion of AF of 48 h Duration or Less: There is uncertainty over the precise duration of AF necessary for thrombus to develop and, hence, the threshold of AF duration below which precardioversion anticoagulation can be safely avoided. For AF of short duration (eg, $\leq 48 \mathrm{~h}$ ), a common practice is to cardiovert without a TEE or prolonged precardioversion anticoagulation. However, observational studies have found left atrial thrombus on TEE in as many as $14 \%$ of patients with acute AF of short duration. ${ }^{158,159}$ Moreover, because many individuals develop AF asymptomatically, it is often difficult to accurately determine a patient's duration of AF, making the 48-h rule difficult to apply. ${ }^{160}$ No RCTs have compared different anticoagulation strategies in patients with AF of documented duration of $\leq 48 \mathrm{~h}$. Observational data suggest that the risk of stroke or thromboembolism in these patients is similar to those who have received conventional anticoagulation for a minimum of 3 weeks before cardioversion. ${ }^{140,161}$

\section{Recommendation}

4.1.2. For patients with AF of documented duration of $48 \mathrm{~h}$ or less undergoing elective cardioversion (electrical or pharmacologic), we suggest starting anticoagulation at presentation (low-molecular-weight heparin or unfractionated heparin at full venous thromboembolism treatment doses) and proceeding to cardioversion rather than delaying cardioversion for 3 weeks of therapeutic anticoagulation or a TEE-guided approach (Grade 2C). After successful cardioversion to sinus rhythm, we recommend therapeutic anticoagulation for at least 4 weeks rather than no anticoagulation, regardless of baseline stroke risk (Grade 2C). Decisions about long-term anticoagulation after cardioversion should be made in accordance with our risk-based recommendations for long-term antithrombotic therapy in section 2.1 .

\subsection{Patients Undergoing Urgent Cardioversion for Hemodynamically Unstable AF}

There are no published data regarding the optimal anticoagulation strategy to use before or during urgent cardioversion for patients with $\mathrm{AF}$ and hemodynamic instability. Initiation of anticoagulation immediately before urgent cardioversion (eg, with IV unfractionated heparin or low-molecularweight heparin) would be expected to reduce the risk of stroke or thromboembolism based on studies 
of elective cardioversion. It is important to note that the initiation of anticoagulation therapy should not delay any emergency interventions to stabilize the patient.

\section{Recommendation}

4.2. For patients with $\mathrm{AF}$ and hemodynamic instability undergoing urgent cardioversion (electrical or pharmacologic), we suggest that therapeutic-dose parenteral anticoagulation be started before cardioversion, if possible (Grade 2C), but that initiation of anticoagulation must not delay any emergency intervention (Grade 2C). After successful cardioversion to sinus rhythm, we suggest therapeutic anticoagulation for at least 4 weeks after successful cardioversion to sinus rhythm rather than no anticoagulation, regardless of baseline stroke risk (Grade 2C). Decisions about anticoagulation beyond 4 weeks should be made in accordance with our risk-based recommendations for longterm antithrombotic therapy in section 2.1.

\subsection{Patients Undergoing Elective or Urgent Cardioversion for Atrial Flutter}

There are no published data regarding the optimal anticoagulation strategy to use for patients undergoing cardioversion for atrial flutter. Although some observational studies suggest that the risk of thromboembolism after cardioversion for atrial flutter is low, even without anticoagulation, other studies have documented a similar risk of thromboembolism in patients after cardioversion for atrial flutter and AF. ${ }^{140,162,163}$ This may be because AF and atrial flutter often coexist.

\section{Recommendation}

4.3. For patients with atrial flutter undergoing elective or urgent pharmacologic or electrical cardioversion, we suggest that the same approach to thromboprophylaxis be used as for patients with atrial fibrillation undergoing cardioversion.

\subsection{Practical Issues in the MANAGEMENT OF VKA THERAPY}

\subsection{Optimal Target INR Range}

For a full discussion of optimal target INR range with VKA therapy across a variety of indications, see Holbrook et al ${ }^{91}$ regarding evidence-based management of anticoagulation in this guideline. With respect to patients with AF specifically, several stud- ies assessed oral anticoagulation at very-low INR targets or fixed low doses compared with adjusteddose anticoagulation targeted at an INR of 2.0 to 3.0 and found that anticoagulation targeted at an INR of 2.0 to 3.0 was more effective in reducing the risk of stroke. ${ }^{164}$ Observational studies have shown that the risk of ischemic stroke is much greater once INR levels are $<2.0$ and that there are no appreciable gains in efficacy with levels $>2$.0. However, there is a sharp increase in the risk of bleeding complications, particularly intracranial hemorrhage, as INR levels rise to $>3.0$ to $4.0 .{ }^{165-169}$ A target INR value of 2.0 will result in patients spending a substantial proportion of time at subtherapeutic INR levels (ie, <2.0). ${ }^{170}$ Given that bleeding risk does not rise substantially until INR levels are $>3.0$, and particularly $>4.0$, these data from $\mathrm{AF}$ populations support an optimal target INR range of 2.0 to 3.0, with a target value of 2.5 to maximize the time spent in the optimal INR range. ${ }^{165-170}$

\subsection{Time in Therapeutic Range}

For a full discussion of the importance of time in therapeutic range while on adjusted-dose VKA therapy, see Ageno et al ${ }^{171}$ regarding oral anticoagulation in this guideline. With respect to patients with $\mathrm{AF}$, there are several observational studies indicating that increasing time out of range is associated with poorer outcomes (eg, mortality, ischemic stroke, thromboembolism, major bleeding). ${ }^{172-175}$

\subsection{Future Research}

Approximately one in every three patients with $\mathrm{AF}$ also has coronary artery disease. ${ }^{51}$ However, the optimal approach to antithrombotic therapy in these patients is unclear. Research is needed to determine the effect of treatment with oral anticoagulation and aspirin compared with oral anticoagulation alone on patient-important outcomes of vascular death, nonfatal stroke, nonfatal MI, nonfatal major extracranial bleeding, and nonfatal systemic embolism. Research is also needed to inform recommendations about different antithrombotic therapy regimens for patients with AF undergoing placement of an intracoronary artery stent or who experience an ACS (eg, triple therapy with oral anticoagulation, clopidogrel, and aspirin; dual antiplatelet therapy with clopidogrel and aspirin; or combination oral anticoagulation and aspirin or clopidogrel). Finally, all existing stroke risk stratification and bleeding risk stratification schema for patients with AF have modest predictive value, and development of more-accurate risk stratification systems is needed to facilitate a more-accurate estimation of net clinical benefit for individual patients. 


\subsection{CONCLUSIONS}

Stroke is a serious complication of $\mathrm{AF}$, but its risk varies considerably across different groups of patients with AF. Antithrombotic prophylaxis for stroke is associated with an increased risk of bleeding. We provide recommendations for antithrombotic treatment based on net clinical benefit for patients with $\mathrm{AF}$ at varying levels of stroke risk. Oral anticoagulation is the optimal choice of antithrombotic therapy for patients with $\mathrm{AF}$ at high risk of stroke (eg, $\mathrm{CHADS}_{2}$ score $\geq 2$ ). At lower levels of stroke risk, antithrombotic treatment decisions will require a more individualized approach that takes into consideration patient values and preferences, bleeding risk, and the presence of non-CHADS 2 stroke risk factors. The role of oral anticoagulation for the prevention of stroke in patients with $\mathrm{AF}$ will evolve as the results of large, ongoing, phase 3 RCTs of new oral anticoagulants are published and as experience with these new agents in clinical practice continues to grow.

\section{ACKNOWLEDGMENTS}

Author contributions: As Topic Editor, Dr You oversaw the development of this article, including the data analysis and subsequent development of the recommendations contained herein. Dr You: contributed as Topic Editor.

Dr Singer: contributed as a panelist.

Dr Howard: contributed as a panelist.

Dr Lane: contributed as a panelist.

Dr Eckman: contributed as a resource consultant.

Dr Fang: contributed as a panelist.

Dr Hylek: contributed as a panelist.

Dr Schulman: contributed as a panelist.

Dr Go: contributed as a panelist.

Dr Hughes: contributed as a panelist.

Dr Spencer: contributed as a panelist.

Dr Manning: contributed as a panelist.

Dr Halperin: contributed as a panelist.

Dr Lip: contributed as Deputy Editor and senior author.

Financial/nonfinancial disclosures: The authors of this guideline provided detailed conflict of interest information related to each individual recommendation made in this article. A grid of these disclosures is available online at http://chestjournal. chestpubs.org/content/141/2_suppl/e531S/suppl/DC1. In summary, the authors have reported to CHEST the following conflicts of interest: Over the past 3 years, Dr Singer has received grant support from the Eliot B. and Edith C. Shoolman fund of Massachusetts General Hospital (MGH) to study stroke in atrial fibrillation. He has also received research grant support (through MGH) from Daiichi-Sankyo, Inc, to study hemorrhage risk in patients with atrial fibrillation taking warfarin. Dr Singer has been supported by the National Institutes of Health (National Heart, Lung, and Blood Institute and National Institute on Aging) grant funding to study stroke risk in patients with atrial fibrillation. He has served as a consultant on stroke prevention in atrial fibrillation to Bayer Healthcare Pharmaceuticals; Boehringer Ingelheim GmbH; Bristol-Myers Squibb; Daiichi-Sankyo, Inc; Johnson \& Johnson; Merck and Co, Inc; Pfizer Inc; and Sanofi-Aventis LLC. Dr. Singer has published numerous articles on stroke prevention in atrial fibrillation and has given numerous lectures and research presentations on this topic. Dr Lane is in receipt of an investigator-initiated educational grant from Bayer Healthcare Pharmaceuticals and has participated in speaker activities for Bayer Healthcare Pharmaceuticals, Boehringer Ingelheim GmbH, Bristol-Myers Squibb/Pfizer Inc, and the Thrombosis Research Institute. She has also received support (travel and accommodation) to attend conferences from AstraZeneca and Boehringer Ingelheim GmbH. Dr Eckman has received a number of grants, including university grants for "Using Decision Analytic Modeling to Guide the ACCP Guideline Development Process for Antithrombotic Therapy in Atrial Fibrillation" (Foundation for Informed Medical Decision Making; $\$ 185,000)$ and has the following industry grants: "Cost-Effectiveness of Screening for Chronic Hepatitis C Infection" (Merck/ScheringPlough; September 2012; \$58,000) and "Cost-Effectiveness of Screening for Chronic Hepatitis B Infection" (Gilead Sciences Inc; $\$ 56,000)$. He served as a consultant for Savient Pharmaceuticals $(\sim \$ 300)$. Dr Hylek has participated in a symposium sponsored by Boehringer Ingelheim, served on advisory boards (Bayer Healthcare Pharmaceuticals; Boehringer Ingelheim $\mathrm{GmbH}$; Bristol-Myers Squibb; Daiichi-Sankyo, Inc; Johnson \& Johnson; Merck and Co, Inc; Ortho-McNeil Pharmaceutical, Inc; and Pfizer Inc) for amounts totaling $<\$ 10,000$ and participated at the steering committee level for several pharmaceutical-sponsored studies (ARISTOTLE trial sponsored by Bristol-Myers Squibb and Pfizer Inc $[<\$ 10,000]$ and ORBIT-AF Registry sponsored by Ortho-McNeil Pharmaceutical, Inc $[<\$ 10,000])$. Dr Go has received research funding from the National Heart, Lung, and Blood Institute related to antithrombotic therapy in atrial fibrillation and was a site principal investigator for a clinical trial sponsored by Johnson \& Johnson and Bayer Healthcare Pharmaceuticals. Dr Halperin has received consulting fees from the following pharmaceutical manufacturers for advisory activities involving the development of anticoagulant drugs, none of which are currently approved for clinical use in any indication in the United States: Astellas Pharma, US; Bayer AG HealthCare; Boehringer Ingelheim; Daiichi Sankyo; Johnson \& Johnson; and Sanofi-Aventis. He has received honoraria from Portola Pharmaceuticals, Inc as a member of the Data Safety Monitoring Board of its Phase II EXPLORE-AF trial involving an investigational anticoagulant for prevention of thromboembolism in patients with atrial fibrillation. He has received consulting fees from Biotronik, Inc as co-chair of the Steering Committee for the IMPACT clinical trial evaluating the use ambulatory monitoring technology in approved implanted cardiac arrhythmia devices to guide anticoagulation therapy for stroke prevention. He has received a consulting fee from the Bristol-Myers Squibb/Sanofi Partnership for advisory activities related to the use of the platelet inhibitor drug, clopidogrel, for prevention of thromboembolism in patients with atrial fibrillation. He has been a speaker at CME Symposia that derived partial funding from the following sponsors involved in the development of anticoagulants for potential use in patients with AF: Bayer AG HealthCare, Boehringer Ingelheim, and SanofiAventis. Dr Lip has served as a consultant for Bayer, Astellas, Merck, Daiichi-Sankyo, AstraZeneca, Sanofi-Aventis, BMS/Pfizer, Biotronik, Portola, and Boehringer Ingelheim and has been on the speakers bureau for Bayer, Bristol-Myers Squibb/Pfizer, Boehringer Ingelheim, and Sanofi-Aventis. Drs You, Howard, Fang, Schulman, Hughes, Manning, and Spencer have reported that no potential conflicts of interest exist with any companies/organizations whose products or services may be discussed in this article.

Role of sponsors: The sponsors played no role in the development of these guidelines. Sponsoring organizations cannot recommend panelists or topics, nor are they allowed prepublication access to the manuscripts and recommendations. Guideline panel members, including the chair, and members of the Health $\&$ Science Policy Committee are blinded to the funding sources. Further details on the Conflict of Interest Policy are available online at http://chestnet.org.

Other contributions: We thank Louis Kuritzky, MD, for sharing his perspective as a frontline clinician during the development of our recommendations.

Endorsements: This guideline is endorsed by the American Association for Clinical Chemistry, the American College of Clinical Pharmacy, the American Society of Health-System Pharmacists, the American Society of Hematology, and the International Society of Thrombosis and Hematosis.

Additional information: The supplement Tables can be found in the Online Data Supplement at http://chestjournal.chestpubs.org/ content/141/2_suppl/e531S/suppl/DC1. 


\section{REFERENCES}

1. Lloyd-Jones DM, Wang TJ, Leip EP, et al. Lifetime risk for development of atrial fibrillation: the Framingham Heart Study. Circulation. 2004;110(9):1042-1046.

2. Miyasaka Y, Barnes ME, Gersh BJ, et al. Secular trends in incidence of atrial fibrillation in Olmsted County, Minnesota, 1980 to 2000, and implications on the projections for future prevalence. Circulation. 2006;114(2):119-125.

3. Wolf PA, Abbott RD, Kannel WB. Atrial fibrillation as an independent risk factor for stroke: the Framingham Study. Stroke. 1991;22(8):983-988.

4. Risk factors for stroke and efficacy of antithrombotic therapy in atrial fibrillation. Analysis of pooled data from five randomized controlled trials [published correction in Arch Intern Med. 1994;154(19):2254]. Arch Intern Med. 1994; 154(13):1449-1457.

5. Douketis JD, Spyropoulos AC, Spencer FA, et al. Perioperative management of antithrombotic therapy: antithrombotic therapy and prevention of thrombosis, 9th ed: American College of Chest Physicians evidence-based clinical practice guidelines. Chest. 2012;141(2)(suppl):e326S-e350S.

6. Lansberg MG, O’Donnell MJ, Khatri P, et al. Antithrombotic and thrombolytic therapy for ischemic stroke: antithrombotic therapy and prevention of thrombosis, 9th ed: American College of Chest Physicians evidence-based clinical practice guidelines. Chest. 2012;141(2)(suppl):e601S-e636S.

7. Whitlock RP, Sun JC, Fremes SE, Rubens FD, Teoh KH. Antithrombotic and thrombolytic therapy for valvular disease: antithrombotic therapy and prevention of thrombosis, 9th ed: American College of Chest Physicians evidencebased clinical practice guidelines. Chest. 2012;141(2)(suppl): e576S-e600S.

8. Bates SM, Greer IA, Middeldorp S, Veenstra D, Prabulos A-M, Vandvik PO. VTE, thrombophilia, antithrombotic therapy, and pregnancy: antithrombotic therapy and prevention of thrombosis, 9th ed: American College of Chest Physicians evidence-based clinical practice guidelines. Chest. 2012;141(2)(suppl):e691S-e736S.

9. MacLean S, Mulla S, Akl EA, et al. Patient values and preferences in decision making for antithrombotic therapy: a systematic review: antithrombotic therapy and prevention of thrombosis, 9th ed: American College of Chest Physicians evidence-based clinical practice guidelines. Chest. 2012;141(2)(suppl):e1S-e23S.

10. Guyatt GH, Norris SL, Schulman S, et al. Methodology for the development of antithrombotic therapy and prevention of thrombosis guidelines: antithrombotic therapy and prevention of thrombosis, 9th ed: American College of Chest Physicians evidence-based clinical practice guidelines. Chest. 2012;141(2)(suppl):53S-70S.

11. Andersen KK, Olsen TS, Dehlendorff C, Kammersgaard LP. Hemorrhagic and ischemic strokes compared: stroke severity, mortality, and risk factors. Stroke. 2009;40(6):2068-2072.

12. Stroke Risk in Atrial Fibrillation Working Group. Comparison of 12 risk stratification schemes to predict stroke in patients with nonvalvular atrial fibrillation. Stroke. 2008; 39(6):1901-1910.

13. Lévy S, Camm AJ, Saksena S, et al; Working Group on Arrhythmias, Working Group on Cardiac Pacing of the European Society of Cardiology, North American Society of Pacing and Electrophysiology. International consensus on nomenclature and classification of atrial fibrillation; a collaborative project of the Working Group on Arrhythmias and the Working Group on Cardiac Pacing of the European Society of Cardiology and the North American Society of Pacing and Electrophysiology. Europace. 2003;5(2): 119-122.
14. Petersen P. Thromboembolic complications in atrial fibrillation. Stroke. 1990;21(1):4-13.

15. Brand FN, Abbott RD, Kannel WB, Wolf PA. Characteristics and prognosis of lone atrial fibrillation. 30-year follow-up in the Framingham Study. JAMA. 1985;254(24):3449-3453.

16. Hart RG, Pearce LA, Rothbart RM, McAnulty JH, Asinger RW, Halperin JL; Stroke Prevention in Atrial Fibrillation Investigators. Stroke with intermittent atrial fibrillation: incidence and predictors during aspirin therapy. J Am Coll Cardiol. 2000;35(1):183-187.

17. Hohnloser SH, Pajitnev D, Pogue J, et al; ACTIVE W Investigators. Incidence of stroke in paroxysmal versus sustained atrial fibrillation in patients taking oral anticoagulation or combined antiplatelet therapy: an ACTIVE W Substudy. J Am Coll Cardiol. 2007;50(22):2156-2161.

18. Stroke Risk in Atrial Fibrillation Working Group. Independent predictors of stroke in patients with atrial fibrillation: a systematic review. Neurology. 2007;69(6):546-554.

19. Hughes M, Lip GY; Guideline Development Group, National Clinical Guideline for Management of Atrial Fibrillation in Primary and Secondary Care, National Institute for Health and Clinical Excellence. Stroke and thromboembolism in atrial fibrillation: a systematic review of stroke risk factors, risk stratification schema and cost effectiveness data. Thromb Haemost. 2008;99(2):295-304.

20. van Walraven C, Hart RG, Connolly S, et al. Effect of age on stroke prevention therapy in patients with atrial fibrillation: the atrial fibrillation investigators. Stroke. 2009;40(4): 1410-1416.

21. Lin LY, Lee CH, Yu CC, et al. Risk factors and incidence of ischemic stroke in Taiwanese with nonvalvular atrial fibrillation-a nation wide database analysis. Atherosclerosis. 2011;217(1):292-295.

22. Frost L, Engholm G, Johnsen S, Møller H, Husted S. Incident stroke after discharge from the hospital with a diagnosis of atrial fibrillation. Am J Med. 2000;108(1):36-40.

23. The Stroke Prevention in Atrial Fibrillation Investigators Committee on Echocardiography. Transesophageal echocardiographic correlates of thromboembolism in high-risk patients with nonvalvular atrial fibrillation. Ann Intern Med. 1998;128(8):639-647.

24. Olesen JB, Lip GY, Hansen ML, et al. Validation of risk stratification schemes for predicting stroke and thromboembolism in patients with atrial fibrillation: nationwide cohort study. BMJ. 2011;342:d124.

25. Stroke Prevention in Atrial Fibrillation Investigators. Risk factors for thromboembolism during aspirin therapy in patients with atrial fibrillation: the Stroke Prevention in Atrial Fibrillation Study. J Stroke Cerebrovasc Dis. 1995;5(3): 147-157.

26. van Latum JC, Koudstaal PJ, Venables GS, van Gijn J, Kappelle LJ, Algra A; European Atrial Fibrillation Trial (EAFT) Study Group. Predictors of major vascular events in patients with a transient ischemic attack or minor ischemic stroke and with nonrheumatic atrial fibrillation. Stroke. 1995;26(5):801-806.

27. Echocardiographic predictors of stroke in patients with atrial fibrillation: a prospective study of 1066 patients from 3 clinical trials. Arch Intern Med. 1998;158(12):1316-1320.

28. Hart RG, Pearce LA, McBride R, Rothbart RM, Asinger RW; The Stroke Prevention in Atrial Fibrillation (SPAF) Investigators. Factors associated with ischemic stroke during aspirin therapy in atrial fibrillation: analysis of 2012 participants in the SPAF I-III clinical trials. Stroke. 1999;30(6):1223-1229.

29. Fuster V, Rydén LE, Cannom DS, et al; American College of Cardiology/American Heart Association Task Force 
on Practice Guidelines; European Society of Cardiology Committee for Practice Guidelines; European Heart Rhythm Association; Heart Rhythm Society. ACC/AHA/ ESC 2006 Guidelines for the Management of Patients with Atrial Fibrillation: a report of the American College of Cardiology/American Heart Association Task Force on Practice Guidelines and the European Society of Cardiology Committee for Practice Guidelines (Writing Committee to Revise the 2001 Guidelines for the Management of Patients With Atrial Fibrillation): developed in collaboration with the European Heart Rhythm Association and the Heart Rhythm Society. Circulation. 2006;114(7):e257-e354.

30. Gage BF, Waterman AD, Shannon W, Boechler M, Rich MW, Radford MJ. Validation of clinical classification schemes for predicting stroke: results from the National Registry of Atrial Fibrillation. JAMA. 2001;285(22):2864-2870.

31. Albers GW, Dalen JE, Laupacis A, Manning WJ, Petersen P, Singer DE. Antithrombotic therapy in atrial fibrillation. Chest. 2001;119( suppl 1):194S-206S.

32. Wang TJ, Massaro JM, Levy D, et al. A risk score for predicting stroke or death in individuals with new-onset atrial fibrillation in the community: the Framingham Heart Study. JAMA. 2003;290(8):1049-1056.

33. van Walraven C, Hart RG, Wells GA, et al. A clinical prediction rule to identify patients with atrial fibrillation and a low risk for stroke while taking aspirin. Arch Intern Med. 2003;163(8):936-943.

34. Singer DE, Albers GW, Dalen JE, Go AS, Halperin JL, Manning WJ. Antithrombotic therapy in atrial fibrillation: the Seventh ACCP Conference on Antithrombotic and Thrombolytic Therapy. Chest. 2004;126(suppl 3):429S-456S.

35. Lip GY, Lane D, Van Walraven C, Hart RG. Additive role of plasma von Willebrand factor levels to clinical factors for risk stratification of patients with atrial fibrillation. Stroke. 2006;37(9):2294-2300.

36. Lip GY, Nieuwlaat R, Pisters R, Lane DA, Crijns HJ. Refining clinical risk stratification for predicting stroke and thromboembolism in atrial fibrillation using a novel risk factor-based approach: the euro heart survey on atrial fibrillation. Chest. 2010;137(2):263-272.

37. Gage BF, van Walraven C, Pearce L, et al. Selecting patients with atrial fibrillation for anticoagulation: stroke risk stratification in patients taking aspirin. Circulation. 2004;110(16):2287-2292.

38. Baruch L, Gage BF, Horrow J, et al. Can patients at elevated risk of stroke treated with anticoagulants be further risk stratified? Stroke. 2007;38(9):2459-2463.

39. Fang MC, Go AS, Chang Y, Borowsky L, Pomernacki NK, Singer DE; ATRIA Study Group. Comparison of risk stratification schemes to predict thromboembolism in people with nonvalvular atrial fibrillation. I Am Coll Cardiol. 2008;51(8):810-815.

40. Poli D, Lip GY, Antonucci E, Grifoni E, Lane D. Stroke risk stratification in a "real-world" elderly anticoagulated atrial fibrillation population. J Cardiovasc Electrophysiol. 2010;22(1):25-30

41. Ruiz Ortiz M, Romo E, Mesa D, et al. Oral anticoagulation in nonvalvular atrial fibrillation in clinical practice: impact of $\operatorname{CHADS}\left({ }_{2}\right)$ score on outcome. Cardiology. 2010;115(3): 200-204.

42. Lip GY, Frison L, Halperin JL, Lane DA. Identifying patients at high risk for stroke despite anticoagulation: a comparison of contemporary stroke risk stratification schemes in an anticoagulated atrial fibrillation cohort. Stroke. 2010;41(12):2731-2738.

43. Van Staa TP, Setakis E, Di Tanna GL, Lane DA, Lip GY. A comparison of risk stratification schemes for stroke in
79,884 atrial fibrillation patients in general practice. J Thromb Haemost. 2011;9(1):39-48.

44. Go AS, Hylek EM, Chang Y, et al. Anticoagulation therapy for stroke prevention in atrial fibrillation: how well do randomized trials translate into clinical practice? JAMA. 2003;290(20):2685-2692.

45. Fang MC, Singer DE, Chang Y, et al. Gender differences in the risk of ischemic stroke and peripheral embolism in atrial fibrillation: the AnTicoagulation and Risk factors In Atrial fibrillation (ATRIA) study. Circulation. 2005;112(12): 1687-1691.

46. Healey JS, Hart RG, Pogue J, et al. Risks and benefits of oral anticoagulation compared with clopidogrel plus aspirin in patients with atrial fibrillation according to stroke risk: the atrial fibrillation clopidogrel trial with irbesartan for prevention of vascular events (ACTIVE-W). Stroke. 2008;39(5):1482-1486.

47. Arima H, Hart RG, Colman S, et al; PROGRESS Collaborative Group. Perindopril-based blood pressure-lowering reduces major vascular events in patients with atrial fibrillation and prior stroke or transient ischemic attack. Stroke. 2005;36(10):2164-2169.

48. Lip GY, Frison L, Grind M; SPORTIF Investigators. Effect of hypertension on anticoagulated patients with atrial fibrillation. Eur Heart J. 2007;28(6):752-759.

49. Eckman MH, Singer DE, Rosand J, Greenberg SM. Moving the tipping point: the decision to anticoagulate patients with atrial fibrillation. Circ Cardiovasc Qual Outcomes. 2011; $4(1): 14-21$.

50. National Collaborating Centre for Chronic Conditions. Atrial fibrillation: national clinical guideline for management in primary and secondary care. London, England: Royal College of Physicians; 2006:104. Available at: http:// www.nice.org.uk/nicemedia/live/10982/30055/30055.pdf. Accessed November 22, 2011.

51. Singer DE, Chang Y, Fang MC, et al. The net clinical benefit of warfarin anticoagulation in atrial fibrillation. Ann Intern Med. 2009;151(5):297-305.

52. Hart RG, Pearce LA. Current status of stroke risk stratification in patients with atrial fibrillation. Stroke. 2009; 40(7):2607-2610.

53. Pisters R, Lane DA, Nieuwlaat R, de Vos CB, Crijns HJ, Lip GY. A novel user-friendly score (HAS-BLED) to assess 1-year risk of major bleeding in patients with atrial fibrillation: The Euro Heart Survey. Chest. 2010;138(5):1093-1100.

54. van der Meer FJ, Rosendaal FR, Vandenbroucke JP, Briët E. Bleeding complications in oral anticoagulant therapy. An analysis of risk factors. Arch Intern Med. 1993;153(13):1557-1562.

55. Petersen P, Boysen G, Godtfredsen J, Andersen ED, Andersen B. Placebo-controlled, randomised trial of warfarin and aspirin for prevention of thromboembolic complications in chronic atrial fibrillation. The Copenhagen AFASAK study. Lancet. 1989;1(8631):175-179.

56. The Boston Area Anticoagulation Trial for Atrial Fibrillation Investigators. The effect of low-dose warfarin on the risk of stroke in patients with nonrheumatic atrial fibrillation. N Engl J Med. 1990;323(22):1505-1511.

57. Connolly SJ, Laupacis A, Gent M, Roberts RS, Cairns JA, Joyner C. Canadian Atrial Fibrillation Anticoagulation (CAFA) Study. J Am Coll Cardiol. 1991;18(2):349-355.

58. Stroke Prevention in Atrial Fibrillation Study. Final results. Circulation. 1991;84(2):527-539.

59. Ezekowitz MD, Bridgers SL, James KE, et al; Veterans Affairs Stroke Prevention in Nonrheumatic Atrial Fibrillation Investigators. Warfarin in the prevention of stroke associated with nonrheumatic atrial fibrillation. $N$ Engl J Med. 1992;327(20):1406-1412. 
60. EAFT (European Atrial Fibrillation Trial) Study Group. Secondary prevention in non-rheumatic atrial fibrillation after transient ischaemic attack or minor stroke. Lancet. 1993;342(8882): 1255-1262.

61. van Walraven C, Hart RG, Singer DE, et al. Oral anticoagulants vs aspirin in nonvalvular atrial fibrillation: an individual patient meta-analysis. JAMA. 2002;288(19):2441-2448

62. Benavente O, Hart R, Koudstaal P, Laupacis A, McBride R. Antiplatelet therapy for preventing stroke in patients with atrial fibrillation and no previous history of stroke or transient ischemic attacks. In: Warlow C, Van Gijn J, Sandercock P, eds. Stroke Module of the Cochrane Database of Systematic Reviews. Oxford, England: The Cochrane Collaboration; 1999.

63. Posada IS, Barriales V; LASAF Pilot Study Group. Alternateday dosing of aspirin in atrial fibrillation. Am Heart J. 1999; 138(1 pt 1):137-143.

64. Sato H, Ishikawa K, Kitabatake A, et al; Japan Atrial Fibrillation Stroke Trial Group. Low-dose aspirin for prevention of stroke in low-risk patients with atrial fibrillation: Japan Atrial Fibrillation Stroke Trial. Stroke. 2006;37(2): 447-451.

65. Diener HC, Lowenthal A. Antiplatelet therapy to prevent stroke: risk of brain hemorrhage and efficacy in atrial fibrillation. J Neurol Sci. 1997;153(1):112.

66. Edvardsson N, Juul-Möller S, Omblus R, Pehrsson K. Effects of low-dose warfarin and aspirin versus no treatment on stroke in a medium-risk patient population with atrial fibrillation. J Intern Med. 2003;254(1):95-101.

67. Baigent C, Blackwell L, Collins R, et al; Antithrombotic Trialists' (ATT) Collaboration. Aspirin in the primary and secondary prevention of vascular disease: collaborative metaanalysis of individual participant data from randomised trials. Lancet. 2009;373(9678):1849-1860.

68. Antithrombotic Trialists' Collaboration; Baigent C, Blackwell L, Collins R, et al. Collaborative meta-analysis of randomised trials of antiplatelet therapy for prevention of death, myocardial infarction, and stroke in high risk patients. BMJ. 2002;324(7329):71-86.

69. Vemmos KN, Tsivgoulis G, Spengos K, et al. Primary prevention of arterial thromboembolism in the oldest old with atrial fibrillation — a randomized pilot trial comparing adjusted-dose and fixed low-dose coumadin with aspirin. Eur J Intern Med. 2006;17(1):48-52.

70. Gulløv AL, Koefoed BG, Petersen P, et al. Fixed minidose warfarin and aspirin alone and in combination vs adjusteddose warfarin for stroke prevention in atrial fibrillation: Second Copenhagen Atrial Fibrillation, Aspirin, and Anticoagulation Study. Arch Intern Med. 1998;158(14):1513-1521.

71. Mant J, Hobbs FD, Fletcher K, et al; BAFTA Investigators; Midland Research Practices Network (MidReC). Warfarin versus aspirin for stroke prevention in an elderly community population with atrial fibrillation (the Birmingham Atrial Fibrillation Treatment of the Aged Study, BAFTA): a randomised controlled trial. Lancet. 2007;370(9586):493-503.

72. Pérez-Gómez F, Alegría E, Berjón J, et al; NASPEAF Investigators. Comparative effects of antiplatelet, anticoagulant, or combined therapy in patients with valvular and nonvalvular atrial fibrillation: a randomized multicenter study. J Am Coll Cardiol. 2004;44(8):1557-1566.

73. Hellemons BS, Langenberg M, Lodder J, et al. Primary prevention of arterial thromboembolism in non-rheumatic atrial fibrillation in primary care: randomised controlled trial comparing two intensities of coumarin with aspirin. BMJ. 1999;319(7215):958-964.

74. Morocutti C, Amabile G, Fattapposta F, et al; SIFA (Studio Italiano Fibrillazione Atriale) Investigators. Indobufen ver- sus warfarin in the secondary prevention of major vascular events in nonrheumatic atrial fibrillation. Stroke. 1997; 28(5):1015-1021.

75. Warfarin versus aspirin for prevention of thromboembolism in atrial fibrillation: Stroke Prevention in Atrial Fibrillation II Study. Lancet. 1994;343(8899):687-691.

76. Adjusted-dose warfarin versus low-intensity, fixed-dose warfarin plus aspirin for high-risk patients with atrial fibrillation: Stroke Prevention in Atrial Fibrillation III randomised clinical trial. Lancet. 1996;348(9028):633-638.

77. Rash A, Downes T, Portner R, Yeo WW, Morgan N, Channer KS. A randomised controlled trial of warfarin versus aspirin for stroke prevention in octogenarians with atrial fibrillation (WASPO). Age Ageing. 2007;36(2):151-156.

78. Anand SS, Yusuf S. Oral anticoagulants in patients with coronary artery disease. J Am Coll Cardiol. 2003;41(4)(suppl S): 62S-69S.

79. Chimowitz MI, Lynn MJ, Howlett-Smith H, et al; WarfarinAspirin Symptomatic Intracranial Disease Trial Investigators. Comparison of warfarin and aspirin for symptomatic intracranial arterial stenosis. N Engl J Med. 2005;352(13):1305-1316.

80. Connolly S, Pogue J, Hart R, et al; ACTIVE Writing Group of the ACTIVE Investigators. Clopidogrel plus aspirin versus oral anticoagulation for atrial fibrillation in the Atrial fibrillation Clopidogrel Trial with Irbesartan for prevention of Vascular Events (ACTIVE W): a randomised controlled trial. Lancet. 2006;367(9526):1903-1912.

81. Connolly SJ, Pogue J, Hart RG, et al; ACTIVE Investigators. Effect of clopidogrel added to aspirin in patients with atrial fibrillation. N Engl J Med. 2009;360(20):2066-2078.

82. Olsson SB; Executive Steering Committee of the SPORTIF III Investigators. Stroke prevention with the oral direct thrombin inhibitor ximelagatran compared with warfarin in patients with non-valvular atrial fibrillation (SPORTIF III): randomised controlled trial. Lancet. 2003; 362(9397):1691-1698.

83. Albers GW, Diener HC, Frison L, et al; SPORTIF Executive Steering Committee for the SPORTIF V Investigators. Ximelagatran vs warfarin for stroke prevention in patients with nonvalvular atrial fibrillation: a randomized trial. JAMA. 2005;293(6):690-698.

84. Connolly SJ, Ezekowitz MD, Yusuf S, et al; RE-LY Steering Committee and Investigators. Dabigatran versus warfarin in patients with atrial fibrillation. $N$ Engl J Med. 2009;361(12):1139-1151.

85. Patel MR, Mahaffey KW, Garg J, et al; ROCKET AF Investigators. Rivaroxaban versus warfarin in nonvalvular atrial fibrillation. N Engl J Med. 2011;365(10):883-891.

86. Connolly SJ, Eikelboom J, Joyner C, et al; AVERROES Steering Committee and Investigators. Apixaban in patients with atrial fibrillation. N Engl J Med. 2011;364(9):806-817.

87. Granger CB, Alexander JH, McMurray JJ, et al; ARISTOTLE Committees and Investigators. Apixaban versus warfarin in patients with atrial fibrillation. $N$ Engl J Med. 2011;365(11): 981-992.

88. Roskell NS, Lip GY, Noack H, Clemens A, Plumb JM. Treatments for stroke prevention in atrial fibrillation: a network meta-analysis and indirect comparisons versus dabigatran etexilate. Thromb Haemost. 2010;104(6):1106-1115.

89. Label approved on 03/04/2011 for Pradaxa, NDA no. 022512. In: United States Food and Drug Administration; 2010.

90. van Ryn J, Stangier J, Haertter S, et al. Dabigatran etexilatea novel, reversible, oral direct thrombin inhibitor: interpretation of coagulation assays and reversal of anticoagulant activity. Thromb Haemost. 2010;103(6):1116-1127.

91. Holbrook A, Schulman S, Witt DM, et al. Evidence-based management of anticoagulant therapy: antithrombotic 
therapy and prevention of thrombosis, 9th ed: American College of Chest Physicians evidence-based clinical practice guidelines. Chest. 2012;141(2)(suppl):e152S-e184S.

92. Bloomfield HE, Krause A, Greer N, et al. Meta-analysis: effect of patient self-testing and self-management of longterm anticoagulation on major clinical outcomes. Ann Intern Med. 2011;154(7):472-482.

93. Freeman JV, Zhu RP, Owens DK, et al. Cost-effectiveness of dabigatran compared with warfarin for stroke prevention in atrial fibrillation. Ann Intern Med. 2011;154(1):1-11.

94. Hughes M, Lip GY; Guideline Development Group for the NICE national clinical guideline for management of atrial fibrillation in primary and secondary care. Risk factors for anticoagulation-related bleeding complications in patients with atrial fibrillation: a systematic review. QJM. 2007;100(10):599-607.

95. Beyth RJ, Quinn LM, Landefeld CS. Prospective evaluation of an index for predicting the risk of major bleeding in outpatients treated with warfarin. Am J Med. 1998;105(2): 91-99.

96. Landefeld CS, Goldman L. Major bleeding in outpatients treated with warfarin: incidence and prediction by factors known at the start of outpatient therapy. Am J Med. 1989;87(2):144-152.

97. Shireman TI, Mahnken JD, Howard PA, Kresowik TF, Hou Q, Ellerbeck EF. Development of a contemporary bleeding risk model for elderly warfarin recipients. Chest. 2006;130(5):1390-1396.

98. Gage BF, Yan Y, Milligan PE, et al. Clinical classification schemes for predicting hemorrhage: results from the National Registry of Atrial Fibrillation (NRAF). Am Heart J. 2006;151(3):713-719.

99. Lip GY, Frison L, Halperin JL, Lane DA. Comparative validation of a novel risk score for predicting bleeding risk in anticoagulated patients with atrial fibrillation: the HAS-BLED (Hypertension, Abnormal Renal/Liver Function, Stroke, Bleeding History or Predisposition, Labile INR, Elderly, Drugs/Alcohol Concomitantly) score. J Am Coll Cardiol. 2011;57(2):173-180.

100. Holmes DR, Reddy VY, Turi ZG, et al; PROTECT AF Investigators. Percutaneous closure of the left atrial appendage versus warfarin therapy for prevention of stroke in patients with atrial fibrillation: a randomised non-inferiority trial. Lancet. 2009;374(9689):534-542.

101. Ostermayer SH, Reisman M, Kramer PH, et al. Percutaneous left atrial appendage transcatheter occlusion (PLAATO system) to prevent stroke in high-risk patients with non-rheumatic atrial fibrillation: results from the international multi-center feasibility trials. J Am Coll Cardiol. 2005;46(1):9-14.

102. Block PC, Burstein S, Casale PN, et al. Percutaneous left atrial appendage occlusion for patients in atrial fibrillation suboptimal for warfarin therapy: 5-year results of the PLAATO (Percutaneous Left Atrial Appendage Transcatheter Occlusion) Study. JACC Cardiovasc Interv. 2009; 2(7):594-600.

103. Lechat $\mathrm{P}$, Lardoux H, Mallet A, et al; FFAACS (Fluindione, Fibrillation Auriculaire, Aspirin et Contraste Spontané) Investigators. Anticoagulant (fluindione)-aspirin combination in patients with high-risk atrial fibrillation. A randomized trial (Fluindione, Fibrillation Auriculaire, Aspirin et Contraste Spontané; FFAACS). Cerebrovasc Dis. 2001;12(3): 245-252.

104. Flaker GC, Gruber M, Connolly SJ, et al; SPORTIF Investigators. Risks and benefits of combining aspirin with anticoagulant therapy in patients with atrial fibrillation: an exploratory analysis of stroke prevention using an oral thrombin inhibitor in atrial fibrillation (SPORTIF) trials. Am Heart J. 2006;152(5):967-973.

105. Clinical review for Pradaxa, NDA 22-512. In: United States Food and Drug Administration; 2010:96.

106. Hansen ML, Sørensen R, Clausen MT, et al. Risk of bleeding with single, dual, or triple therapy with warfarin, aspirin, and clopidogrel in patients with atrial fibrillation. Arch Intern Med. 2010;170(16):1433-1441.

107. Dentali F, Douketis JD, Lim W, Crowther M. Combined aspirin-oral anticoagulant therapy compared with oral anticoagulant therapy alone among patients at risk for cardiovascular disease: a meta-analysis of randomized trials. Arch Intern Med. 2007;167(2):117-124.

108. Vandvik PO, Lincoff AM, Gore JM, et al. Primary and secondary prevention of cardiovascular disease: antithrombotic therapy and prevention of thrombosis, 9th ed: American College of Chest Physicians evidence-based clinical practice guidelines. Chest. 2012;141(2)(suppl):e637S-e668S.

109. Iakovou I, Schmidt T, Bonizzoni E, et al. Incidence, predictors, and outcome of thrombosis after successful implantation of drug-eluting stents. JAMA. 2005;293(17):2126-2130.

110. Serruys PW, Strauss BH, Beatt KJ, et al. Angiographic follow-up after placement of a self-expanding coronary-artery stent. N Engl J Med. 1991;324(1):13-17.

111. Roubin GS, Cannon AD, Agrawal SK, et al. Intracoronary stenting for acute and threatened closure complicating percutaneous transluminal coronary angioplasty. Circulation. 1992;85(3):916-927.

112. Foley JB, Brown RI, Penn IM. Thrombosis and restenosis after stenting in failed angioplasty: comparison with elective stenting. Am Heart J. 1994;128(1):12-20.

113. Cook S, Windecker S. Early stent thrombosis: past, present, and future. Circulation. 2009;119(5):657-659

114. Cosmi B, Rubboli A, Castelvetri C, Milandri M. Ticlopidine versus oral anticoagulation for coronary stenting. Cochrane Database Syst Rev. 2001;(4):CD002133.

115. Lip GY, Huber K, Andreotti F, et al; European Society of Cardiology Working Group on Thrombosis. Management of antithrombotic therapy in atrial fibrillation patients presenting with acute coronary syndrome and/or undergoing percutaneous coronary intervention/ stenting published correction in Thromb Haemost. 2010;104(3):653. Dosage error in article text]. Thromb Haemost. 2010;103(1):13-28.

116. Faxon DP, Eikelboom JW, Berger PB, Holmes DR, Bhatt DL, Moliterno DJ, Becker RC, Angiolillo DJ. Consensus document: antithrombotic therapy in patients with atrial fibrillation undergoing coronary stenting: a North-American perspective. Thromb Haemost. 2011;106(4):572-584.

117. Rossini R, Musumeci G, Lettieri C, et al. Long-term outcomes in patients undergoing coronary stenting on dual oral antiplatelet treatment requiring oral anticoagulant therapy. Am J Cardiol. 2008;102(12):1618-1623.

118. Sarafoff N, Ndrepepa G, Mehilli J, et al. Aspirin and clopidogrel with or without phenprocoumon after drug eluting coronary stent placement in patients on chronic oral anticoagulation. J Intern Med. 2008;264(5):472-480.

119. Sambola A, Ferreira-González I, Angel J, et al. Therapeutic strategies after coronary stenting in chronically anticoagulated patients: the MUSICA study. Heart. 2009;95(18):1483-1488.

120. Gao F, Zhou YJ, Wang ZJ, et al. Comparison of different antithrombotic regimens for patients with atrial fibrillation undergoing drug-eluting stent implantation. Circ J. 2010;74(4):701-708.

121. Rothberg MB, Celestin C, Fiore LD, Lawler E, Cook JR. Warfarin plus aspirin after myocardial infarction or the acute coronary syndrome: meta-analysis with estimates of risk and benefit. Ann Intern Med. 2005;143(4):241-250. 
122. Wallentin L, Becker RC, Budaj A, et al; PLATO Investigators. Ticagrelor versus clopidogrel in patients with acute coronary syndromes. N Engl J Med. 2009;361(11):1045-1057.

123. Holmes DR Jr, Kereiakes DJ, Garg S, et al. Stent thrombosis. J Am Coll Cardiol. 2010;56(17):1357-1365.

124. Yusuf S, Zhao F, Mehta SR, Chrolavicius S, Tognoni G, Fox KK. Effects of clopidogrel in addition to aspirin in patients with acute coronary syndromes without ST-segment elevation. N Engl J Med. 2001;345:494-502.

125. Sherman DG, Kim SG, Boop BS, et al; National Heart, Lung, and Blood Institute AFFIRM Investigators. Occurrence and characteristics of stroke events in the Atrial Fibrillation Follow-up Investigation of Sinus Rhythm Management (AFFIRM) study. Arch Intern Med. 2005; 165(10):1185-1191.

126. Krittayaphong R, Raungrattanaamporn O, Bhuripanyo K, et al. A randomized clinical trial of the efficacy of radiofrequency catheter ablation and amiodarone in the treatment of symptomatic atrial fibrillation. J Med Assoc Thai. 2003;86(suppl 1):S8-S16.

127. Wazni OM, Marrouche NF, Martin DO, et al. Radiofrequency ablation vs antiarrhythmic drugs as first-line treatment of symptomatic atrial fibrillation: a randomized trial. JAMA. 2005;293(21):2634-2640.

128. Oral H, Pappone C, Chugh A, et al. Circumferential pulmonary-vein ablation for chronic atrial fibrillation. $N$ Engl J Med. 2006;354(9):934-941.

129. Pappone C, Augello G, Sala S, et al. A randomized trial of circumferential pulmonary vein ablation versus antiarrhythmic drug therapy in paroxysmal atrial fibrillation: the APAF Study. J Am Coll Cardiol. 2006;48(11):2340-2347.

130. Stabile G, Bertaglia E, Senatore G, et al. Catheter ablation treatment in patients with drug-refractory atrial fibrillation: a prospective, multi-centre, randomized, controlled study (Catheter Ablation For The Cure Of Atrial Fibrillation Study). Eur Heart J. 2006;27(2):216-221.

131. Jaïs P, Cauchemez B, Macle L, et al. Catheter ablation versus antiarrhythmic drugs for atrial fibrillation: the A4 study. Circulation. 2008;118(24):2498-2505.

132. Wilber DJ, Pappone C, Neuzil P, et al; ThermoCool AF Trial Investigators. Comparison of antiarrhythmic drug therapy and radiofrequency catheter ablation in patients with paroxysmal atrial fibrillation: a randomized controlled trial. JAMA. 2010;303(4):333-340.

133. Omran H, Jung W, Rabahieh R, et al. Left atrial appendage function in patients with atrial flutter. Heart. 1997;78(3): 250-254.

134. Seidl K, Hauer B, Schwick NG, Zellner D, Zahn R, Senges J. Risk of thromboembolic events in patients with atrial flutter. Am J Cardiol. 1998;82(5):580-583.

135. Corrado G, Sgalambro A, Mantero A, et al. Thromboembolic risk in atrial flutter. The FLASIEC (FLutter Atriale Società Italiana di Ecografia Cardiovascolare) multicentre study. Eur Heart J. 2001;22(12):1042-1051.

136. Schmidt H, von der Recke G, Illien S, et al. Prevalence of left atrial chamber and appendage thrombi in patients with atrial flutter and its clinical significance. J Am Coll Cardiol. 2001;38(3):778-784.

137. Weiss R, Marcovitz P, Knight BP, et al. Acute changes in spontaneous echo contrast and atrial function after cardioversion of persistent atrial flutter. Am J Cardiol. 1998; 82(9):1052-1055.

138. Bikkina M, Alpert MA, Mulekar M, Shakoor A, Massey CV, Covin FA. Prevalence of intraatrial thrombus in patients with atrial flutter. Am J Cardiol. 1995;76(3):186-189.

139. Moreyra E, Finkelhor RS, Cebul RD. Limitations of transesophageal echocardiography in the risk assessment of patients before nonanticoagulated cardioversion from atrial fibrillation and flutter: an analysis of pooled trials. Am Heart J. 1995;129(1):71-75.

140. Gallagher MM, Hennessy BJ, Edvardsson N, et al. Embolic complications of direct current cardioversion of atrial arrhythmias: association with low intensity of anticoagulation at the time of cardioversion. J Am Coll Cardiol. 2002; 40(5):926-933.

141. Berger M, Schweitzer P. Timing of thromboembolic events after electrical cardioversion of atrial fibrillation or flutter: a retrospective analysis. Am J Cardiol. 1998;82: 1545-1547, A8.

142. Manning WJ, Leeman DE, Gotch PJ, Come PC. Pulsed Doppler evaluation of atrial mechanical function after electrical cardioversion of atrial fibrillation. J Am Coll Cardiol. 1989;13(3):617-623.

143. Nagarakanti R, Ezekowitz MD, Oldgren J, et al. Dabigatran versus warfarin in patients with atrial fibrillation: an analysis of patients undergoing cardioversion. Circulation. 2011; 123(2):131-136.

144. Manning WJ, Silverman DI, Gordon SP, Krumholz HM, Douglas PS. Cardioversion from atrial fibrillation without prolonged anticoagulation with use of transesophageal echocardiography to exclude the presence of atrial thrombi. N Engl J Med. 1993;328(11):750-755.

145. Klein AL, Grimm RA, Murray RD, et al; Assessment of Cardioversion Using Transesophageal Echocardiography Investigators. Use of transesophageal echocardiography to guide cardioversion in patients with atrial fibrillation. $N \mathrm{Engl}$ J Med. 2001;344(19):1411-1420.

146. Hoppensteadt D, Fareed J, Klein AL, et al; Assessment of Cardioversion Using Transesophageal Echocardiography (ACUTE) II Investigators. Comparison of anticoagulant and anti-inflammatory responses using enoxaparin versus unfractionated heparin for transesophageal echocardiography-guided cardioversion of atrial fibrillation. Am J Cardiol. 2008;102(7):842-846.

147. Klein AL, Jasper SE, Katz WE, et al; ACUTE II Steering and Publications Committee for the ACUTE II Investigators. The use of enoxaparin compared with unfractionated heparin for short-term antithrombotic therapy in atrial fibrillation patients undergoing transoesophageal echocardiography-guided cardioversion: Assessment of Cardioversion Using Transoesophageal Echocardiography (ACUTE) II randomized multicentre study. Eur Heart J. 2006;27(23): 2858-2865.

148. de Luca I, Sorino M, De Luca L, Colonna P, Del Salvatore B, Corlianò L. Pre- and post-cardioversion transesophageal echocardiography for brief anticoagulation therapy with enoxaparin in atrial fibrillation patients: a prospective study with a 1-year follow-up. Int J Cardiol. 2005;102(3): 447-454.

149. Wu LA, Chandrasekaran K, Friedman PA, et al. Safety of expedited anticoagulation in patients undergoing transesophageal echocardiographic-guided cardioversion. Am J Med. 2006;119(2):142-146.

150. Stellbrink C, Nixdorff U, Hofmann T, et al; ACE (Anticoagulation in Cardioversion using Enoxaparin) Study Group. Safety and efficacy of enoxaparin compared with unfractionated heparin and oral anticoagulants for prevention of thromboembolic complications in cardioversion of nonvalvular atrial fibrillation: the Anticoagulation in Cardioversion using Enoxaparin (ACE) trial. Circulation. 2004;109(8):997-1003.

151. Stangier J. Clinical pharmacokinetics and pharmacodynamics of the oral direct thrombin inhibitor dabigatran etexilate. Clin Pharmacokinet. 2008;47(5):285-295. 
152. Antonielli E, Pizzuti A, Pálinkás A, et al. Clinical value of left atrial appendage flow for prediction of long-term sinus rhythm maintenance in patients with nonvalvular atrial fibrillation. J Am Coll Cardiol. 2002;39(9):1443-1449.

153. Berry C, Stewart S, Payne EM, McArthur JD, McMurray JJ. Electrical cardioversion for atrial fibrillation: outcomes in "real-life" clinical practice. Int J Cardiol. 2001;81(1):29-35.

154. Arnar DO, Danielsen R. Factors predicting maintenance of sinus rhythm after direct current cardioversion of atrial fibrillation and flutter: a reanalysis with recently acquired data. Cardiology. 1996;87(3):181-188.

155. Paraskevaidis IA, Dodouras T, Tsiapras D, Kremastinos DT. Prediction of successful cardioversion and maintenance of sinus rhythm in patients with lone atrial fibrillation. Chest. 2005; 127(2):488-494.

156. Pérez Y, Duval AM, Carville C, et al. Is left atrial appendage flow a predictor for outcome of cardioversion of nonvalvular atrial fibrillation? A transthoracic and transesophageal echocardiographic study. Am Heart J. 1997;134(4):745-751.

157. Page RL, Wilkinson WE, Clair WK, McCarthy EA, Pritchett EL. Asymptomatic arrhythmias in patients with symptomatic paroxysmal atrial fibrillation and paroxysmal supraventricular tachycardia. Circulation. 1994;89(1):224-227.

158. Stoddard MF, Dawkins PR, Prince CR, Ammash NM. Left atrial appendage thrombus is not uncommon in patients with acute atrial fibrillation and a recent embolic event: a transesophageal echocardiographic study. J Am Coll Cardiol. 1995;25(2):452-459.

159. Kleemann T, Becker T, Strauss M, Schneider S, Seidl K. Prevalence of left atrial thrombus and dense spontaneous echo contrast in patients with short-term atrial fibrillation $<48$ hours undergoing cardioversion: value of transesophageal echocardiography to guide cardioversion. J Am Soc Echocardiogr. 2009;22(12):1403-1408.

160. Flaker GC, Belew K, Beckman K, et al; AFFIRM Investigators. Asymptomatic atrial fibrillation: demographic features and prognostic information from the Atrial Fibrillation Follow-up Investigation of Rhythm Management (AFFIRM) study. Am Heart J. 2005; 149(4):657-663.

161. Weigner MJ, Caulfield TA, Danias PG, Silverman DI, Manning WJ. Risk for clinical thromboembolism associated with conversion to sinus rhythm in patients with atrial fibrillation lasting less than 48 hours. Ann Intern Med. 1997;126(8):615-620.

162. Arnold AZ, Mick MJ, Mazurek RP, Loop FD, Trohman RG. Role of prophylactic anticoagulation for direct current cardioversion in patients with atrial fibrillation or atrial flutter. J Am Coll Cardiol. 1992;19(4):851-855.

163. Chalasani P, Cambre S, Silverman ME. Direct-current cardioversion for the conversion of atrial flutter. Am J Cardiol. 1996;77(8):658-660.
164. Hart RG, Benavente O, McBride R, Pearce LA. Antithrombotic therapy to prevent stroke in patients with atrial fibrillation: a meta-analysis. Ann Intern Med. 1999;131(7): 492-501.

165. Fang MC, Chang Y, Hylek EM, et al. Advanced age, anticoagulation intensity, and risk for intracranial hemorrhage among patients taking warfarin for atrial fibrillation. Ann Intern Med. 2004;141(10):745-752.

166. Hylek EM, Go AS, Chang Y, et al. Effect of intensity of oral anticoagulation on stroke severity and mortality in atrial fibrillation. N Engl J Med. 2003;349(11):1019-1026.

167. Hylek EM, Skates SJ, Sheehan MA, Singer DE. An analysis of the lowest effective intensity of prophylactic anticoagulation for patients with nonrheumatic atrial fibrillation. $N$ Engl J Med. 1996;335(8):540-546.

168. Walker AM, Bennett D. Epidemiology and outcomes in patients with atrial fibrillation in the United States. Heart Rhythm. 2008;5(10):1365-1372.

169. Singer DE, Chang Y, Fang MC, et al. Should patient characteristics influence target anticoagulation intensity for stroke prevention in nonvalvular atrial fibrillation?: the ATRIA study. Circ Cardiovasc Qual Outcomes. 2009;2(4): 297-304.

170. Rose AJ, Ozonoff A, Henault LE, Hylek EM. Warfarin for atrial fibrillation in community-based practise. I Thromb Haemost. 2008;6(10):1647-1654.

171. Ageno W, Gallus AS, Wittkowsky A, Crowther M, Hylek EM, Palareti G. Oral anticoagulant therapy: antithrombotic therapy and prevention of thrombosis, 9th ed: American College of Chest Physicians evidence-based clinical practice guidelines. Chest. 2012;141(2)(suppl):e44S-e88S.

172. Jones M, McEwan P, Morgan CL, Peters JR, Goodfellow J, Currie CJ. Evaluation of the pattern of treatment, level of anticoagulation control, and outcome of treatment with warfarin in patients with non-valvar atrial fibrillation: a record linkage study in a large British population. Heart. 2005;91(4):472-477.

173. White HD, Gruber M, Feyzi J, et al. Comparison of outcomes among patients randomized to warfarin therapy according to anticoagulant control: results from SPORTIF III and V. Arch Intern Med. 2007;167(3):239-245.

174. Connolly SJ, Pogue J, Eikelboom J, et al; ACTIVE W Investigators. Benefit of oral anticoagulant over antiplatelet therapy in atrial fibrillation depends on the quality of international normalized ratio control achieved by centers and countries as measured by time in therapeutic range. Circulation. 2008;118(20):2029-2037.

175. Wan Y, Heneghan C, Perera R, et al. Anticoagulation control and prediction of adverse events in patients with atrial fibrillation: a systematic review. Circ Cardiovasc Qual Outcomes. 2008;1(2):84-91. 